Western University

Scholarship@Western

Digitized Theses

Digitized Special Collections

1975

\title{
A Study Of Phosphoglycerate Kinase In Human Erythrocytes
}

Muslim Ali

Follow this and additional works at: https://ir.lib.uwo.ca/digitizedtheses

\section{Recommended Citation}

Ali, Muslim, "A Study Of Phosphoglycerate Kinase In Human Erythrocytes" (1975). Digitized Theses. 831.

https://ir.lib.uwo.ca/digitizedtheses/831

This Dissertation is brought to you for free and open access by the Digitized Special Collections at Scholarship@Western. It has been accepted for inclusion in Digitized Theses by an authorized administrator of Scholarship@Western. For more information, please contact tadam@uwo.ca,

wlswadmin@uwo.ca. 
A' STUDY OF PHOSPHOGLYCERATE KINASE INCHUMAN ERYTHROCYTES

by.

Mus lim Ali

M.Sc.

Department of Pathological Chemistry

Submitted in partial fulfillment

of the requirements for the degree of

Doctor of Philosophy

$\therefore$

Doctor of Philosophy.

$\therefore>$

c

$\therefore \quad \vdots$

- . Faculty of Graduate Studies : ...

The University of Western Ontario

London, Ontario

Augus t, 1974

(c) Muslim 1974 ., 



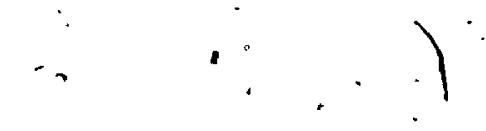

varying concentrations of 1;3-DPG. A biphasic cứrye was obtained in both linear and double reciproeal plots demonstrating two $\mathrm{K}_{\mathrm{m}}$ 's. The ealculated Michaelis constants weré:, 1,3-DPG, $K_{m_{1}} 1: 9 \times 10^{-6} \mathrm{M}$, $\mathrm{K}_{\mathrm{m}_{2}} 9.8 \times 10^{-6} \mathrm{M} ; \mathrm{ADP}, \mathrm{K}_{\mathrm{m}_{1}} 0.17 \times 10^{-4} \mathrm{M}, \mathrm{K}_{\mathrm{m}_{2}} 1,0 \times 10^{-4} \mathrm{M}^{\prime}$ and $\mathrm{Mg}^{+}$, $5.7 \times 10^{-4} \mathrm{M}$ : The relationship of $\mathrm{Mg}^{2+}$ and $\mathrm{ADP}$ with respect to $1,3-D P G$ was of a noncompetitive and uncompetitive type respectively. Michaeị̂s-Menten kinetics were observẹd in both linear and double reciprocal plots at fixed levels of $1, \dot{3}-\dot{D P G}$ or ADP and varying concentrations of $\mathrm{Mg}^{2^{+}}$. Both $1 ; 3-\mathrm{DPG}$ and $\mathrm{ADP}$ demonstrated a noncompetitive relationship with respect to $\mathrm{Mg}^{\mathbf{2}^{+}}$. $D$

Apparent Michaelis-Menten kinetics were observéd in .1 inear plo.ts wheq conditions of fixed concentrations of 1,3-DPG or $\mathrm{Mg}^{2+}$, , were maintained with varying concentrations of ADP. However, the : double reciprocal plots demonstrated biphasic cuirves with two $\mathrm{K}_{\mathrm{m}}$ 's. A nonicompetitive type of relationship was observed between $\mathrm{Mg}^{2+}$ and ADP.

PGK activity was found to be inhibited at physiological correntrations of 'AMP and, 2, 3-DPG. Substrate activation by 1,3-DPG was maintained in the presence of AMP or 2,3-DPG but with reduced enzyme activity, At higher concentrations of AMp or, $2,3-D P G$ (5mM) activation was abolished and the curve approached the hyperbolic; AMP was found to inhibit enzyme activity noncompetitively with respect to 1,3-DPG, ADP and $\mathrm{Mg}^{2+}$. 2,3-DPG inhibits PGR activity noncompeti$1 \cdot$ tively with respect to $1,3-\mathrm{DPG}$. 


\section{ACKNOW LEDGEMENTS}

I wish to express my gratitude to' my supervisor,

Dr.: Y.S. Brownstone, for his constant guidance and encouragement throughout the course of this study.

I. am thankful to Dr.P.C. Fitz-James, Department of

Bacteriology and Imminology and Department of Biochemistry for the use of the Analytical. Ultracentrifuge and his invaluable assistance. ,

I also wish to extend my thanks to Dr. A. Bakerspigel, Department of Bacteriology and Immuriology, Victoria Hospital for his assistance in the microphotography of the crystals of PGK.

I wish to thank Dr. W.C. Wațson, Gastrointestinal Unit, Victoria Hospital for the use of the electrofocusing equipment.

I an grateful to my friend M.K. Ali for his help with the computer programine.

I would like to express my thanks to $\mathrm{Dr}, \mathrm{P} . \mathrm{J}$. Ainsworth and M. Saleem for their help in discussion of the manuscript.

I am indebted to Mrs. Marsha Jazey and Mrs. Sandra Davy for typing this thesis.

I would like to express iny sincerest gratitude to my. wife; son and my parents for their inspiration and support throughout this study.

This'study, was supported by a grant the Medical Research Councii of Canada to Dr. Y.S: Brownstone (Grant No. MA-4056). 
TABLE OF CONTENTS

'Page

CERTIFICATE OF EXAMINATION

ABSTRACT

ACKNOWLEDGEMENTS

.

TABLE OF CONTENTS $\ldots \ldots \ldots \ldots \ldots \ldots \ldots \ldots \ldots \ldots \ldots \ldots \ldots \ldots \ldots \ldots$

LIST OF TABLES $\ldots \ldots \ldots \ldots \ldots \ldots \ldots \ldots \ldots \ldots \ldots \ldots \ldots \ldots \ldots \ldots \ldots \ldots \ldots$

LIST OF FIGURES $\ldots \ldots \ldots \ldots \ldots \ldots \ldots \ldots \ldots \ldots \ldots \ldots \ldots \ldots \ldots \ldots \ldots \ldots \ldots \ldots \ldots$

ABBREVIATIONS $\ldots \ldots \ldots \ldots \ldots \ldots \ldots \ldots \ldots \ldots \ldots \ldots \ldots \ldots \ldots \ldots \ldots \ldots \ldots \ldots \ldots$

INTRODUCTION $\ldots \ldots \ldots \ldots \ldots \ldots \ldots \ldots \ldots \ldots \ldots \ldots \ldots \ldots \ldots \ldots \ldots \ldots \ldots \ldots \ldots$

I. Metabolism of human red cells $\ldots \ldots \ldots \ldots \ldots \ldots \ldots \ldots$

II. Phosphoglycerate kinase $\ldots \ldots \ldots \ldots \ldots \ldots \ldots \ldots \ldots,{ }^{\circ}$

III. Diphosphoglycerate metabolis in erythrocytes ..... 11

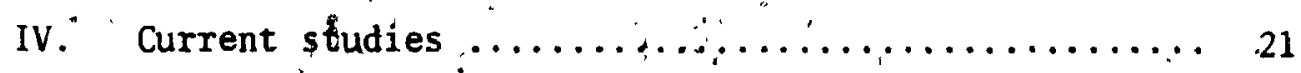

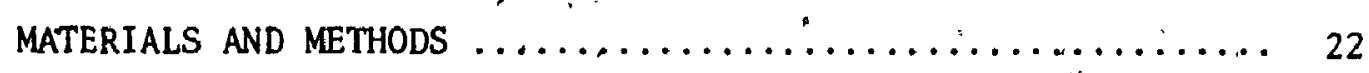

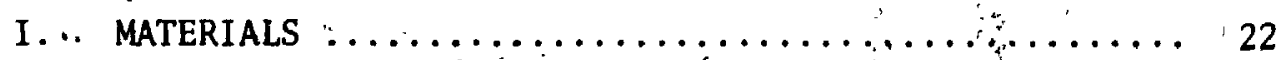

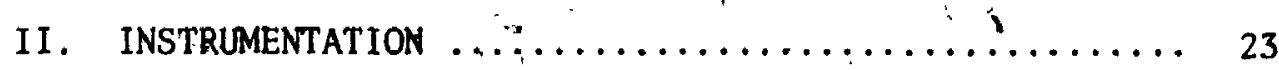

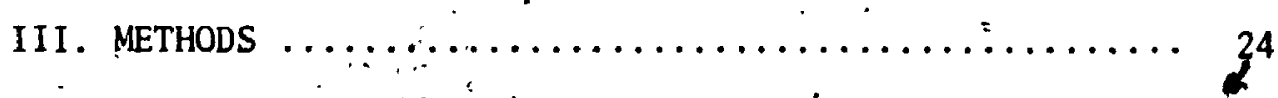

1. Substrate: 1,3-diphosphogiyceric acid ..... 24

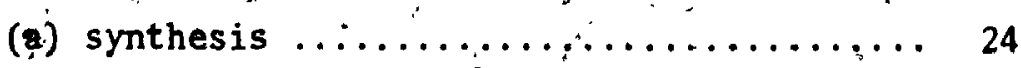

(b) quantitation $\ldots \ldots \ldots \ldots \ldots \ldots \ldots \ldots \ldots, 25$

2. Enzyme: phosphoglycerate kinase 
3. Estimation of proteins ..............

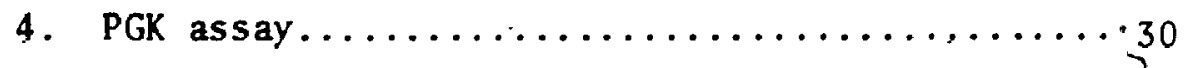

(a) reaction mixture of fluorimetric assay.... 33

(b) fiuorometric determination......... 34

(c) spectrophotometric determination....... 34

(d) inearity of assay .............. 37

5. Polyacrylamide gel electrophoresis.........68

6. Sedimentation velocity and molecular weight determination by analytical ultracentri-' .

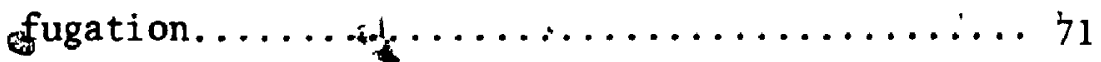

I. Purification of $1,3-D P G$

II. Stability of substrate $(1,3-D P G) \ldots \ldots \ldots \ldots \ldots \ldots \ldots \ldots$

III. Isolation and purification of PGK.............. 74

1. Crystallization of PGK.................. 77

2. Further purification by electrofocusing........8 80

3. Further crystallization of PGK............ 80

IV. Properties of PGK.......................... 87

1. Stability of PGK during storage............87

2. Influence of temperature on the activity of PGK... 87

3, Effect of pH on PGK activity ................ 92

4. Polyacrylamide gel electrophoresis........... 92

5. Sedimentation pattern of PGK............... 97

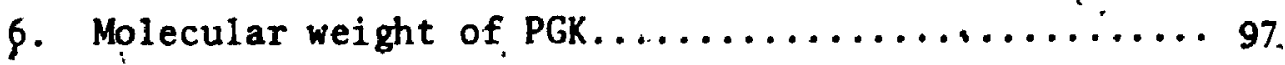

V. Kinetic properties of PGK....................... 107 
1. The Effect of ADP or $\dot{\mathrm{M}}{ }^{2+}$ on PGK Activity.

(fixed $[A D P]$ or $\left[\mathrm{Mg}^{2+}\right]$, variable $[1,3-D P G]$ )

2. The Effect of 1,3-DPG and ADP or $\mathrm{Mg}^{2+}$ on PGK Acțivity (fixed $[1,3-D P G]$, variable $[A D P]$ or $\left.\left[\mathrm{Mg}^{2+}\right]\right)$

3. The Effect of $\mathrm{Mg}^{2+}$ and ADP on PGK Activity

- (fixed $\left[\mathrm{Mg}^{2+}\right]$, variable $[\mathrm{ADP}]$ )

4. The Effect of $A D P$ and $\mathrm{Mg}^{2+}$ on $\mathrm{PGK}$ Activity (fixed $[\mathrm{ADP}]$, variable $\left[\mathrm{Mg}^{2+}\right]$ )

VI. Effects of AMP on PGK Activity. 124

1. The Effect of AMP rand 1,3-DPG on PGK Activity

(fixed $[A M P]$, variable $[1,3-D P G]$ )

2. The Effect of AMP and ADP on PGK Activity

(fixed $[A M P]$, variable $[A D P]$ ) $\therefore$

3. The Effect of AMP and $\mathrm{Mg}^{2+}$ on PGK Activity.

(fixed $[A M P]$, variable $\left[\mathrm{Mo}^{2+}\right]$ )

VII. The Effect of 2,3-DPG on PGK Activity.

DISCUSSION.

SUMMARY

APPENDIX.

BIBLIOGRAPHY

VITA. 


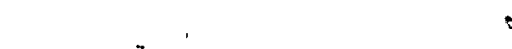

,

\section{LIST OF TABLES}

Table

I. - The effect of varying values of $\mathrm{K}_{2}$ on the

. $\quad$ PGK assay.

II. The effect of varying values of $\mathrm{K}_{3}$ on the

PGK assay..................

III. The effect of varying values of $K_{4}$ on the

PGK assay............................. 65

IV. The effect of varying values of $\mathrm{K}_{5}$ on the

PGK assay................................ 67

v. The purification of Phosphoglycerate. kinase

from human erythrocytes.................. 86 VI. Stability of PGK during storage at $4^{\circ} \mathrm{C}$ and $-20^{\circ} \mathrm{C} \ldots \ldots .91$

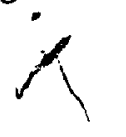




\section{LIST OF FIGURES}

Figure

1 Glycolysis in red cells.................... 3

2 The isolation and purification of PGK from

$\ldots$ human erythrocytes...................... 28

3 The scheme for assaying the purified PGK by utifizing lactate dehydrogenase as the indicator reaction.

4

A typical PGK as.say......................... 36

5 : The linearity of phosphoglycerate kinase assay..... 39. 6 Assay of PGK activity at varying concentrations of: (a) PGM (b) Enolase.................. 42

7 Assay of PGK activity at varying concentrations of: (a) PK (b) LDH..................... 45

8 Parallel assays using $1,3-D P G$ and $3-P G A$ as substrate.......................... 48

9 The effect of varying ADP concentrations......... 51

10 The effect of varying $\mathrm{Mg}^{2+}$ concentrations......... 53

11 A theoretical family of curves at varying

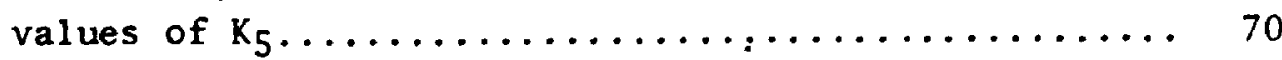

12 Stability of 1,3-DPG during storage in 1iquid

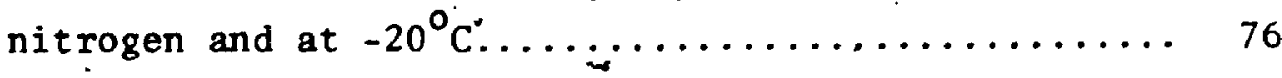


. Figure

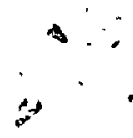

Pquacrylamide gel electrophoresis of

0 cryştalline PGK

Description

Page.

79

14

Separation of PGK by electrofocusing $\mathrm{pH}$

- ranges between 3 to 10 '

Separation of PGK by elettrofocusing $\mathrm{pH}$

ranges between 7 to 9

$84^{\circ}$

Crystals'of phosphoglycerate kinase grown

at $\mathrm{pH} 7.0$

17 . The influence of tèmperature on PGK activity

The influence of hydrogen ion concentration on the activity. of PGK ....... Polyacrylamide gel electrophorésis of

purified PGK from electrofoeusing

Sedimentation of PGK in $0.1 \mathrm{M}$ phosphate

buffer, $\mathrm{pH} 7.0$ containing $5 \mathrm{mM}$ cysteine

HCI

101

21

Sedimentation patteinn. of PGK in $0: 1 M$

- phosphate buffer, $\mathrm{pH} 7.0$ containing $5 \mathrm{mM}$ of cysteine. $\mathrm{HCl}$

Molecular weight determination of PGK by" the sedimentation equilibrium method. The

- $\log$ plot of the optical density (278.5 nm) versus $\left(x^{2}\right)$ from the axis of rotation 
Figure

23 The effect of ADP and 1,3-DPG on PGK activity (fixd $\left[A D P{ }^{\circ}\right.$, variable $=[1,3-D P G]$ )

24i. The effect of $\mathrm{Mg}^{2+}$ and 1,3-DPG on PGK activity - (fixed $\left[\mathrm{Mg}^{2+}\right]$, variable $\left.[1,3-\mathrm{DPG}]\right) \ldots \ldots \ldots \ldots$ The effect of 1,3-DPG and $\mathrm{Mg}^{2+}$ on, PGK activity (fixed $[1,3-\mathrm{DPG}]$, variable $\left[\dot{\mathrm{Mg}}^{2+}\right]$ ) $\ldots$.

The effect of 1,3-DPG and ADP on PGK activity (fixed $[\mathrm{A}, 3-D P G]$, váriable $[A D P]$ ) $\ldots \ldots \ldots \ldots$ The effect of ${ }^{\circ} \mathrm{Mg}^{2+}$ and ADP on PGK activity (fixed $\left[\mathrm{Mg}^{2 *}\right]$, variable $[A D P]$ ) $\ldots \ldots \ldots \ldots \ldots$ The effect of $A D P$ and $\mathrm{Mg}^{2+}$ on PGK activity (fixed $[\mathrm{ADP}]^{\circ}$, variable $\left[\mathrm{Mg}^{2+}\right]$ )

Effect of AMP on PGK activity.

The effect of AMP and 1,3 DPPG on PGK activity (fixed [AMP], variable $[1,3-D P G]$ ).

.31 The effect of AMP and ADP on PGK activity (fixed $[A M P]$, variable $[A D P]$ ) . .............

32. The effect of $\mathrm{AMP}$ and $\mathrm{Mg}^{2+}$ on PGK activity (fixed $[A M P]$, variable $\left[\mathrm{Mg}^{2+}\right]$ ) $\ldots \ldots \ldots \ldots \ldots$ 


\section{ABBREVIATIONS}

$\theta$

$\stackrel{\circ}{\text { A: }} \quad \stackrel{\circ}{\text { angstrom }}$

$A C D$ : acid citrate dextrose

is ADP: 'adenosine-5'-diphosphate

AMP: , adenosine-5'-monophosphate

ATP: adenosine-5'-triphosphate

DEAE-

Cellulose: diethyl aminoethyl cellulose

1,3-DRG: 1,3-diphosphoglyceric acid

2,3-DPG: · 2,3-diphosphoglyceric acid

DPGM: diphosphoglyceromutase

GDP: - guanosipe-5!'-diphosphate

\section{G-3-P: glyceraldehyde 3-phosphate}

IDP: inosine-5'-diphosphate

NAD: nicotinamide adenine dinucleotide :

A NADH: reduced nictotinamide adenine dinucleotide

NADP: ,nicotinamide adenine dinucleotide phosphate

NADPH: reduced nicotinamide adenine dinucleotide phosphate

3-PGA: 3-phosphoglyceric açid

PGK: phosphoglycerate kinase

pI : isoelectric point

$\Delta R: \quad$ change' in fluorescence per minute

SDS: 'sodiun dodecyl sulfate

Trís: 'tris (hydroxymethyl)-amino-methane' 
The author of this thesis has granted The University of Western Ontario a non-exclusive license to reproduce and distribute copies of this thesis to users of Western Libraries. Copyright remains with the author.

Electronic theses and dissertations available in The University of Western Ontario's institutional repository (Scholarship@Western) are solely for the purpose of private study and research. They may not be copied or reproduced, except as permitted by copyright laws, without written authority of the copyright owner. Any commercial use or publication is strictly prohibited.

The original copyright license attesting to these terms and signed by the author of this thesis may be found in the original print version of the thesis, held by Western Libraries.

The thesis approval page signed by the examining committee may also be found in the original print version of the thesis held in Western Libraries.

Please contact Western Libraries for further information:

E-mail: libadmin@uwo.ca

Telephone: (519) 661-2111 Ext. 84796

Web site: http://www.lib.uwo.ca/ 


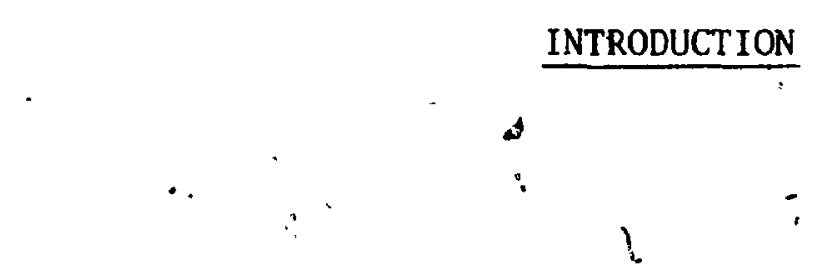

1. Metabolism of Human Red Cells

The enefgy of maure red cells is derived mainly from anaerobic glycolysis. Although NADPH may be produced by the pentiose phosphate pathway it cannot be used for energy purposes because of the absence of a cytochrome system (81). The mature mammalian red: cell lacks nucleus, endoplasmic reticulum, tricarboxylic acid cycle, $\checkmark$ electron transport system (96) and is incapable of de novo biosynthesis of protein and lipid $(47,105)$. Studies of glycolysis and the pentose phosphate metabolic pathway and their functions in intact mamulian red cells are described by several workers $(5,6,16$ 18).

The breakdown of glucose is carried out almost exclusively a by way of Embden-Meyerhof pathway (Figure 1). About 90\% of the glucose utilized is metabolized through glycolysis generating two molecules of ATP per molecule of glucose $(4,71)$. ATP is hydrolyzed to ADP and inorganiç phosphate by adenosine triphosphatase and the energy released by hydrolysis is utilized for the active transport of cations across the red cell membrane (79). Another important function of ATP is the maintenance of the normal biconcave discoidal shape of the red cells (72). 
FIGURE 1

to

1

Glycolysis in Red Cells

Legend:

1. Hexokinase

2. Phosphóglucose isomerase

3. Phosphofructokinase

4. Aldolase

5. Triose phosphate isomerase

6. G1yceraldehyde-3-P-dehydrogenase

6a. 2,3-DPG mutase

6b. DPG-phosphatase

7. Phosphoglycerate kinase

8. Phosphog1yceromutase

9. Enolase

- 10: Pyruvate kinase

11. Lactate dehydrogenase 
3

Pentose

phosphate pathway

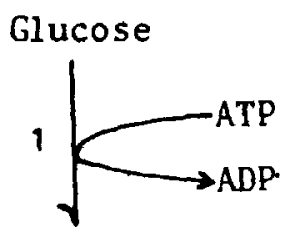

Glucose 6-Phosphate

Fructose 6-Phosphate
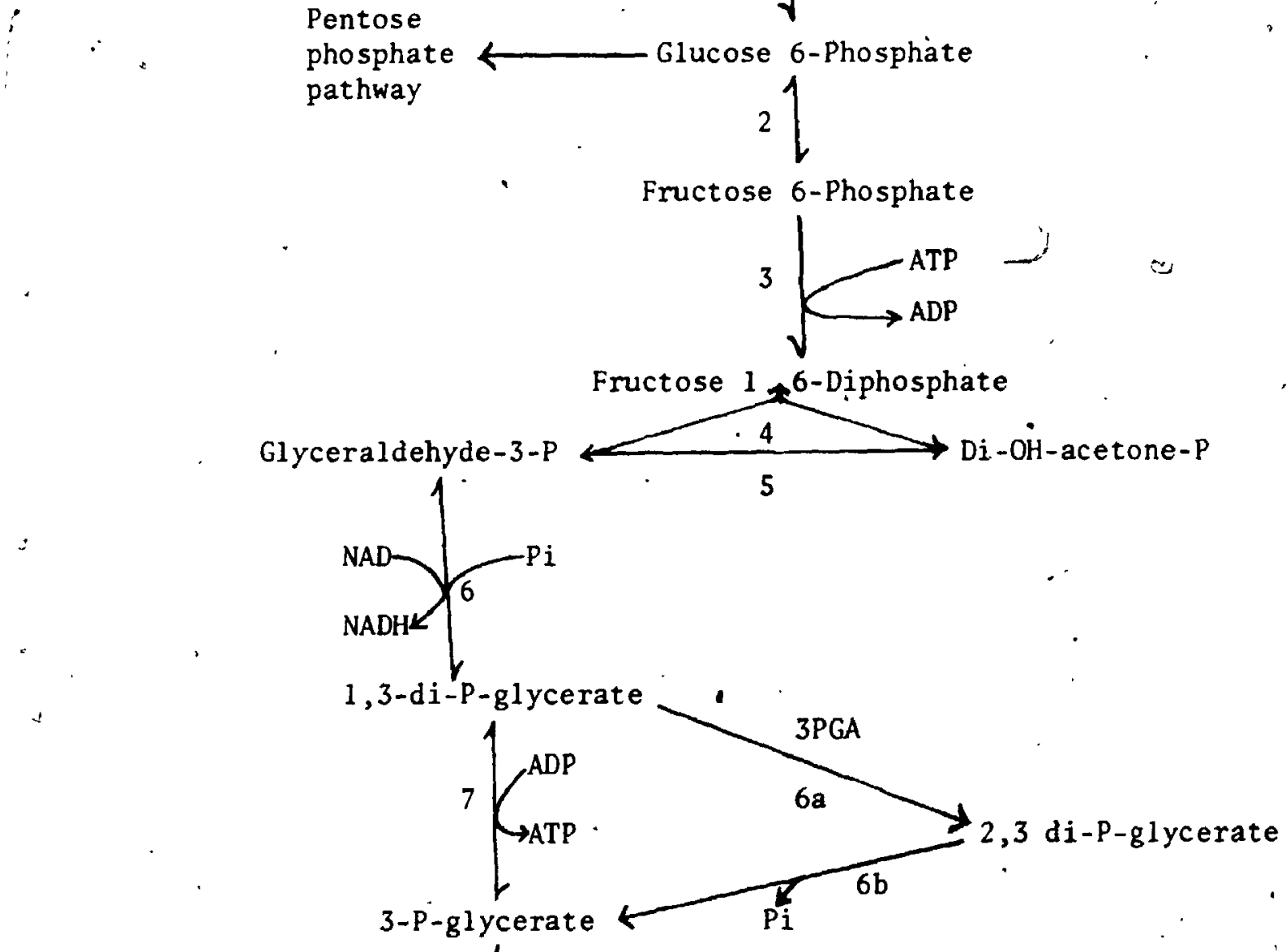

$\because$

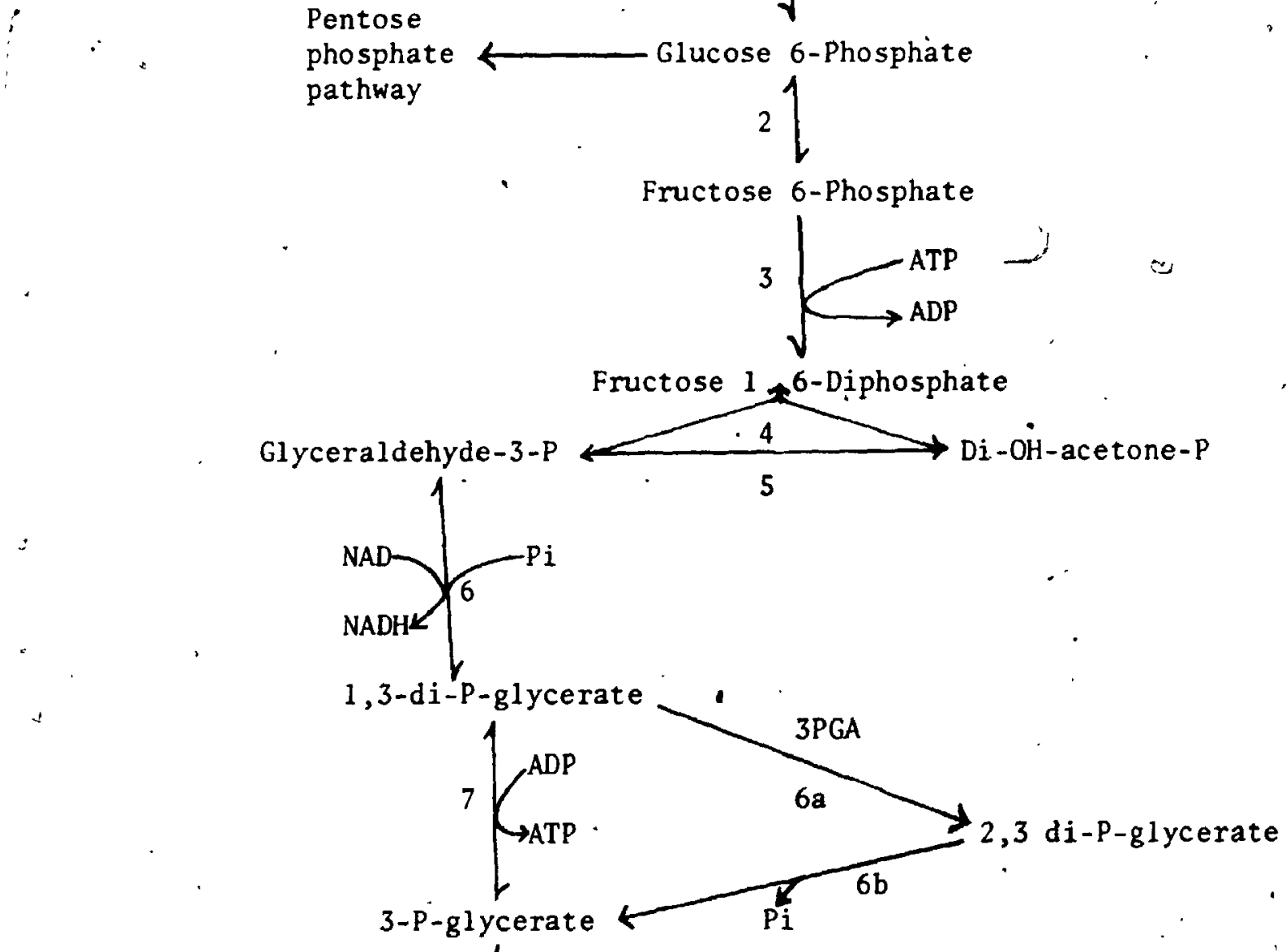

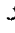

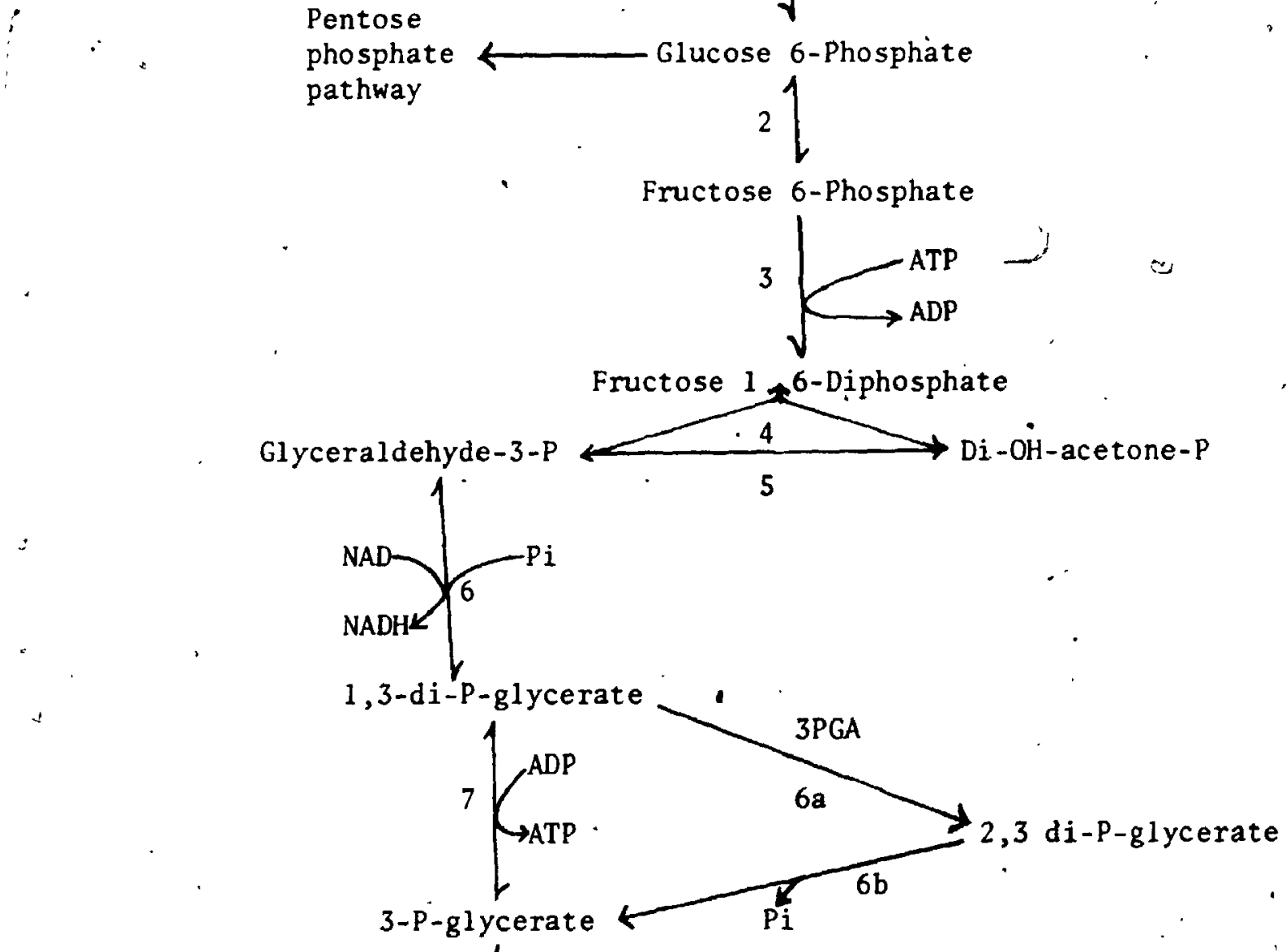

1,3-di-P-glycerate

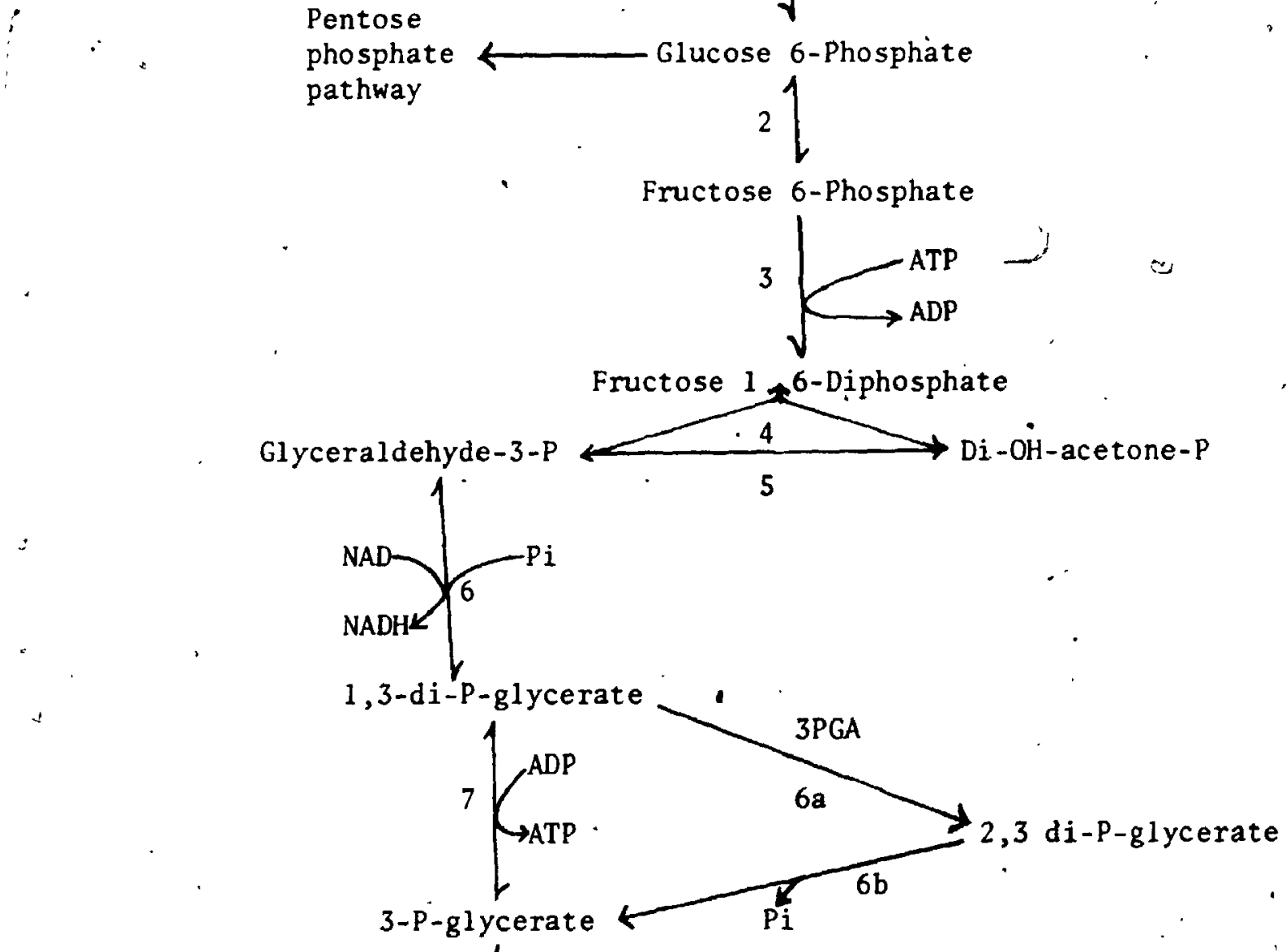

3-P-glycerate

!

$\cdot$

2-P-glycerate
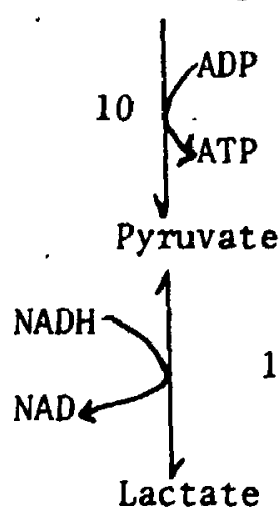

11 


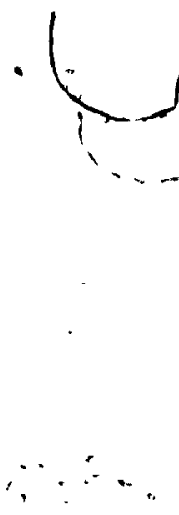

A number of enzymes of the glycolytic system have been isolated in crystalline form (Figure 1) from human erythrocytes: phosphofructokinase (63), triosephosphate isomerase (95), glyceraldehyde 3-phosphate dehydrogenase (75), diphosphoglycerate mutase (94), 2-3diphosphoglycerate phosphatase (43), phosphoglycerate kinase $(45,76$, - 113) and pyruvate kinase (21).

- The activity of the hexose monophosphate shunt o' pentose phosphate pathway has been demonstrated in erythrocytes. The metabolic flow through this shunt is estimated to account for only $10 \%$ of the totar glucose metabolism $(71,15,28,77)$. In the non-nucleated erythrocytes the oxidative reactions of the pentose phosphate pathway appear to be the sole mechanism for the conversion of glucose to carbon dioxide and for the generation of reduced nicotinamide adenine dinucleotide phosphate (NADPH) $(15,28,30)$. The NADPH produced by this pathway can be utilized in the reduction of methemoglobin to hemoglobin catalyzed by NADPH-methemoglobin reductase " and thus prevents, the accumulation of methemoglobin (48). Similarly NADPH is utilized in maintaining glutathione in the reduced state as a protection against various oxidants (catalyzed by glutathione reductase) (82).

The metabolism of maturopuman red cells is considered to be controlled by the levels of severdl intermediates and nucleotides (as determined in deproteinized extracts of erythrocytes) (67). Minakami et al. (69) calculated the fres energy change in every step of glycolysis in red cells based on the levels of intermediates and 
nucleotides. On the basis of the free energy change they suggested that the reactions catalyzed by the enzymes hexokinase, phospho-: fructokinase and pyruvic kinase are rate limiting. These three rate limiting steps in the glycolysis of mature red cells are affected by several intermediates and nucleotides. In addition glyceraldehyde-3-phosphate dehydrogenase and phosphoglycerate kinase are considered to be rate limiting steps $(93,97)$.

\section{Phosphoglycerate Kinase}

Phosphogiycerate kinase (E.C.2.7.2.3; ATP:D-3 phosphoglycerate 1-phosphotransferase) catalyzesithe reversible transfer of the "phosphoryl group from the cárboxyl group of 1,3-diphosphoglycerate, to ADP.

Phosphoglyceryl phosphate + ADP $¥ 3$-phosphoglyceric açid + ATP. This reaction is a part of the Embden-Meyerhof glycolytic'scheme.

A detailed investigation of this enzyme was made by Bücher (19) who isolated phosphoglycerate kinase in crystalline form from yeast. Later Krietsch and Bücher. (55) isolated phosphoglycerate

- kinase in a highly purified form from rabbit. muscle and compared its chemical, physical and kinetic properties to yeast PGK. The' enzyme has also been partially purified from pea seeds (3), E. coli (27), yeast (19), liver (49) and muscle $(84,103)$. Recently, Scopes (104) puriffied PGK from yeast. 
The presence of PGK in human erythrocytes was first demonstrated.by Blanchaer et al. (13). Phosphoglycerate kinase was isolated in crystalline form from human red cells in 1962 by Hashimoto and Yoshikawa (44) and later with some improvements in the purifica-. tion procedure in 1964 (45). Recently Yoshida and Watanabe (113)

; isolated phosphöglycerate kinase in crystalline form from human erythrocytes, but they did not describe the* kinetic properties of their enzyme.

Larsson-Raznikiewicz (59) found tha't free ATP and $\mathrm{Mg}^{2+}$ have an "inhibitory effect on yeast. PGK activity. The inhibition of $\mathrm{Mg}^{2+}$. was abolished by increasing the $3-\mathrm{PGA}$ concentration. A competitive type of inhibition was reported with. respect to both $\mathrm{Mg}^{2+}$ and $\mathrm{ATP}^{4-}$. It was further reported (60) that $\mathrm{Mg}^{+}$at high concentration inhibits the enzyme noncompetitively with respect to 3 -phosphogfycer:

- ate. The kinetic relationships were changed and nonlinear LineweaverBurk plots were obtained for two substrates. This was interpreted in terms of two different binding sites for each substrate; the second site was involved only at high $\mathrm{Mg}^{2}$ concentration.

Inhibition of yeast PGK by $\mathrm{ADP}_{4}$ and $\mathrm{AMP}$ with $\mathrm{Mg}-\mathrm{ATP}^{2-}$ and 3phospho-D-glycerate as substrates at high and $10 \mathrm{w} \mathrm{Mg}^{2+}$ concentration was studied by Larssón-Raznikiewicz et al. (62). They observed that . this enzyme contains at least two nucleotide binding sites, one presumably binding $\mathrm{Mg}^{-\mathrm{ATP}^{2-}}$ and the other ADP. The $\mathrm{ADP}^{3-}$ binding site 4 might bind $\mathrm{Mg}-\mathrm{ADP} \mathrm{P}^{-}$also. AMP probably competes for the same site as 
$\mathrm{MgATP}^{2+} ; \mathrm{ADP}^{3^{-}}$and MgADP ${ }^{1-}$ are competitive inhibitors and $\mathrm{AMP}^{2-}$ is. a noncompetitive inhibitor of 3-PGA. The inhibitory effects of ADP and AMP were stronger at the higher concentrations of $\mathrm{Mg}^{2}$. It was suggested that this was probably due to conformational and/or other differences of the enzyme at these two metal ion concentrations.

PGK of human-red cells was reported by Ponce et al. (78) to be inhibited by 2,3-diphosphoglycerate. At normal intracellular .. concentrations of 2,3-DPG the enzyme was inhibited $80 \%$. A competitive type of inhibition was reported with respect to ATP, ATP$2 \mathrm{Mg}^{2}$ and $3-\mathrm{PGA}$. These authors found that yeast PGK was also susceptible to inhibition by 2,3-DPG. A competitive type of inhibition was found with respect to $\mathrm{Mg}^{2+}$, ATP and ATP-2Mg ${ }^{2+}$ and a mixed type of inhibition with 3-PGA. However in the same year, Beutler reported that humari red cell PGK was not influenced by the presence of $5.0 \mathrm{mM}$ of 2,3-DPG (11). However, Beutler used a crude hemolysate as the , source of the enzyme and his findings have been disputed (107a) .

Bucher $(19,55)$ on the basis of his kinetic studies with yeast phosphoglycerate kinase has postulated three different sites for the substrates of the enzyme. Accordingly, in the forward reaction 1,3-DPG is bound to site 1 and 2 and site 3 is occupied by ADP. The terminal phosphate in ADP then reacts with acylphosphate on 1,3-diphosphoglycerate and at the same time the adenosine group dissociates from site 3, leaving 3-PGA bound via its phosphate to site 1, ATP (via the terminal phosphate) is bound to site 2, and site. $\therefore$ 
3 is unoccupied. Cohn (24) showed that it is the O-P bond which is split in the transfer of the phosphate group from 1,3-DPG to ADP as is characteristic for phosphoryl-transferring enzyme. In the forward reaction phosphoglycerate kinase is "absolutely specific" for ic thet phosphate donor 1,3-DPG, put IDP ànd GDP. can be used an addition to ADP as a phosphate acceptor (55). Rao and Oesper (84) concluded that PGK, is "absolutely specific" for ATP, ADP, 3-PGA and 1,3-DPG.

Eariier workers have attempted to purify the enzyme phosphoglycerate kinase from different sources $(3,19,27,59,84,103)$ but their preparations, however, were all amorphous and contained at least two other proteins. Recently, it has been highly purified in crystalline form from yeast $(55)$ muscle $(55,104)$ and human red cells $(45,76,113)$ with a specific activity between 600 to 1000 units per. $\mathrm{mg}$ of protein. In these studies, all the enzymatic assays were carried out in the backward reaction. .

The earlier measurements of the molecular weight of the PGK from yeast (58), pig and rabbit musgle (103) were in the range of 34,000 to. 38,000 . Later estimate of the molecular weight of phosphóglycerate kinase from yeast (\$.5), horse (12) and rabbit muscle $(5 \$, 104)$ "are, between 47,000 to 50,000 . Recently Yơshida et at?. (11D) calculated the molecular weight of their enzyme from human red cells to be 49,600 by the sedimentation equilibrium method. It was reported that phosphoglycerate kiñase from yeast (55), muscle (12, $55,104)$ and human red cells (113) does not dissociate into subunits 
under conditions which commonly cause dissociation. Yoshida et al. (113) found that SDS and guanidine hydrochloride did not effect the fragmentation of their enzyme from human red cells. They have reported a molecular weight of 46,300 of PGK in the presence of guanidine hydrochloride. Blake et al. (12) have stated that horse muscle PGK was not dissociated by SDS. A molecular weight of 48,000 was reported by these workers by polyacrylamide SDS gel electrophoresis of the enzyme.

The early work of Rao and Oesper (84) on muscle phosphoglycerate kinase demonstrated that the enzyme required SH groups for its activity. They reported inhibition of enzymatic activity by the -SH group binding reagents para-chioromercuribenzoate, $\mathrm{p}$ chloromercuriphenyl sulfonic acid and heavy"metal ions such as $\mathrm{Cu}^{2+}$. Bücher et al. (55) in their investigations of yeast and muscle phosphoglycerate kinase demonstrated that the muscle enzyme is inhibited by 5,5'-dithiobis (2-nitrobenzoic acid) and p-chloromercuribenzoate in equimolar concentrations to about $90 \%$ while the single -SH group in yeast shows no diminution of activity even at 50 fold molar excess of these reagents. These workers further observed that whereas. ADP-Mg delays the reaction rate of the two fast - SH groups with 5,5'-dithiobis (2-nitrobenzoic acid) in muscle phosphoglycerate kinase, ATP-Mg has no, effect on the reaction. They suggested that ADP-Mg has a binding site separate from that of ATP-Mg. A similar inhibition of $-\mathrm{SH}$ groups by thiol reagents was also demonstrated 
recently by Blake et al. (12) in horse muscle PGK. Their x-ray crystallographic studies of the enzyme indicated that one or two thiols are close to the $\mathrm{Mg}-\mathrm{ADP}$ binding site. The presence of a single -SH group in the yeast enzyme was also recently demonstrated by Arvidsson and Larsscn-Raznikiewicz (1). They found that the enzyme modified by the addition of $-\mathrm{SH}$ blocking reagents was fully active and the stability of the enzyme appeared to be unaffected by thiol reagents. The kinetic parameters of $\mathrm{MgATP}^{2-}$, MgADP tand 3 , phosphoglycerate respectively, are identical for the modified and unmodified enzymes. They concluded that the -SH group does not seem to be directly located in the active site region and that modification of the enzyme does not appear to influence substrate binding. Yoshida et al. (113) estimated that there are eleven cysteine residues in phosphoglycerate kinase from human red cel1s.

Recent studies of horse muscle (12) and yeast PGK (22) by X-ray diffraction suggest that PGK from both sources has a bilobular structure linked by an elongated, thin neck region. $X$-ray intensity data were collected to a resolution of $6 \AA$ and $5 \AA$ in horse muscle. and yeast PGK respectively. With horse PGK it was shown that MgADP binds to the inner surface of one of the lobes. This binding site faces the other lobe of the molecule about $15 \AA$ away across the interlobular gap. Wendel1 et al. (112) in their experiments with crystals of yeast PGK were unable to detect binding of MgADP, MgATP or 3phosphoglycerate: 
111. Diphosphoglycerate Metabolism in Erythrocytes

Human red cells contain a high concentration of $2,3-\mathrm{DPG}$ compared to $1,3-D P G(74)$. The phosphate groups of $2,3-D P G$ are stable to acid in contrast to the labile primary phosphate of $1,3-D P G$. The isolation and characterization of 2,3-DPG was first accomplished by Greenwald in 1925 (39). 2,3-DPG is found in the red ce11s of human, guinea pig, rabbit and other mammals. It has been also isolited" from muscle'by Sutherland et al. (108). They demonstrated its role as a coenzyme of phosphoglyceric mutase in the interconversion of 3-PGA and 2-PGA. It has been estimated that $2,3-$ DPG is found in concentration of $4.0 \mathrm{mM}(67)$ compared to $0.5 \mu \mathrm{M}$ of $1,3-\mathrm{DPG}$ (68) in the circulating red blood cells. The low level of $1,3-\mathrm{DPG}$ is not surprising since the high energy phosphate is rapidly converted to 3-PGA by phosphoglycerate kinase. The red cells of species having nucleated erythrocytes are dẹvoid of 2,3-DPG (86).

\section{Several enzyme syștems are known to be involved in the} symthesis and breakdown of the 2,3-DPG '(Figure 1.) but it is uncertain how these operate under physiological conditions. It is formed from 1,3-DPG and decomposed to 3-PGA. Rapoport and Leubering (88) were the first to show that the formation of 2,3-DPG was catalyzed by a - diphosphoglycerate mutase (scheme on page 15 ) that they purified partially by ammonium sulfate fractionation of hemolysate. These workers reported the formation of 2,3-DPG from the precursors ATP and 3-phosphoglycerate. They were unable to demonstrate the reverse 


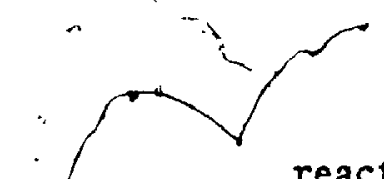

reaction. Later studies of Rapoport and Leubering on the diphospho-

2

'glycerate mutase of the -rabbit erythrocyte were carried out with a system which generated 1,3-DPG from fructose 1,6-diphosphate in the presence of NAD, ajdolase and 3-phosphoglyceraldehyde dehydrogenase (90). They showed that this reaction is accelerated by 3-phosphoglycerate. 'These workers further found that the product of the reaction 2,3-DPG tended to inhibit the reaction. The findings of Rapoport et al. were donfirmed by Joyce and Grisolia (52) with purified DPG-mutase from muscle: the irreversibility of the reaction, the stimulation of the reaction by 3-PGA and inhibition by the product of the reaction, 2,3-DP, DPG-mutase has also been purified from * human erythrocytes and $i$ ts properties have been described in detail (94). A $K_{m}$ value of $0.53 \mu \mathrm{M}$ for $1,3-D P G$ was calculated for DPG-mutase. 2,3-DPG was shown to be a competitive inhibitor of 1,3-DPG with a Ki of $0.83 \mu \mathrm{M}$. The author proposed a bimolecular reaction in which 1,3-DPG combined with the free enzyme followed by combination with 3-phospho- . glycerate to form ternary complex.. 3-phosphoglycerate is a cofactor in this reaction. In the conversion to products; 3-phosphoglycerate is released before $2,3-D P G$.

- The hydrolytic cleavage of 2,3-DPG to 3-PGA by the enzyme DPG-phosphatase has been demonstrated in red blood cells . $(23,43,89)$, muscle $(51,89)$ and yeast $(51)$. 3-phosphoglycerate has an inhibitory effect on phosphatase activity. Rapoport et al. (89) showed that muscle exhibits considerable DPG-phosphatase activity. 
whereas red cells-exhibited only little activity. They surmised that red cells tend to accumulate 2,3-DPG because of the low level of çDPG-phosphatase activity.

- $i$ There has been considerable controversy as to whether glycolysis proceeds via the direct pathway (1,3-DPG to 3-PGA catalyzed by phosphoglycerate kinase) or through the RapoportLeubẹring 2,3-DPG bypass. When Prankerd et ą . (80) incubated red cells with $\mathrm{P}^{32}$ they found that the incorporation of the label into organic phosphate is higher: in $2,3-\mathrm{PPG}$ than ATP and suggested that the former was the precursor of the latter. Prankerd (81) pointed. out later that allowance had not been mad in their earlier calculation for the nonlabelied $P$ of ATP. This would reconcile their results witK" those of Gerlach et al." (36), who reported that ATP was the precursor of $2,3-D P G$. Similar results were obtained by Gouriley (18). After incubation of red cells with $\mathrm{P}^{32}$-labelied orthophosphate at $37^{\circ} \mathrm{C}$ for several hours he found $90 \%$ of the added phosphate was incorpórated in the cellular organic phosphaté compounds. $\mathrm{P}^{32}$ was incorporated in the terminal phosphate, of ATP faster than into 2,3-diphosphoglycerate. He further interpreted his findings as support for the hypothesis that inorganic phosphate normally enters the red cell by the formation of ATP at the cell membrane. Studies on the incegrporation of radioactive $P i$ have supported the conclusion that the path via 2,3-DPG is of minor importance, since the rate of renewal of this compound appears to be much lower than that of the terminal phosphate of ATP (92). These studies suggest 
that glycolysis by the way of phosphoglycerate kinase is the primary route while that via DPG-mutase is secondary under physiological conditions (38). Working with the erythrocytes of normal adults and of patients with hereditary spherocytosis Zipursky et al: (115) found that when the cells were incubated with $\mathrm{P}^{32}$ much radioactivity was incorporated in ATP and inorganic phosphate in contrast to a smaller amount in 2,3-DPG. Subsequent incubations with nonradioactive phosphate led to a more rapid fall in radioactivity in ATP, suggesting a precursor relationship of ATP to 2,3-DPG. No difference was observed between the erythrocytes of normal adults and of patients with hereditary spherocytosis. A distinct lag period was observed (70) during incorporation of $\mathrm{P}^{32}$ into 2,3-DPG, whereas incorporation into: ATP showed no lag. The effect of $\mathrm{pH}$ during incorporation of $\mathrm{p}^{32}$ into 2,3-DPG, was also observed by these workers. They showed (70) that at acidic $\mathrm{pH}$ the incorporation into diphosphoglycerate was low and increased with the increase of $\mathrm{pH}$. The incorporation of $\mathrm{p}^{32}$ into ATP was little affected by changes in the $\mathrm{pH}$.

The case for a self-regulatory cycle at the phosphoglycerate level was suggested by Rapoport (89). Grisolia (40) indicated that a blockage in glycolysis at pyruvate kinase or low levels of $\mathrm{Pi}$; and ADP could result in the accumulation of 3-PGA. This in turn would stimulate the DPG-mutase reaction and result in the actumulation of 2,3-DPG. Furthermore 3-PGA would inhibit the dephosphorylation of 2,3-DPG to monophosphoglycerate $(51,89)$. Grisolia $(40)$ noted that once the blockage is removed the accumulated 2,3-DPG would cause an 
15

increase in the activity of monophosphoglycerate mutase and glycolysis will proceed:

$$
\text { 1,3-DPG occupies a strategic position in the glycolytic. }
$$

- chain of reactions. It may be metabolized by at least three alternaLive paths other than the reversal of the glyceraldehyde 3-phosphate dehydrogenase step. The following scheme represents the possible routes for 1,3-DPG metabolism (16):

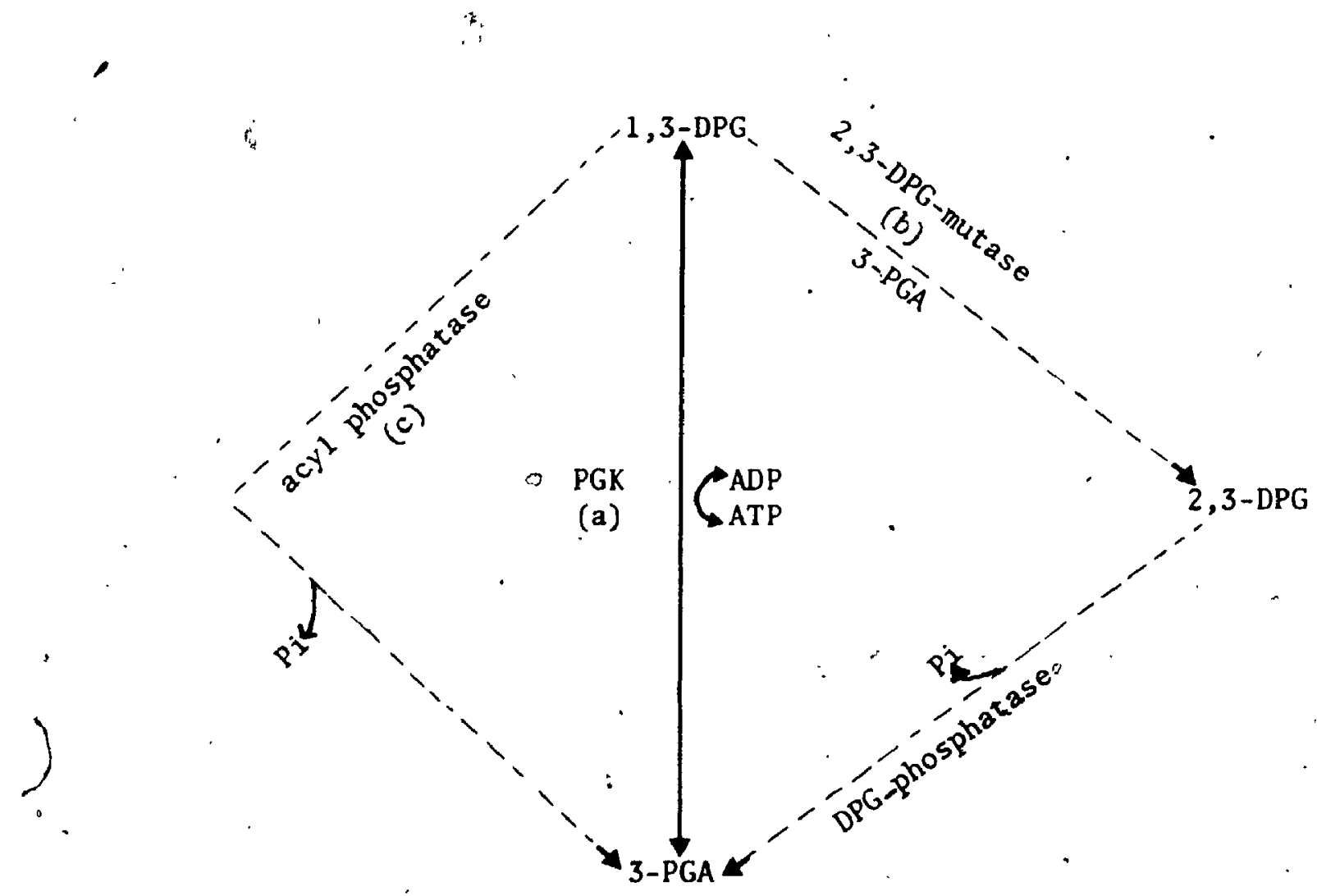


The usual route of glycolysis to 3 -PGA, via phosphoglycerate. kinase (a) involves the formation of ATP and a net gain in free energy (54). An alternative route (c) catalyzed by an acylphosphatase to give 3-PGA and $\mathrm{Pi}$, involves the dissipation of a high-energy bond (42). This enzyme has been isolated from various sources $(29,42)$ and in purified form from human erythrocytes (83). Rakitzis et äl. (83) suggested that this enzyme is a regulatory enzyme and under usual conditions it would function only minimally on the basis of the concentration of $1,3-$ DPG $(0.5 \mu \mathrm{M})$ in the normal metabolizing erythrocytes. However, in the presence of elevated levels of 1,3-DPG it would act as a 'safety valve' and prevent excessive accumulation of $1,3-D P G$ by catalyzing the hydrolysis of 1,3-DPG to 3-PGA. In the other alternative route (b) the formation of 2,3-DPG from 1,3-DPG is catalyzed by the enzyme.DPG-mutase, followed by DPG-phosphatase to form 3-PGA and inorganic phosphate. Besides these routes, another alternative exis's in tissues in which the phosphorylation of creatine take place; creatine phosphate and 3-PGA are the products of the reaction (25). As a rule, ADP is present in relatively small amounts compared to the concentration of other nucleotides (e.g. ATP) ịn human red cells (6). In the presence of an adequate supply of ADP, glycolysis proceeds mainly by way of PGK. It has been reported by severa1 workers $(3,92,101,102)$ that the rate of synthesis of $2 ; 3-D P G$ in hemolysate is markedly influenced by the concentration of ADP. At high levels of ADP little formation of 2,3-DPG occurs and at low levels of ADP 2,3-DPG is synthesized in larger amounts (31). 
The role of the concentration of ADP in limiting the

rate of synthesis of 2,3-DPG in human erythrocytes was also studied by Duhm et al. (32). Their studies showed that added dipyridamole (which strongly reduces the permeability of red cells to phosphate) induces a fall in the concentration of ADP and a stabilization of 2,3-DPG levels in these cells, without causing detectable changes in the levels of glycolytic intermediates. They found that dipyridamole maintains the 2,3-DPG level in glycolyzing red cells by stimulating 2,3-DPG synthesis rather than by inhibiting 2,3-DPG phosphatase. Under the influence of dipyridamole (32) the selective reduction of ADP resulted in an increase in 1,3-DPG concentration. As a result of this elevation in 1,3-DPG. (and presumably a decrease in PGK activity due to low ADP) the formation of 2,3-DPG inereases. The relationship between the concentration, of ADP and the rate of 2,3DPG synthesis was also demonstrated by Gerlach et al. (37). At. very low concentrations of ADP (below physiological concentration i.e. $0.05 \mu$ moles/ml R.B.C.) they found that the rate of 2,3-DPG synthesis is highest and diminishes progressively when ADP concentration increases. From these findings they suggested (37) that in the glycolyzing erythrocytes, as in hemolysates, synthesis of 2,3-DPG is indirectly controlled by the level of ADP. Working on dialyzed stroma-free hemolysate of human erythrocytes Blostein (14) found that the rate of 1,3-DPG utilization is 100 times greater with ADP than without: She reported that both enzyme systems (PGK and 
DPG-mutase) retained.most of their original activity after dialysis of the hemolysate. The level of 2,3-DPG increases concomitantly with the level of ATP (97). This may indicate that the level of 1,3-DPG increases as the ATP level increases due to an increased supply of triose phosphate or alternatively to the reduction in $\mathrm{PGK}$ activity (97). A model study on the competition between the production of ATP and PGK and the production of 2,3-DPG by DPGM has been carried out in hemolysates by Rapoport et al. (91). When the concentrations of ADP, ATP and 2,3-DPG were varied in this system, the primary factor determining the proportion of the two pathways was found to be the concentration of ADP. They found that with increasing ADP concentrations PGK activity dominated. At ADP levels such as are likely to occur in the red cell 2,3-DPG formation predominated. ATP and 2,3-DPG in concentrations approximating those. in erythrocytes inhibited their synthesis.

It has been demfinstrated by several workers $(31,92)$ that about $20 \%$ of the total glycolytic flux passes through the 2,3-DPG poo1 under pHsiological conditions. As in other tissues the main pathway of glycolysis in R.B.C. is via the phosphoglycerate kinase reaction.

The level of 2,3-DPG is also controlled by $\mathrm{pH}$. At low $\mathrm{pH}$ values in vivo or in vitro the level of 2,3-DPG falls rapjaly (37). Rapoport ( 87 ) found that the storage of blood in $\mathrm{ACD}$ at $4^{\circ} \mathrm{C}$ leads to a progressive decline in the level of organic phosphates with a concomitant lgss of viability of the cells. Similar findings were 
reported by Bartlett et.al. (7) during storage of biood at $4^{\circ} \mathrm{C}$ in ACD preservative. They found that the concentration of organic phosphates, particularly 2,3-DPG and ATP of the red cell decreases and inorganic phosphate increases. Valtis and Kennedy (109) observed that the $\mathrm{O}_{2}$ dissociation curves of blood shifted progressively to the left during storage in ACD. The restoration of 2,3-DPG and ATP by incubating stored blood in the presence of inosine at a physiological pH caused the oxygen dissociation curve to shift back to the right (8).

Two phosphate compounds, adenosine triphosphate and 2,3diphosphoglycerate have been shown to facilitate the release of oxygen from hemoglobin $(10,20)$. Chanutin et al. (20) studied the effect of organic and inorganic phosphate on the functional properties of adult hemoglobin. They demonstrated that adenosinetriphosphate, guanosine triphosphate and 2,3-diphosphoglyceric acid are particularly effective in decreasing the oxygen affinity of hemoglobin and are responsible for a small change in heme-heme interaction. The oxygen affinity of hemoglobin is decreased in the presence of 2,3-DPG over a wide $\mathrm{pH}$ range: These authors (20) have also reported that 2,3-DPG and ATP which account for about $60 \%$ and $20 \%$ respectively of the organic phosphate in the normal red cell are capable of increasing the dissociation of oxyhemoglobin. Inorganic phosphate also reduces the oxygen affinity of hemoglobin, but the effect is much weaker than that of 2,3-DPG and ATP $(9,20)$. Benesch et al. (10) have shown 
that 2,3-DPG forms a complex with purified deoxyhemoglobin and thereby reduces the affinity of hemoglobin for oxygen. They suggested that the affinity of this compound is greater for the deoxy-form of hemoglobin than for the oxy-form. The binding of 2,3-DPG and ATP to human hemoglobin was studied in solutions of high hemoglobin concentration and varying amounts of 2,3-DPG, ATP, $\mathrm{Pi}$, magnesium and hydrogen ions (35). The affinity of hemoglobin for 2,3-DPG in physiological conditions was about twice as great as that for the ATP. They reported two binding sites for 2,3-DPG and strong cooperation between these sites was observed: Binding of both phospho-compounds decreased at elevated hydrogen ion concentrations. They have also reported that $\mathrm{Pi}$ up to $10 \mathrm{mM}$ had no effect on the binding by hemoglobin of either compound.

The relationship between oxygen disspciation and 2,3-DPG in red cells has been studied by Lefant et al., (64) in subjects. moving from low to high altitude and vice versa. They found that in twenty-four hours following the change in altitude there was a change in hemoglobin affinity for oxygen and this represented an important rapid adaptive mechanism to anoxia Since the organic phosphate react only with reduced hemoglobin, the greater the anoxia the greater the amount of reduced hemoglobin will be present and the larger the amount of 2,3-DPG bound to deoxyhemoglobin. This binding will result in the depletion of soluble organic phosphate in the cells and glycolysis will be stimulated to produce more 2,3-DPG. Increased glycolysis and organic phosphate has been demonstrated to 
occur in vitro in deoxygenated blood (2). It was concluded that such a mechanism would automatically control the balance between oxyhemoglobin and deoxyhemoglob in and would counteract the effects of an increase in reduced hemoglobin.

\section{Current Studies}

Human red cells as have been stated above depend on glycolysis for their energy requirements in the form of ATP. Two moles of ATP are produced at the step catalyzed by phosphoglycerate kinase. Therefore, from the point of view of cellular energetics PGK is an important enzyme.

This enzyme has been purified in crystalline form from yeast $(55,58)$, muscle $(55,104)$ and red cells $(45,76,113)$. Kinetics studies on yeast and muscle PGK have been described in detail. However, these studies were done in the backward reaction. These investigations were undertaken to elucidate the characteristics of PGK in human erythrocytes and the factors which affect its activity. The aim was to prepare the enzyme in a highly purified form using current techniques such as isoelectrofocusing. Since the kinetics of the enzyme have not heretofore been dealt with in the forward reaction a highly sensitive assay" procedure was developed to measure the small changes observed in this system where the affinity of the .... enzyme for substrate is at the micromolar level.

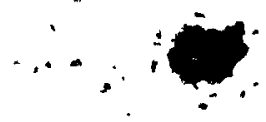


occur in vitro in deoxygenated blood (2). It was concluded that such a mëchanism would.automatically control the balance between oxyhemoglobin and deoxyhemoglobin" and would counteract the effects of an increase in reduced hemoglobin.

\section{Current Studies}

Human red cells as have been stated above depgna or glycolysis for their energy. requirements in the form $f$ ATP. T-Two moles of ATP are produced at the step catalyzed by phosphoglycerate kinase. Therefore, froiñ the point of view of cellular energetics : PGK is an important enzyme.

?This enzyme has been purified in crystalline form from yeast $(55,58)$, muscle $(55,104)$ and red cel1s. $(45,76,113)$. Kinetics studies on yeast and muscle PGK have been described in detail. . However, "these studies were done in the backwardi reaction. These investigations were undertaken to elucidate the characteristics of PGK in human erythrocytes and the factors which affect its aulivity. The aim was to prepare the enzyme in a highly purified form using current techniques such as isoelectrofocusing: Sime the kinetics of the enzyme have not heretofore been dealt with in the forward reactian a highly sensitive assay procedure was developed to measure the small changes observed in this system where the affinity of the enzyme for substrate is at the micromolar level. 


\section{MATERIALS AND METHODS}

Stored,human blood was obtained from the Blood Bank, Victoria Hospital, London, Canada.

d1-Glyceraldehyde 3-phosphoric acid (diethylacetal, monobarium salt); àdenosine 5'-diphosphate (disodium salt from equine muscle; grade I); dithiothreitol (Cleland's reagent; DTT); adenosine 5'-triphosphate (dissodium salt from equine muscle; crystalline); alcohol dehydrogenase (from yeast; 2 x crystallized); phosphoglycerate mutase (from rabbit muscle); L-cysteine hydrochloride hydrate; albumin bovine (Fraction $V$, powder); $\beta$-diphosphopyridine nucleotide ( $B$-DPN; $B-N A D$ from yeast; grade III); adenosine $5^{\prime}$-monophosphoric acid (from equine muscle; Type III sodium salt crystalline) and 2,3diphosphoglyceric acid (ditris salt) were purchased from.Sigma Chemical Company, St. Louis, Misssouri, U.S.A.

Pyruvate kinase; g1yceraldehyde 3-phosphate dehydrogenase (from muscle); lactate dehydrogenase and glycerate-3-phosphate were obtained from Boehringer Mannheim Corporation, New York, U.S.A.

Tris (hydroxymethyl) aminomethane; sodium phosphate dibasic (anhydrous powder); potassium phosphate monobasic; sodium pyrophosphate (crystal); sucrose; potassium chloride; cupric sulphate 
(crystal); magnesium chloride; glycine and ammonium persulphate (granular) were obtained from Fisher Scientific Company, Fairlawn, New Jersey, U.S.A.

Sodium hydroxide; sodium acetate (anhydrous) and potassium hydroxide were obtained from The MCArthur Chemical Company Limited, Montreal, Canada.

Acetaldehyde and strychnine hydrochloride were obtained from $K$ \& $K$ Laboratories, Inc., Plainview, N.Y.

Diethylaminoethyl-sephadex A-50 (anion exchanger particle size 40-120 $\mu$ ) and carboxymethy1-sephadex C-50 (cation exchanger - particle size 40-120 $\mathrm{\mu}$ ) were obtained from Pharmacia Fine Chemicals, Uppsala, Sweden.

Acrylamide (for electrophoresis); N,N-methylenebisacryla'mide and $N, N, N, N^{\prime}$-tetramethylethylene diamine were purchased from - Eastman Organic Chemicals, Rochester, New York, U.S.A.

Bromophenol blue and Buffalo blue black, were obtained from Beckman Instruments, Inc., Fullerton, California.

Ampholine (carrier ampholytes; $\mathrm{pH} 3-10,7-10,7-9)$ were obtained from LKB-Produkter AB Sweden.

\section{I Instrumentation}

i) Spectrophotometer, Gilford 2000 equipped with recorder and controlled temperature cell housing (Gilford Instrument Laboratories Incorporated, Oberlin, Ohio, U.S.A.) . 
ii) Fluorimeter, Eppendorf 1101M (Eppendorf Gerateban,

Nethelen + Heinz GMBH, Hamburg) equipped with a compensating voltage attachment, amplifier, controlled temperature cell housing and connected to a Brinkmann recorder model 2543 .

iii) Analytical Ultracentrifuge, Spinco Model E (Spinco Division of Beckman Instruments, Inc., Stanford Industrial Park, Palo Alţo, California, U.S.A.).

iv) Absorbance Monitor, UA-4 and a dual beam optical unit typé 4 (Instrumentation Specialties Có. Inc).

v) Eraction Collector, LKB-ultrorac 7000

vi) Ampholine Electrofocusing Equipment, LKB 8100 with $110 \mathrm{ml}$, capacity column (LKB-Produkter AB Stockholm-Bromma 1, Sweden).

vii) Electrophoretic apparatus for analytical polyacrylamide gel electrophoresis (Shandon, England).

viii) Ultrafiltration cell, Amicon, Mode1 52 (Amicon Corp., . - Lexingtor, Mass. U.S.A.

ix) pH meter 28 Radiometer (Radiometer, Copenhagen).

I I Methods

1. Substrate: 1,3-Diphosphoglyceric acid

(a) Synthesis

1,3-diphosphoglyceric acid was synthesized according to the method of Negelein (73). 
$\mathrm{G}-3-\mathrm{P}+\mathrm{NAD}^{+}+\mathrm{Pi} \rightleftarrows \mathrm{i}, 3-\mathrm{DPG}+\mathrm{NADH}+\mathrm{H}^{+}$

$\mathrm{NADH}+\mathrm{H}^{+}+$Acetaldehyde $\rightleftarrows \mathrm{NAD}^{+}+$ethanol

The sum of reactions 1 and 2 is

G-3-P $+\mathrm{Pi}+$ Acetaldehyde $\rightleftarrows 1,3-\mathrm{DPG}+$ ethanol.

The procedure was slightly modified: . a larger volume of the enzyme glyceraldehyde-3-phosphate dehydrogenase and.alcohol. dehydrogenase wère used $(1.0 \mathrm{ml}$ each of $0.75 \%$ and $0.6 \%$ respectively. instead of $0.6 \mathrm{ml}$ as reported). All $\mathrm{pH}$ measurements were made electpometrically at $0^{\circ} \mathrm{C}$.

(b) Quantitation

1,3 diphosphoglyceric acid was determined enzymatically according to the method Negelein (74) by measuring the decrease in . optical density at $340 \mathrm{~nm}$ due to the oxidation of NADH.

$\mathrm{G}-3-\mathrm{P}+$ Phosphate $+\mathrm{NAD}^{+} \stackrel{\mathrm{G}_{-}-\mathrm{P}-\mathrm{PD}}{\longrightarrow} 1,3-\mathrm{DPG}+\mathrm{NADH}+\mathrm{H}^{+}$

The total yield was $61 \%$ of that reported. 1,3-DPG

was more stable at $\mathrm{pH} 7.6$ when stored in the frozen state $\left(-25^{\circ} \mathrm{C}\right)$ (73). The loss in 24 hours was then only 1.38 compared to 3.08 as reported. When it was satored in liquid nitrogen there was no measurable loss. The stability of 1,3-DPG was essential in order to avoid the degradative production of $3-P G A$ which in turn would influence the indicator reaction.

-2. Enzyme: Phosphoglycerate Kinase, Isolation and Purification All the steps in the isolation and purification of PGK 
were carried out at $0-4^{\circ} \mathrm{C}$ unless otherwise stated (Figure 2). The enzyme was isolated and purified by a modification of the method of Yoshida and Watanabe (113). Human blood (2-3, weeks old preserved) in $A C D$ ) was centrifuged at $3,000 \mathrm{~g}$ for 10 minutes. The plasma and buffy coat were removed by aspiration:. The red cells were washed thrice with two volumes of cold $1.15 \%$ of potassium chloride solution and centrifuged each time at 3,000 $\times \mathrm{g}$ for 10 minutes. The washed red cells were resuspended in two volumes of cold distillèd water. The hemolysate was prepared by alternately freezing and then thawing three times. The pH of the hemolysate was adjusted to 7.3 with $1 \mathrm{M}$ potassium hydroxide. The hemoglobin was precipitated by adding $1 / 3$ volume of an ethanol-chloroform mixture $(2: 1 \mathrm{~V} / \mathrm{V})$ previously cooled at $-20^{\circ} \mathrm{C}$. . After occasional stirring for 25 minutes the mixture was separated by centrifugation (at $15,000 \times \mathrm{g}$ for 20 minutes) and the sedimented hemoglobin was removed. The enzyme was precipitated by adding 2.5 volumes of ethanol (previously chilled at $-20^{\circ} \mathrm{C}$ ) to the supernatant. After 20 minutes at, $-20^{\circ} \mathrm{C}$ the precipitate was collected by centrifugation $(15,000 \times \mathrm{g}$ for 20 minutes). The precipitate was dissolved in $0.01 \mathrm{M}$ phosphate buffer, $\mathrm{pH} 7.0$ and dialyzed ovemight against this buffer.

The dialyzed enzyme was centrifuged and the insoluble. material was discarded. CM-sephadex $(3 \mathrm{~g}$ equilibrated with $0.01 \mathrm{M}$ phosphate.buffer, $\mathrm{pH} 7.0$ ) was added to the supernatant in small portions with constant stirring and the $\mathrm{pH}$ was maintained at 6.5 with $2 \mathrm{~N}$ actic acid. The mixture was placed on a Buchner funnel and 
$B$

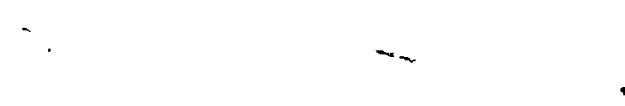

\&

$\because$

FIGURE 2

)

i

The isolation and purification of PGK from human erythrocytes.

(Conditions as described in the text). 
<smiles>[14CH3]</smiles>
2,3 weeks ACD-blood Erythrocytes Plasma and buffy coat $\rightarrow$ Discard $\overbrace{\substack{\text { Washed } \\ \text { Erythrocytes }}}$ Washed, centrifuged $3 x$

Freeze, thaw $3 x$

Hemolyzed Erythrocytes :

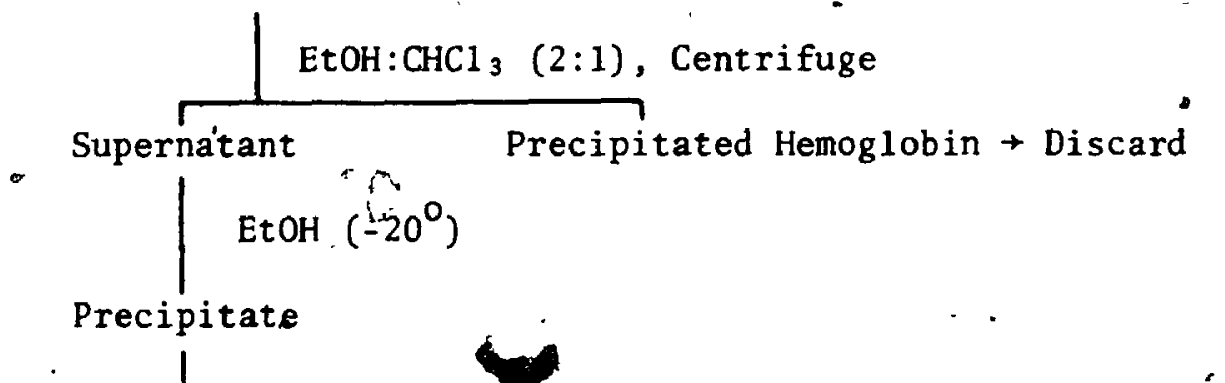

Dissolve in 0:01M Phosphate Buffer, Centrifuge

Soluble Enzyme Solution "Insoluble Material $\rightarrow$ Discard

1. Adsorption CM-Sephadex

2. Elution with 0.1M Phosphate Buffer

3. Concentration

Coloured Enzyme Solution

1. DEAE Sèphadex Column Chromatography

2. Elution with 0.01M Triș Buffer

3. Concentration

Colouriess Enzyme Solution

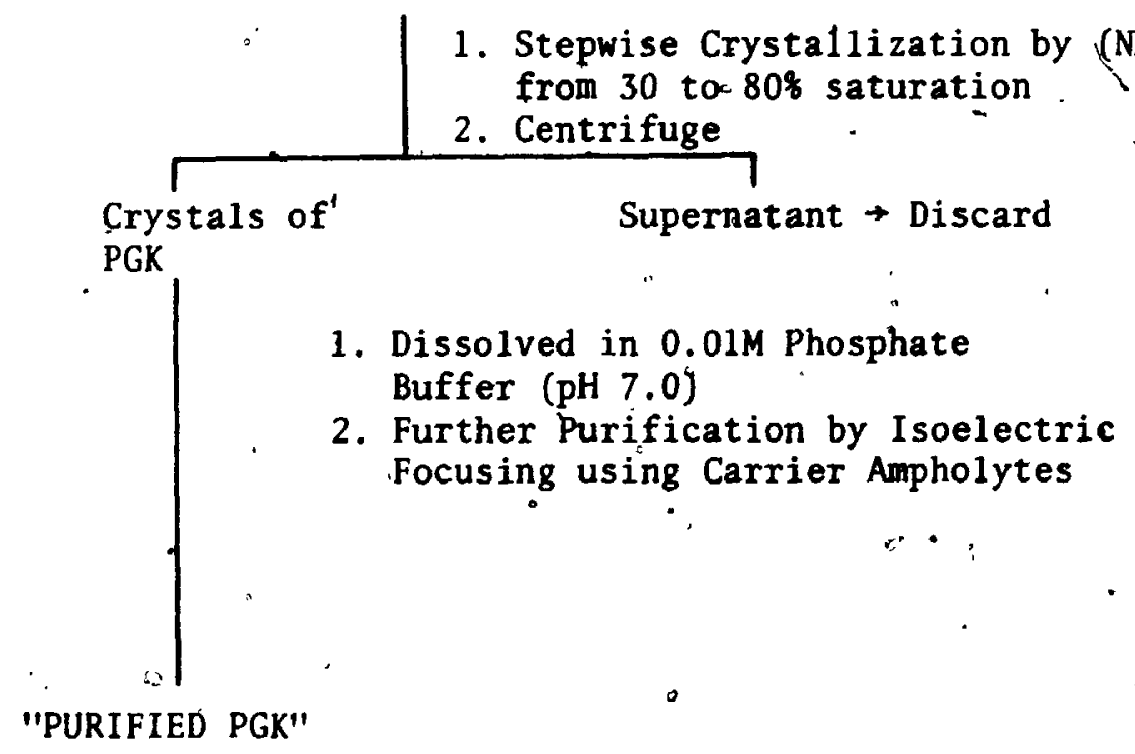


washed with $200 \mathrm{ml}$ of $0.01 \mathrm{M}$ phosphate buffer, $\mathrm{pH} 7.0$. The adsorbed enzyme was eluted with $250 \mathrm{~m} 1$ of $0.1 \mathrm{M}$ phosphate buffer, $\mathrm{pH} 7.0$ and concentrated by ultrafiltration.

The concentrated enzyme solution was dialyzed against $0.01 \mathrm{M}$ Tris buffer, $\mathrm{pH} 8.0$. It was then placed on a DEAE-sephadex column $(2.5 \times 10 \mathrm{cms})$ that had been equilibrated with $0.01 \mathrm{M}$ Tris buffer, $\mathrm{pH}$ 8.0. The enzyme was eluted with the same buffer, while the hemoglobin remained adsorbed on the column. The eluate from the column containing the PGK was adjusted to $\mathrm{pH} 7.0$ with $1 \mathrm{~N}$ acetic acid and concentrated by ultrafiltration.

The concentrated enzyme solution was centrifuged and the insoluble material was discarded. The supernatant was placed in a dialysis bag ( $1 \mathrm{~cm}$ diameter) and dialyzed against $0.1 \mathrm{M}$ phosphate buffer, $\mathrm{pH} 7.0$, containing ammonium sulfate (30\%). The concentration of ammonium sulfate was increased slowly ( $2 \mathrm{ml}$ per hour) from $30 \%$ to $65 \%$ in 24 hours. After 24 hours the concentration of ammonium sulfate was further increased from $65 \%$ to $85 \%$ in 24 hours. The crystals. were collected by centrifugation and the supernatant was discarded. The crystals were dissolved in $0.01 \mathrm{M}$ phosphate buffer, $\mathrm{pH} 7.0$, containing cysteine $(12.0 \mathrm{mM})$ and kept frozen at $-20^{\circ} \mathrm{C}$.

The crystalline enzyme solution was further purified by electrofocusing (110) using carrier ampholytes of different pH ranges $(3-10,7-9$ and $7-10)$. The electrofocu fint was carried out for 3 days (when using ampholine $\mathrm{pH}$ range $3-10$ ) and 5 days (when 
using ampholine $\mathrm{pH}$ ranges $7-9$ and $7-10$ ) at $4^{\circ} \mathrm{C}$. The final potentials were 300 and 600 volts respectively. The column was emptied at a rate of $1 \mathrm{ml}$ per minute with the aid of a peristaltic pump and collected in small volume aliquots with the aid of a fraction collector. The eluted fractions were kept at $4^{\circ} \mathrm{C}$. The $\mathrm{pH}$ of each fraction was measured. The aliquots which contained the highest PGK activity, were diluted several times with $0.01 \mathrm{M}$ phosphate buffer, $\mathrm{pH} 7.0$ and concentrated by ultrafiltration in order to remove the ampholine and sucrose. The concentrated purified enzyme was stored with added cysteine $(12.0 \mathrm{mM})$ at $-20^{\circ} \mathrm{C}$.

\section{Estimation of Protein}

Protein concentration in the PGK was determined spectrophotometrically by the method of Lowry et al. (66). Crystalline bovine albumin was used as the standard.

4. PGK Assay

PGK activity was assayed in the forward direction leading from 1,3-DPG to 3-PGA (Figure 3) by either fluorimetric or spectrophotometric methods. The very low rates of PGK activity in the kinetic studies were estimated by the fluorimetric method. Assays of higher concentrations of PGK activity during its preparation and purification were estimated spectrophotometrically. The reaction mixtures for both methods contained the same ingredients but varied in the concentration used. 
?

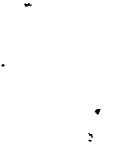

4

$\therefore$.

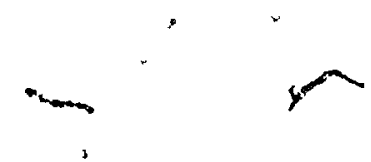

FIGURE 3

The scheme for assaying the purified PGK by utilizing lactate dehydrogenase as the indicator reaction. - (Conditions as described in the text).

$\cdots$

7

$+1$ 

(a) Reaction Mixture of Fluorimetric Assay

- The following ingredients were mixed in a final

volume of $1.0 \mathrm{ml}$ in the concentration noted:

$34.0 \times 10^{-3} \mathrm{M}$ Tris buffer, $\mathrm{pH} 8.5 ; 5.0 \times 10^{-3} \mathrm{M}$ phosphate

buffer, $\mathrm{pH} 7.3 ; 6.0 \times 10^{-3} \mathrm{M}$ cysteine hydrochloride, $\mathrm{pH} 7.0 ; 0.4 \times 10^{-3} \mathrm{M}$ *sodium adenosine diphosphate; ${ }^{*} \mathrm{NADH}, 1.4 \times 10^{-5} \mathrm{M} ;{ }^{*} \mathrm{MgCl}_{2} 1.0 \times 10^{-3} \mathrm{M}$;

${ }^{* 1}$, 3-DPG $10 \times 10^{-6} \mathrm{M}$; ${ }^{*}$ phosphoglycerate kinase; $8.7 \times 10^{-7} \mathrm{mg}\left(2.5 \times 10^{-3}\right.$ units per ml of assay thixture) phosphoglyceromutase, $4.2 \times 10^{-3} \mathrm{mg}$

(5.5 units per, ml of assay mixture) ; -enolase $3.9 \times 10^{-2} \mathrm{mg}$. (7.15 units per $\mathrm{ml}$ of assay mixture); pyruvate kinase $1.7 \dot{7}, 10^{-2}, \mathrm{mg}$ (7.26 units per $\mathrm{ml}$ of assay mixture) and lactăte dehydrogenase $6.0 \times 10^{-3} \mathrm{mg}$ (7.26 units per ml of assay mixture).

*The concentration used in the spectrophotometric $\therefore$ assay are as follows:

$\mathrm{NADH}, 5.5 \times 10^{-4} \mathrm{M} ; \mathrm{MgCl}_{2}, 4.0 \times 10^{-3} \mathrm{M} ; \mathrm{ADP}, 2.0 \times 10^{-3} \mathrm{M}$; 1,3-DPG ${ }^{*} 300-350 \times 10^{-6} \mathrm{M}^{2}$ and phosphoglycerate kinase $\left(5-7 \times 10^{-2}\right.$ units per ml of assay mixture). :

The above listed ingredients were added to a pair of cuvettes of $1.0 \mathrm{~cm}$ light path contaìning a final volume of $1.0 \mathrm{ml}$ at a final pH of 8.3. A series' of blanks were run in which one of the following ingredients respectively was omitted from the assay mixture added to the cuvette $\mathrm{ADP}, \mathrm{Mg}^{2+}, 1,3-\mathrm{DPG}$ and $\mathrm{PGK}$. No appreciable change in fluorescence wass observed when one of the above ingredlents was omitted. 
(b) Fluorimetric Determination

The fluorimetric procedure of Estabrook (33) for NABD coupled enzymes was adapted to the measurement of the reaction rate, at very low substrate concentrations. The oxidation of NADH by LDH was measured by following the change in fluorescence in a fluorimeter at $366 \mathrm{~nm}$ excitation light and secondary emission filter - with a band pass of 400 to $650 \mathrm{~nm}$. The reaction mixture was preincubated at $37^{\circ} \mathrm{C}$ for 15 minutes in the flyorimeter for temperature equilibration before the addition of 1,3-DPG. A typical

- PGK assay is shown in Figure 4. The change in fluorescence was standardized using NADH, whose concentration had been previously determined spectrophotometrically according to Kornberg and Pricer (53). One unit is defined as the quantity of enzyme that will convert one $\mu \mathrm{M}$ of substrate per minute (I.U.) at $37^{\circ} \mathrm{C}$. Enzyme activity was expressed on the basis of change in fluorescence (i.e. $\Delta R$ per minute) throughout the kinetic studies."

(c). Spectrophotometric method

The spectrophotometric method for assay of the purified enzyme (Figure 3) utilized lactate dehydrogenase as the indicator reaction. In these assays the reaction mixture was preincubated at. $37^{\circ} \mathrm{C}$ for 15 minutes in the absence of added 1,3-DPG to equilibrate the temperature of the reaction mixture (all ingredients were maintained

12 at $4^{\circ} \mathrm{C}$ prior to addition of the assay cuvette). The change in the 


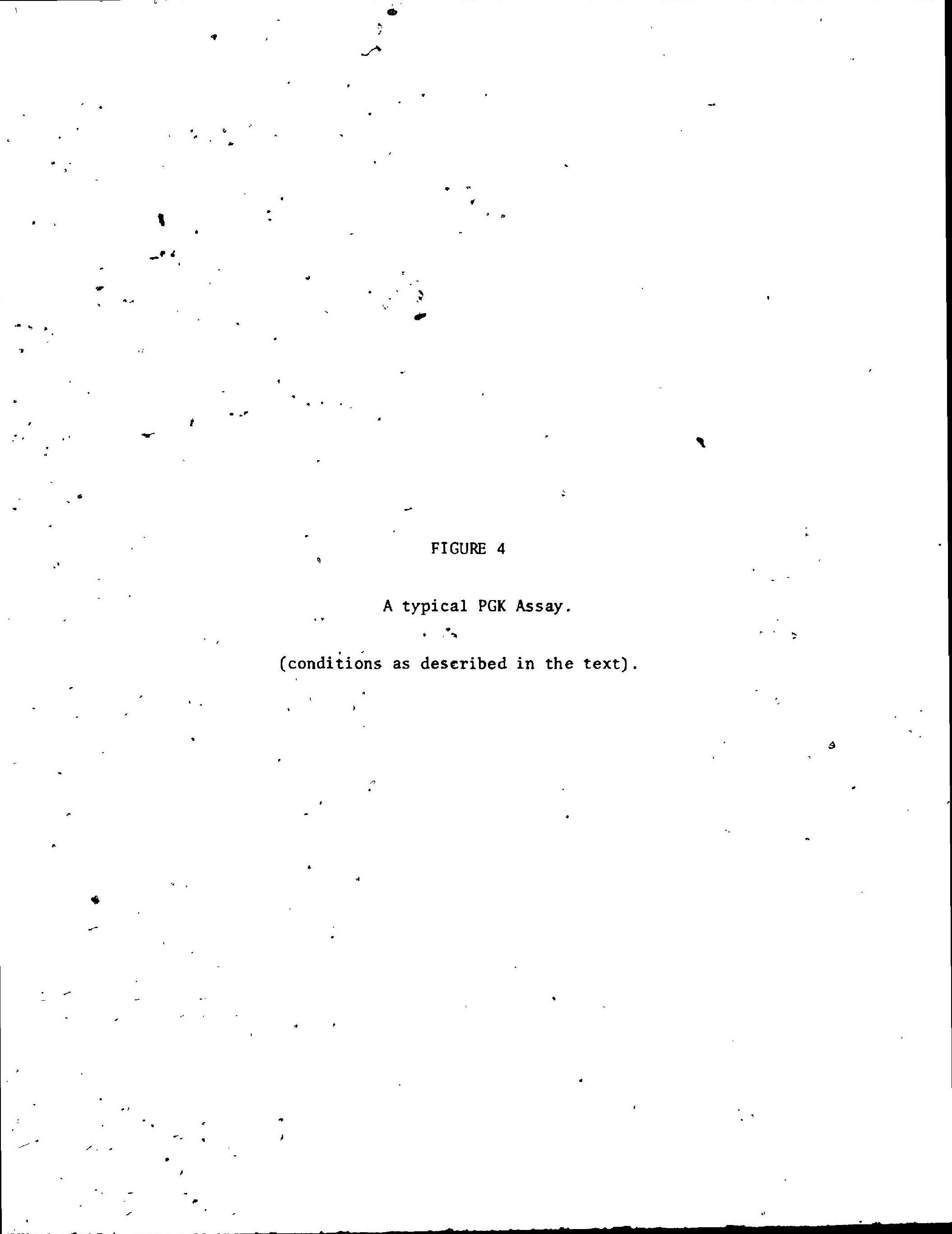




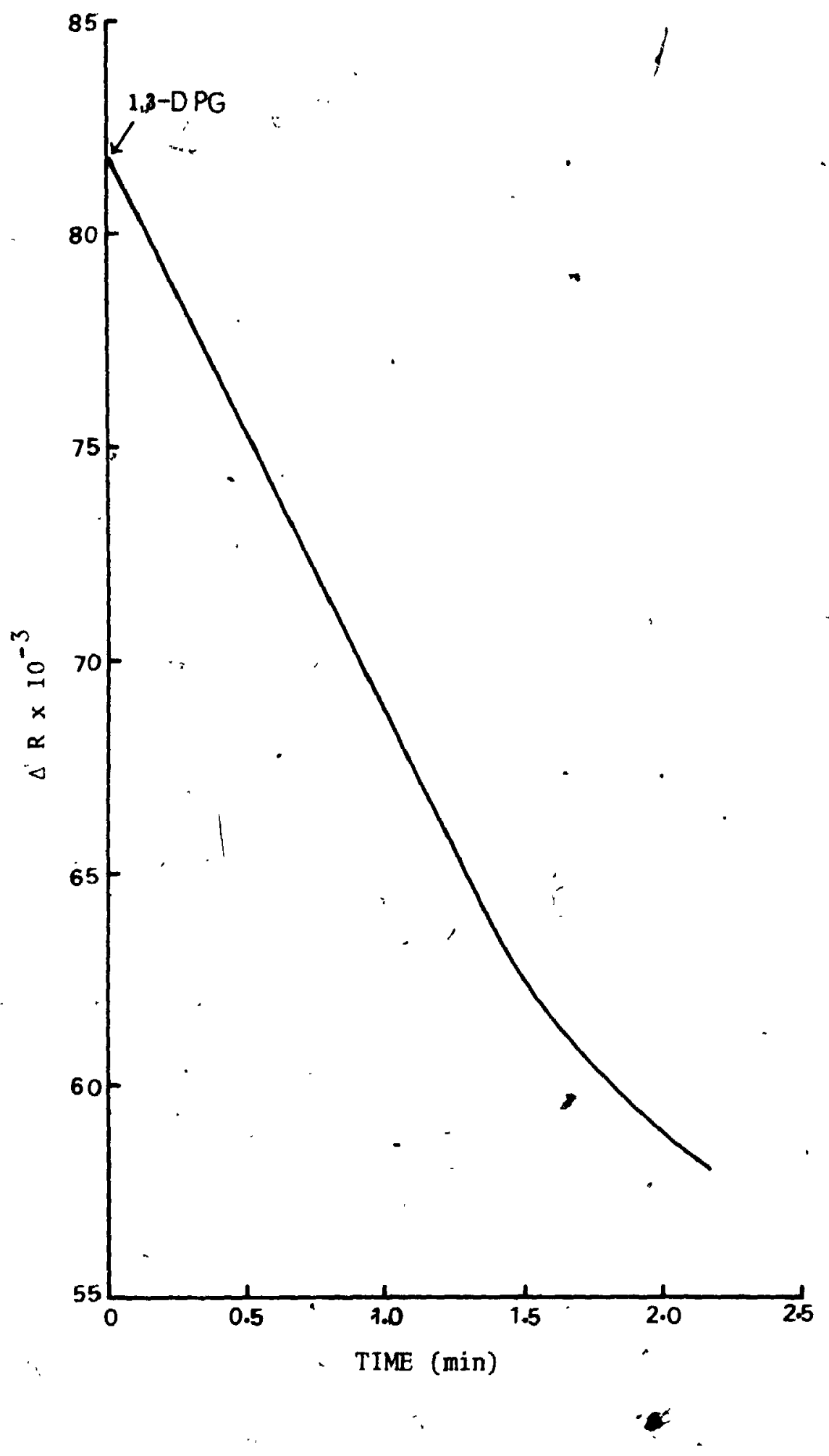




$$
\text { के }
$$

rate of optical density was measured in the spectrophotometer at $340 \mathrm{~nm}$ (recorded automatically at intervals of five seconds). No appreciable increase in optical density at $340 \mathrm{~nm}$ was observed when substrate 1,3-DPG was omitted. When the reaction was initiated by the addition of 1,3-DPG to the test cuvette there was an immediate change in optical density. The change in optical density was recorded for 3 to 4 minutes. Enzyme activity was expressed in the terms of the rate of 1,3-DPG utilized and calculated from the change in optical density per minute.

\section{(d) Linearity of Assay}

0

The fluorimetric assay for phosphoglycerate kinase was used to measure PGK activity in the range $0.6 \times 10^{-3}$ to $2.4 \times 10^{-3}$ units per ml of assay mixture (Figure 5). In this range a zero order curve was described. The assay was performed on the pooled fractions of highest activity obtained from electrofocusing. Saturating levels of $1,3-D P G\left(10 \times 10^{-6} \cdot\right)^{\prime}, \mathrm{Mg}^{2+}\left(1.0 \times 10^{-3} \mathrm{M}\right)$ and $\mathrm{ADP}\left(0.4 \times 10^{-3} \mathrm{M}\right)$ were used in assaying the enzyme. The normal activity range of PGK used in this study was equivalent $<_{2} \times 10^{-3}$ units per $\mathrm{ml}$ of assay mixture.

The assay of tho enzyme phosphoglycerate kinase was carried out in the forward direction leading from 1,3-DPG to 3-PGA. A1 though this assay procedure involves an auxiliary and indicator chain of enzymes, it is not unique in the estimation of enzyme activity i.e. 


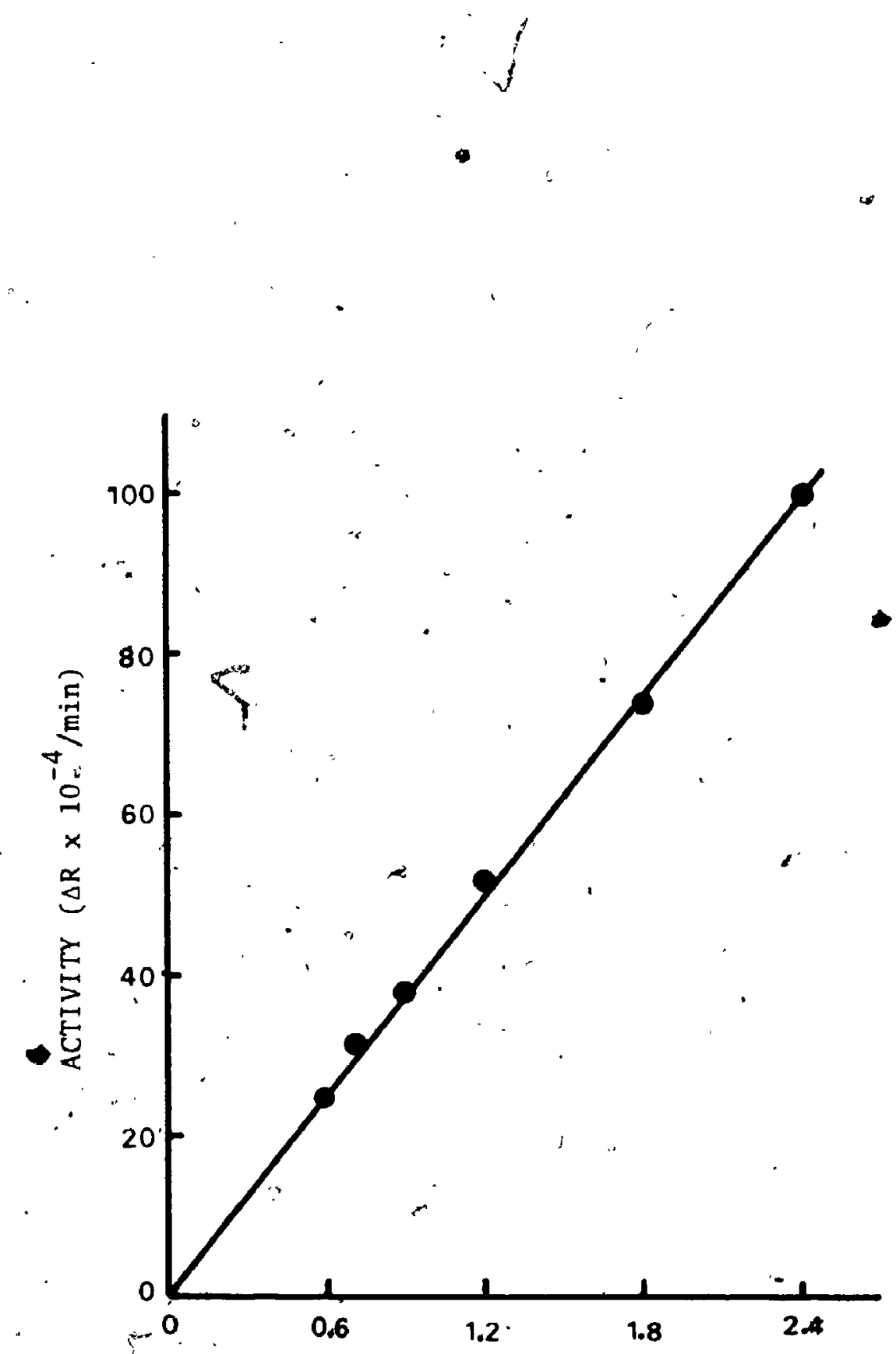

PGK $\times 10^{-3}$ UNITS/m1 OF ASSAY MIXTURE 
.

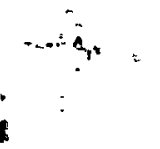

the studies on phosphofructokinase by Lowry and Passonneau (66a).

- As shown in Figure" 3 the product of the test reaction, 3-PGA was coupled via three auxiliary enzymes to an, $\mathrm{NAD}^{+}$linked dehydrogenase $(L D H)$, the latter being the indicatorgenzyme. Both auxiliary and indicator enzymes were added in excess to yield true initial velocity kinetics, i.e. without a time lag upon the addition of substrate. In order to demonstrate that the auxiliary-indicator enzymes were not in fact rate-limiting the following experiments.

- wère carried out.

The level at which each enzyme in the reaction sequence would be rate limiting was tested individually by varying its concentration in the assay mixture while keeping the concentrations - of the other enzymes constant. The concentration of PGK throughout the experiment was kept constant $\left(2.53 \times 10^{-3}\right.$ units per.ml of assay mixture).'The first auxiliary enzyme in the series, i.e. PGM, responsibje for the conversion of 3-PGA to 2-PGA was assayed at varying concentrations. $P G M$ in excess of one unit per ml of assay mixture ceased to be rate limiting (Figure 6a)? Increasing this enzyme up to 22 units per mr of assay mixture did not effect a further increased rate in the assay of PGK. The arrow in Figure $6 \mathrm{a}$ indicates the 1 - $\because$ concentration of PGM (5.5 units per $\mathrm{ml}$ of assay mixture) utilized throughout in the assay proceture; this represents a minimum of a five-fold excess of PGM over tts rate limiting concentrations (i.e. $\because$ : the ratio of PGM activity with respect 00 the PGK assayed was greater than 2000 times). 
FIGURE 6

Assay of PGK activity at varying concentrations of:

(a) PGM

(b) Enolase

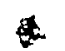

$\rho$

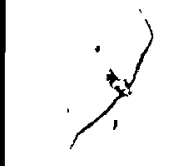

(conditids as described in the text).

$-$

$\because$

$\because$

ins

is

$\cdot 9$

3

a: 

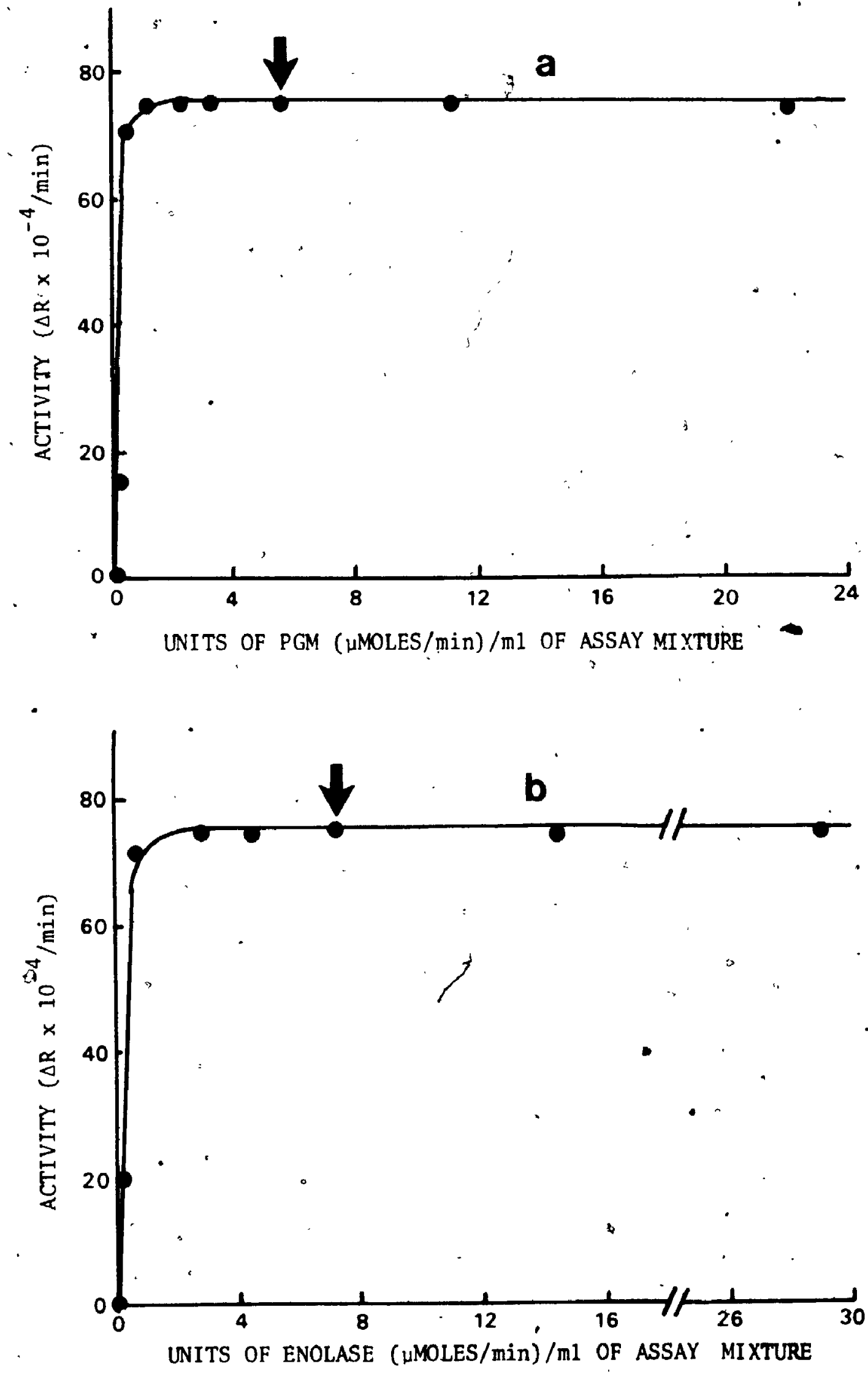

$\theta$ 
Similarly both enolase and pyruvate kinase (Figures 6b and 7a respectively) were rate limiting at concentrations less than 1.5 units per ml of assay mixture. Excess concentrations of either of these enzymes (up to 29 units per $m 1$ of assay mixture were tested) did not effect a further increase in the rate in the assay. Enolase and pyruvate kinase were maintained throughout at a concentration of 7.15 units and 7.26 units per $m 1$ of assay mixture respectively. Both enzymes were used in excess over their rate limiting concentrations (i.e. the ratios of enolase and pyruvate kinase activities with respect to the $P G K$ assayed were greater than 2800 times).

The concentration of indicator enzyme (LDH) was varied in a similar manner to the auxiliary enzymes and showed similar characteristics. LDH was not rate limiting at concentrations in excess of 1.5 units per $\mathrm{ml}$ assgy mixture. Higher concentrations of this enzyme (up to 29 units per ml of assay mixture) did not effect a further increase in the rate of the PGK assay. The arrow in Figure $7 \mathrm{~b}$ indicates the concentration of LDH ( 7.26 units per $\mathrm{ml}$ of assay mixture) utilized throughout in the assay procedures. This represents.

a five fold excess of LDH over its rate limiting concentration (i.e: the ratio of $\mathrm{LDH}$ activity with respect to the PGK assayed was greater than 2800 times).

Thus it is clear from the experimental results described above that the auxiliary-indicator enzymes used in assaying-PGK : activity by the procedure outlined pere present in excess. 
Similarly both enolase and pyruvate kinase (Figures $6 \mathrm{~b}$ and 7a respectively) were rate limiting at concentrations less than 1.5 units per $m l$ of assay mixture. Excess concentrations of either of these enzymes (up te, 29 units per ml of assay mixture were tested): did not effect a further increase in the rate in the assay. Enolase and pyruvate kinase were maintained throughout at a concentration of 7.15 units and 7.26 units per $\mathrm{ml}$ of assay, mixture respectively. Both enzymes were used in excess over their rate limiting concentrations (i.e. the ratios of enolase and pyruvate kinase activities with respect to the PGK assayed were greater than 2800 times).

The concentration of indicator enzyme. (LDH) was varied in a similar manner to the auxiliary enzymes and showed similar characteristics. LDH was not rate limiting at concentrations in excess of 1.5 units per ml assay mixture. Higher concentrations of this enzyme (up to 29 units per ml of assay mixture) did not effect a further increase in the rate of the PGK assay. The arrow in Figure $7 \mathrm{~b}$ indicates. the concentration of $\mathrm{LDH}$ ( 7.26 units per $\mathrm{ml}$ of assay mixture) utilized throughout in the assay procedures. This represents a.five fold excess of LDH over its rate limting concentration (i.e. the ratio of LDH activity with respect to the PGK assayed was greater than 2800 times)'

Thus it is clear from the experimental results described • above that the auxiliary-indicator enzymes used in assaying PGK activity by the procedure outlined were present in excess. 


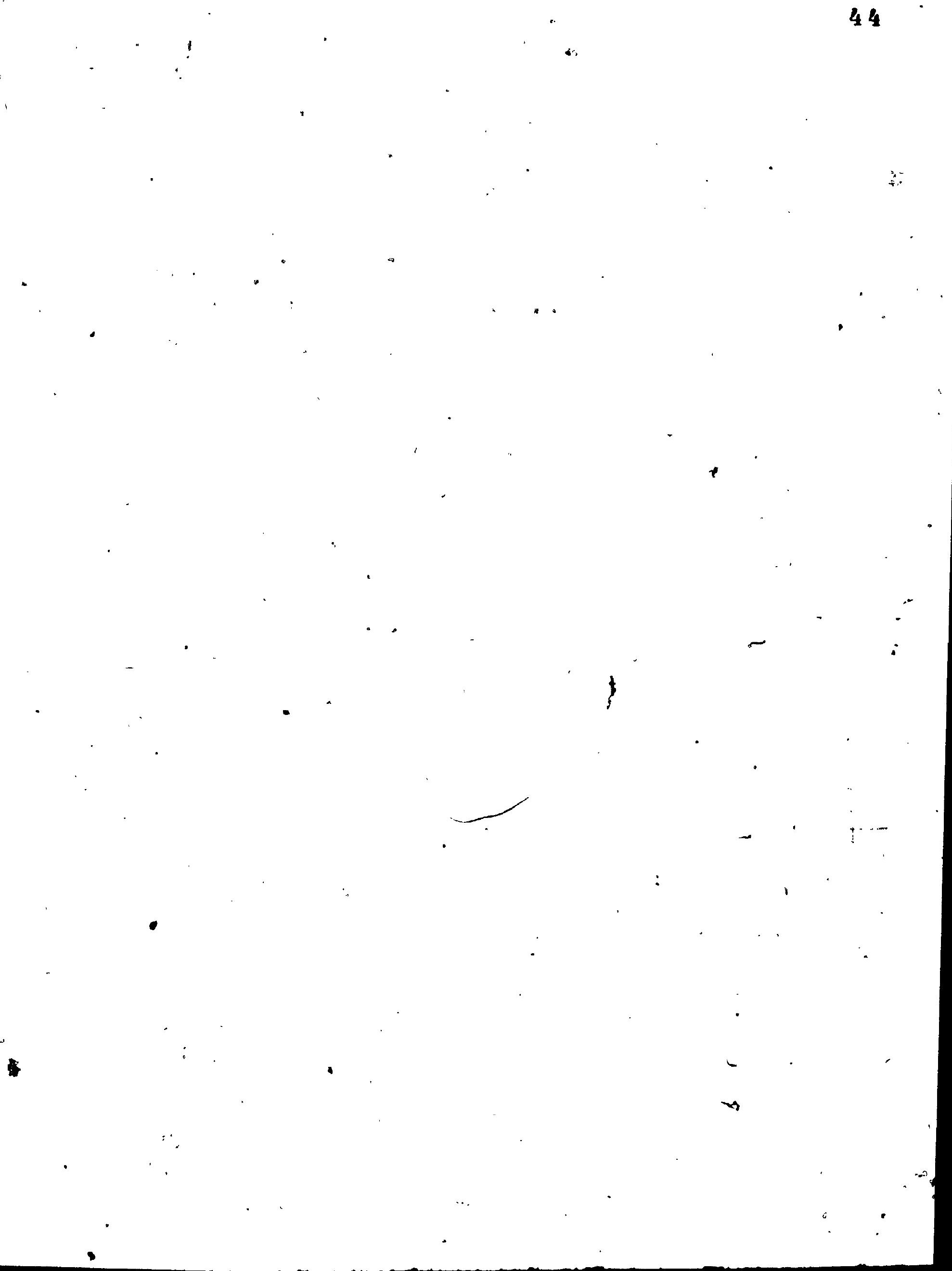


$\cdot$
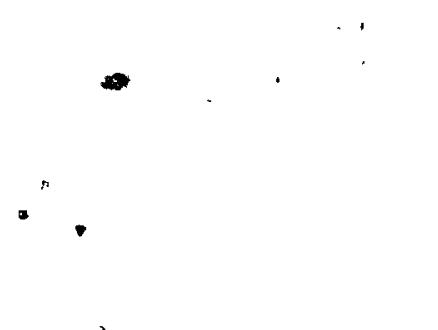

FIGURE 7

ii

- Assay of PGK activity, at varying concentrations of:

(a) P.K

(b) LDH

(conditions as described in the text)

1

0

n 

In addition to ascertaining that the auxisiary-indicator enzymes were added in excess to the assay mixture, ts were carried out to determine the effect of varying substrates and cofactor : concentrations on these enzymes in order to establish whether PGK was rate limiting under these conditions. A comparison was made of the rate of NADH utilization in parallel assay systems when 1,3-DPG or 3-PGA in similar concentrations $\left(1-15 \times 10^{-6} \overline{\mathrm{M}}\right.$ of $1,3-\overline{\mathrm{DPG}}$ and $0.25-20$ $x \cdot 10^{-6} \mathrm{M}$ of 3 -PGA respectively) was the substrate. At very low concentrations activity in the assay system with 3-PGA as substrate was more than double that of the parallel assay with $1,3-\mathrm{DPG}$ as substrate (the scale has been reduced to include the greater change observed with 3-PGA as substrate and compare with Figure 24). This difference magnified with increasing levels of substrate. At the concentration of maximal $1,3-\mathrm{DPG}\left(10 \times 10^{-6} \mathrm{M}\right)$ utilization the system with $3-P G A$ as substrate demonstrated $>8$ times the activity. This ratio increased progressively at higher concentrations. The curve described in the system with 3-PGA-was a straight line whereas that for 1,3-DPG was' the characteristic 'bumpy' curve. Thus the effects observed, i.e. substrate activation can be ascribed to the PGK activity. The linearity in the rate of NADH utilization with increased 3-PGA is further proof that the auxiliary-indicator enzymes were not rate-limiting in this system.

The effect of Varying concentrations of ADP $(0.01-0.4 x$ $\left.10^{-3} \mathrm{M}\right)$ at a fixed concentration of added $1,3-\mathrm{DPG}\left(10 \times 10^{-6} \mathrm{M}\right)$ or $3-\mathrm{PGA}$ 


\section{FIGURE 8}

Parallel assays using $1,3-$ DPG and $3-$ PGA as substrate.

SUBSTRATE:

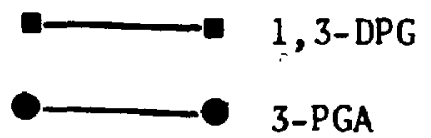

(conditions as described in the text)

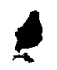

8 
$b$

-

48

9

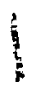

8.

-

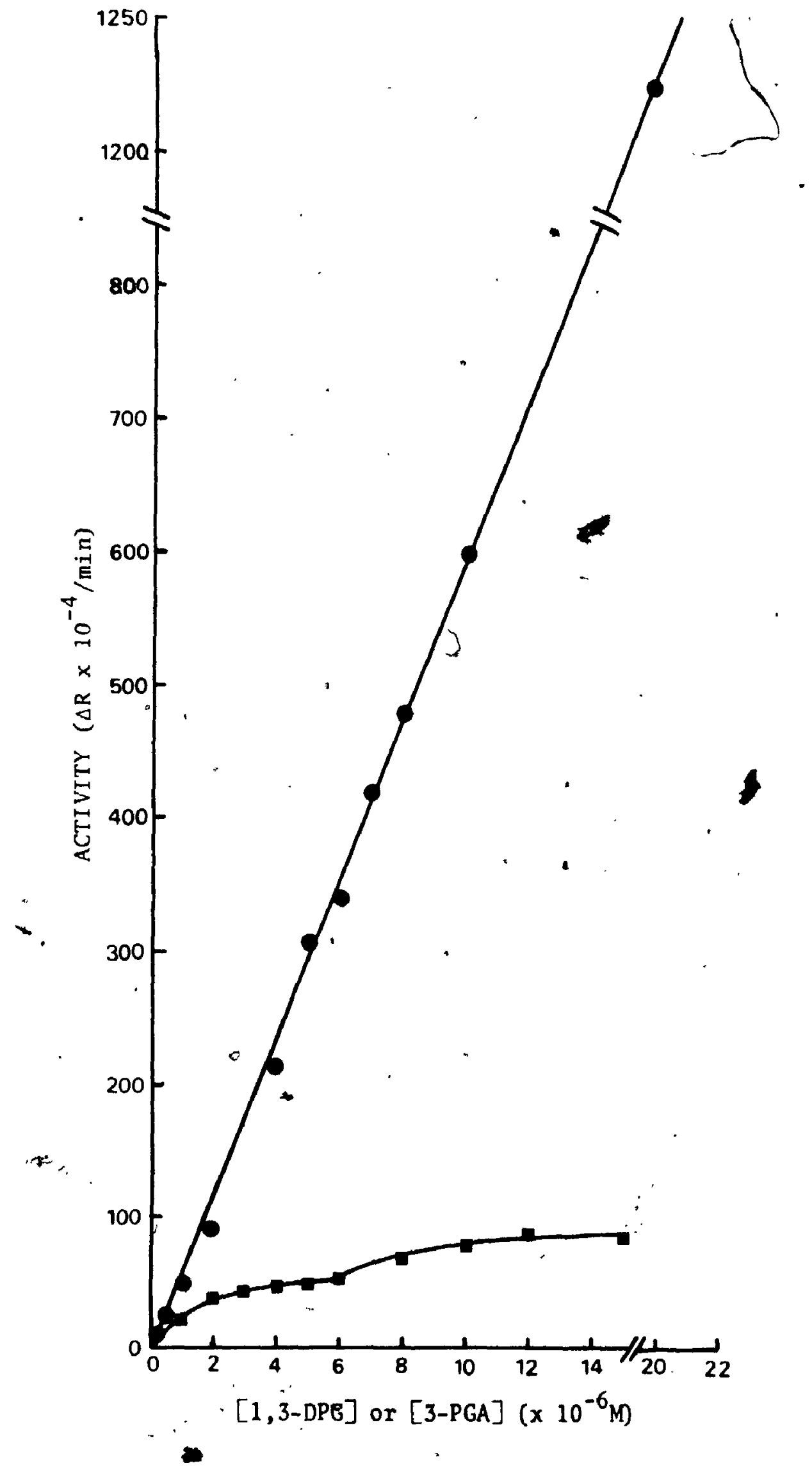


on PGK and auxiliary-indicator enzyme activities were studied in parallel assays. It is apparent from Figure 9 that PGK is ratelimiting at the optimal concentration of ADP $(0.4 \mathrm{mM})$ employed in the normal assay procedure. At the lowest concentration of ADP used $(0.01 \mathrm{mM})$ PGK activity is $<1 / 5$ that of the auxiliary-indicator chain and at $0.10 \mathrm{mM} \mathrm{ADP}$ is reduced to $1 / 12$. The allosteric effects of ADP on PGK activity (see Results below) were not observed with the auxiliary-indicator enzymes when using 3-PGA as the substrate.

The effect of $\mathrm{Mg}^{2+}$ on PGK and auxiliary-indicator enzymes activities were also studied at a fixed level of added 1,3-DPG $\left(10 \times 10^{-6} \mathrm{M}\right)$ or $3-\mathrm{PGA}$ and varying concentrations of $\mathrm{Mg}^{2+}(0.05-1.0$ $\times 10^{-3} \mathrm{M}$ in parallel assays. Similar to the observations above with 1,3-DPG and ADP', the auxiliary-indicator chain activity far exceeded that of the test enzyme (Figure 10 ) in the range of $\mathrm{Mg}^{2+}$ concentrations tested.

To summarize it may be stated that the PGK assay described and utilized herein has been shown to be reliable since:

(a) The auxiliary-indicator enzymes have been shown to be added in excess.

(b) The observed effects of variation in concentrations of substrates and cofactor are an expression of PGK activity. 
in

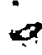

$\alpha$

FIGURE 9

Parallel Assays

0

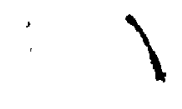

The effect of varying ADP concentrations.

SUBSTRATE :

$1,3-\mathrm{DPG} 10 \times 10^{-6} \mathrm{M}$

-PGA $10 \times 10^{-6} \mathrm{M}$

(conditions as described in the text)

$\$$

C.

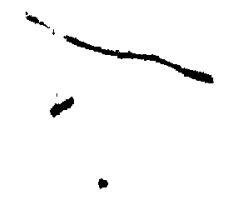

8

2

5 
51

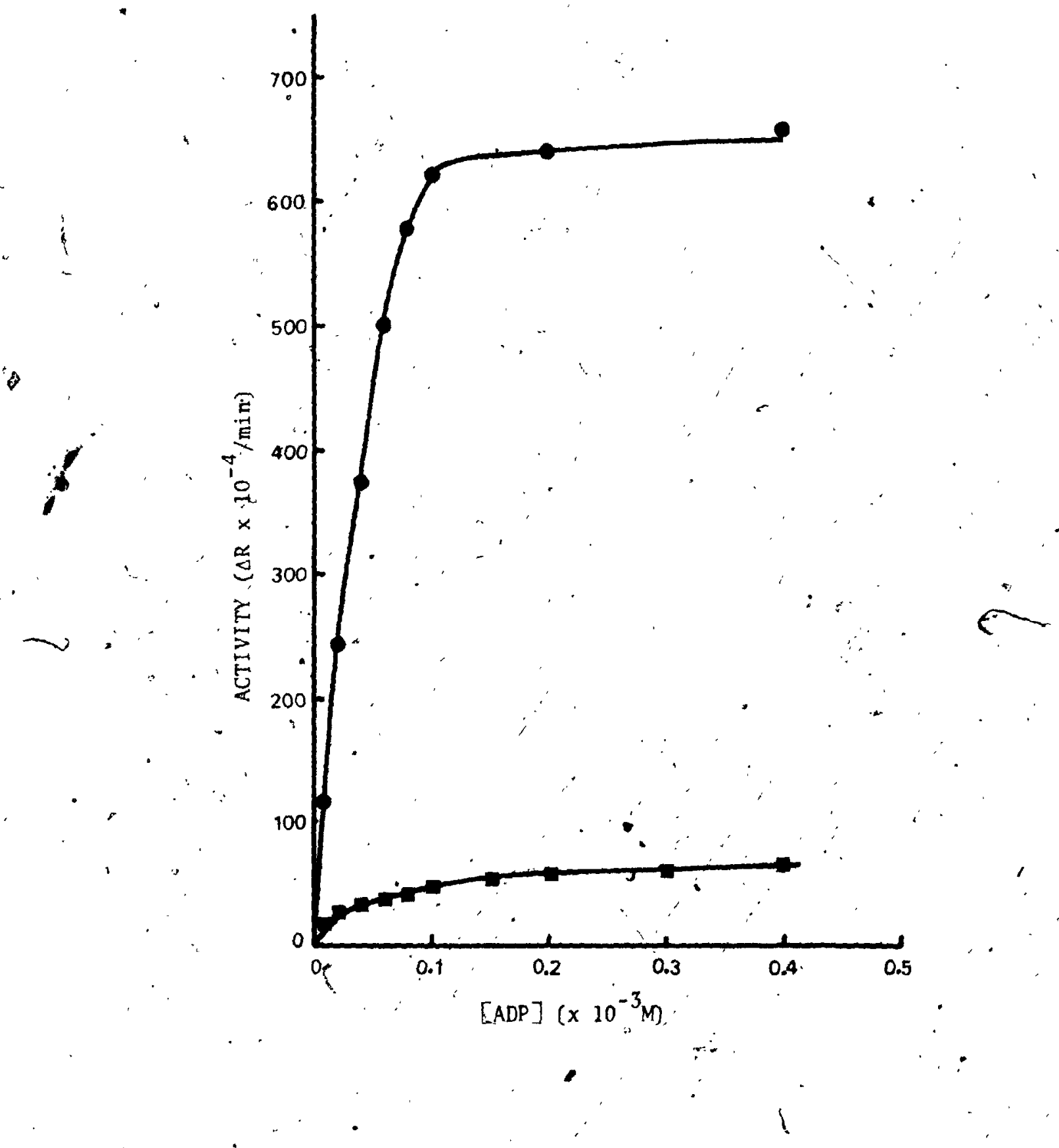





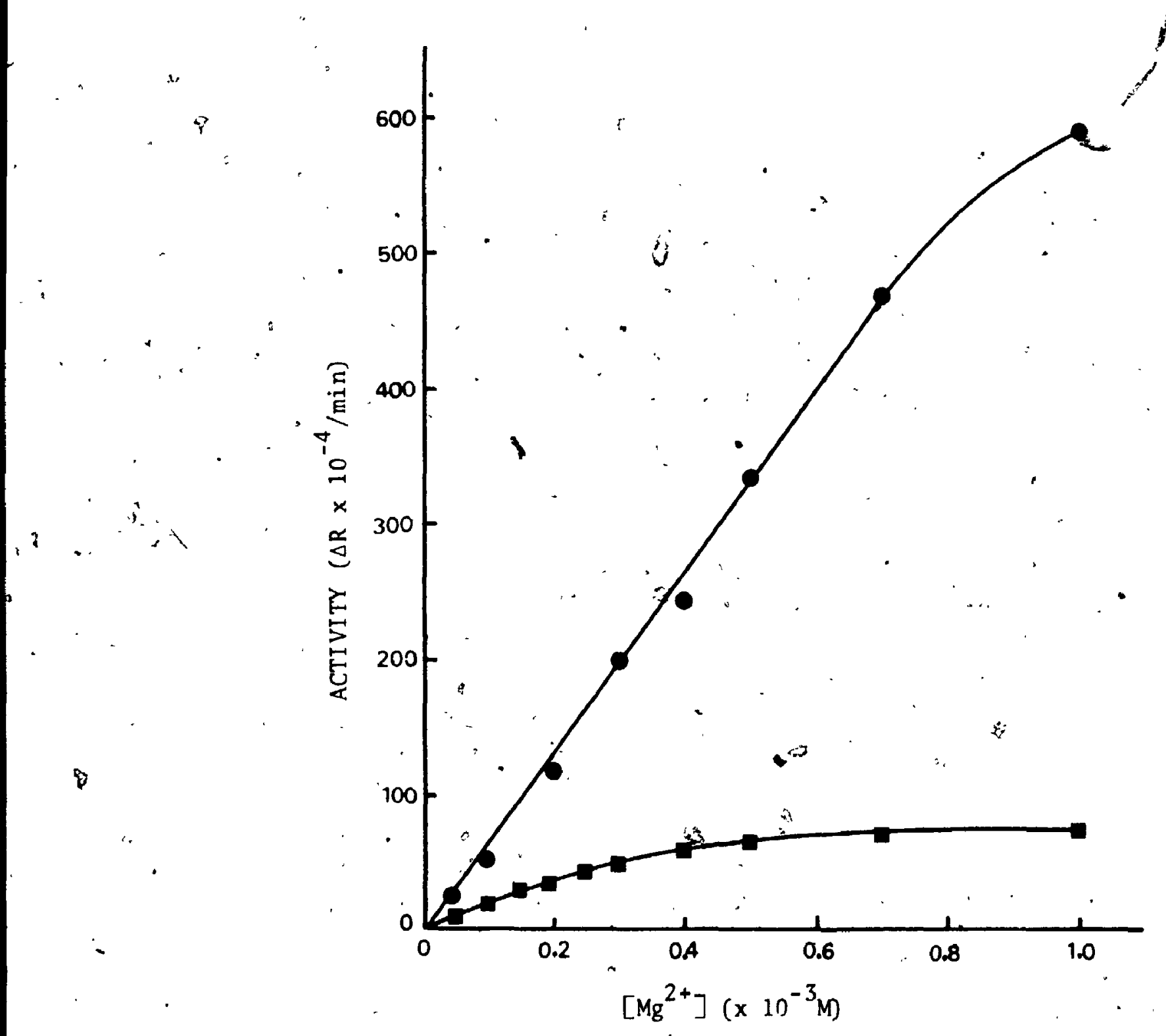

$$
\because 4
$$


A theoretical treatment of the requirement of a five enzyme chain of test, auxiliary and indicator enzyme was undertaken to further 1 establish the efficacy of the assay system. Bergmeyer (10a) has 'previously dealt with a two step system.

If in a chain of continuous reactions, $A$
and $F$ is the end product with $B, C, D$ and $E$
en this can be expressed symbolically as:

$$
\mathrm{A} \stackrel{\mathrm{K}_{1}}{\rightarrow} \mathrm{B} \cdot \stackrel{\mathrm{K}_{2}}{\rightarrow} \mathrm{C} \stackrel{\mathrm{K}_{3}}{\rightarrow} \mathrm{D} \stackrel{\mathrm{K}_{4}}{\rightarrow} \mathrm{E} \stackrel{\mathrm{K}_{5}}{\rightarrow} \mathrm{F}
$$

where

$$
K_{1} \text { is the test enzyme }
$$

$\mathrm{K}_{2}, \mathrm{~K}_{3}$ and $\mathrm{K}_{4}$ are the auxiliary enzymes

- $K_{5}$ is the indicator enzyme

It is assumed that when time $t=0$

$$
{ }_{0} C_{B}=C_{C}=C_{D}=C_{E}=C_{F}={ }^{\circ} 0
$$

4

If $a$ is the initial concentration of $A$, then by definition, after time $t$. when all species are present:

$$
a=C_{A}+C_{B}+C_{C}+C_{D_{F}}+C_{E}+C_{F}
$$

and hence

$$
C_{F}=a-C_{A}-C_{B}-C_{C}-C_{D}-C_{E}
$$

where. $C_{A}, C_{B}, C_{C}, C_{D}, C_{E}$ and $C_{F}$ are the concentrations of the

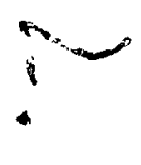

(4), respective reactants in expression (1). 
Assuming that the reaction is irreversible and of first order in nature, the differential equations expressing the reaction vefocities at any instant $t$ read as:

$$
\begin{aligned}
& \frac{d C_{A}}{d t}=-K_{1} C_{A} \\
& \frac{d C_{B}}{d t}=K_{1} C_{A}-K_{2} C_{B} \\
& \frac{d C_{C}}{d t}=K_{2} C_{B}-K_{3} C_{C} \\
& \frac{d C_{D}}{d t}=K_{3} C_{C}-K_{4} C_{D} \\
& \frac{d C_{E}}{d t}=K_{4} C_{D}-K_{5} C_{E}
\end{aligned}
$$

and

$$
\frac{d C_{F}}{d t}=K_{5} C_{E}
$$

Solving this system of linear first ofder differential equations with constant coefficients, see for example (8a), yields:

$$
C_{F}(t)=A_{1} e^{-K_{1} t}+A_{2} e^{-K_{2} t}+A_{3} e^{-K_{3} t}+A_{4} e^{-K_{4} t}+A_{5} e^{-K_{5} t}+a
$$

where

$$
\begin{aligned}
& a=\text { initial concentration of } \mathrm{A} \\
& B=a \mathrm{~K}_{1} \mathrm{~K}_{2} \mathrm{~K}_{3} \mathrm{~K}_{4} \mathrm{~K}_{5}
\end{aligned}
$$




$$
\begin{aligned}
& A_{1}=\frac{-B}{\left(K_{2}-K_{1}\right)\left(K_{3}-K_{1}\right)\left(K_{4}-K_{1}\right)\left(K_{5}-K_{1}\right) K_{1}} \\
& A_{2}=\frac{-\beta}{\left(K_{1}-K_{2}\right)\left(K_{3}-K_{2}\right)\left(K_{4}-K_{2}\right)\left(K_{5}-K_{2}\right) K_{2}}
\end{aligned}
$$

$$
\dot{A_{3}}=\frac{-B}{-\left(K_{1}-K_{3}\right)\left(K_{2}-K_{3}\right)\left(K_{4}-K_{3}\right)\left(K_{5}-K_{3}\right) K_{3}}
$$

$$
A_{4}=\frac{-B}{\left(K_{1}-K_{4}\right)\left(K_{2}-K_{4}\right)\left(K_{3}-K_{4}\right)\left(K_{5}-K_{4}\right) K_{4}}
$$

and

$$
A_{5}=\frac{-B}{\left(K_{1}-K_{5}\right)\left(K_{2}-K_{5}\right)\left(K_{3}-K_{5}\right)\left(K_{4}-K_{5}\right) K_{5}} .
$$

Defining Vefocity of the reaction as:

$$
v=\frac{d_{F}}{d t}
$$

Eq. (11) yields on differentiation with respect to time $t$.

$v=\left[A_{1} K_{1} e^{-K_{1} t}+A_{2} K_{2} e^{-K_{2} t}+A_{3} K_{3} e^{-K_{3} t}+A_{4} K_{4} e^{-K_{4} t}+A_{5} K_{5} e^{-K_{5} t}\right]$ (20);

Hence, if

$$
\begin{aligned}
& A=1, \dot{3} \text {-diphosphoglyceric acid, } \\
& B=3 \text {-phosphoglyceric acid, } \\
& \text { C }=2 \text {-phosphoglyceric acid, } \\
& D=2 \text {-phosphoenolpyruvic acid, }
\end{aligned}
$$


57

$E=$ Pyruvic acid,

and

$$
F=\text { Lactic acid, }
$$

then,

$$
\begin{aligned}
K_{1} & =\text { Phosphoglycerate kinase (PGK), } \\
K_{2} & =\text { Phosphoglycerate mutase (PGM), } \\
K_{3} & =\text { Enolase, } \\
K_{4} & =\text { Pyruvate kinase }\left(P_{K}\right),
\end{aligned}
$$

and

$$
\mathrm{K}_{5} \text { = Lactate dehydrogenase }(\mathrm{LDH}) \text {, }
$$

Where $K$ is the corresponding enzyme activity (specific activity $X$ Protein concentration) expressed as $\mu$ moles. per minute.

Specific activities of the test, auxiliary and indicator enzymes are given below:

PGK: 2900 units/mg.

$$
\text { PG: } \quad 600 \text { units/mg }
$$

Enolase: $\quad 84$ units/mg

$$
\begin{aligned}
& \text { PK: } 200 \mathrm{units} / \mathrm{mg} \\
& \text { LDH: } 550 \mathrm{units} / \mathrm{mg}
\end{aligned}
$$

c

$$
\begin{aligned}
& \cdot K_{1}(\dot{P G K}): 8.75 \times 10^{-7} \mathrm{mg} ; 8.75 \times 10^{-7} \times 2900=2.53 \times 10^{-3} \mu \mathrm{moles} / \mathrm{min} \\
& \mathrm{K}_{2}(\mathrm{PGM}): 4.20 \times 10^{-3} \mathrm{~m} 8 \mathrm{4} 4.2 \times 10^{-3} \times 600=2.50 \mu \mathrm{moles} / \mathrm{min} \\
& \mathrm{K}_{3} \text { (Enolase): } 3=8 \mathrm{x}^{-2} \mathrm{mg} ; 3: 87 \times 10^{2} \times 84=3.25 \mu \mathrm{moles} / \mathrm{min}
\end{aligned}
$$


$\mathrm{K}_{4}(\mathrm{PK}): 1.66 \times 10^{-2} \mathrm{mg} ; 1.66 \times 10^{-2} \times 200=3.30 \mu \mathrm{moles} / \mathrm{min}$

$K_{5}(L D H): 6.0 \times 10^{-3} \mathrm{mg} ; 6.0 \times 10^{-3} \times 550=3.30 . \mu \mathrm{moles} / \mathrm{min}$.

The above values for activities are at $25^{\circ} \mathrm{C}$ except the test enzyme (PGK) which is reported at $37^{\circ} \mathrm{C}$. According to Bergmeyer (10a) for each degree rise in temperature there is $20 \%$ increase in activity. The corrected values are given as follows:

PGK: $.53 \times 10^{-3} \mu \mathrm{moles} / \mathrm{min}$.

PGM: $5.5 \mu \mathrm{moles} / \mathrm{min}$

Enolase: $7.15 \mu \mathrm{moles} / \mathrm{min}$

PK: $7.26 \mu \mathrm{moles} / \mathrm{min}$.

LDH: $7.26 \mu \mathrm{moles} / \mathrm{min}$

The ratio of the rates of auxiliary and indicator enzymes with respect to test enzyme (PGK) w̧as greater than $1: 2000$.

A Fortran IV computer programme (see appendix) was written and employed to determine the concentration of product and the reaction velocity using equation 11 and 20 respectively in a sequence of five steps of uncatalyzed irreversible first order reaction.

In a sequence of five uncatalyzed first order reactions it was possible to demonstrate the ratio of auxiliary-indicator enzymes compared to test enzyme required to give true initial velocity. kinetics of the test enzyme. The ratio between the test and auxiliary-indicator enzyme activities were also used to determine a theoretical family of curves describing the reaction rates at 
different levels of intermediate enzyme actịvities (i.e. $K_{2}, K_{3}, K_{4}$ and $\mathrm{K}_{5}$ ). The following ratios were calculated with respect to the test enzyme from the corrected activities ( $\mu$ moles per mirfute) for the individual enzymes in the sequence. The ratios are:

$$
\begin{aligned}
& K_{1}: K_{2}: K_{3}: K_{4}: K_{5} \\
& \equiv \quad 1: 2178: 2838: 2882: 2882
\end{aligned}
$$

These are the minimum ratios calculated with respect to $k_{1}$; The activity of $K_{1}$ was calculated from the highest PGK activity fraction obtained from electrofocusing. These ratios may be higher depending on the activity of the test enzyme $\left(K_{1}\right)$.

Each value of $K\left(i . e . K_{2}, K_{3}, K_{4}\right.$ and $K_{5}$ ) was varied individually while the remainder were constant. In this way it was possible to determine the value of the ratio of auxiliaryindicator enzyme to the test enzyme $\left(K_{1}\right)$ required to give the true initial velocity of $K_{1}$.

The formation of product at varying values of $K\left(i . e . K_{2}, K_{3}, K_{4}\right.$ and $K_{5}$ ) at time 1 are given in Tables I, I I, II and IV respectively (these Tables are abbreviated versions of a computer print out dealing with seven values of $K_{2} \ldots \ldots K_{5}$ and the rate of conversion of substrate to the indicator product). It may be seen from each Table that the formation of product at time 1 for different values of $K_{2}$ (Table I), $K_{3}$ (Table II), $K_{4}$ (Table III) and $K_{5}$ (Table IV) reached a maximum at values of $k\left(i_{i} . e . K_{2}, K_{3}, K_{4}\right.$ and 
.

-

4

TABLE I

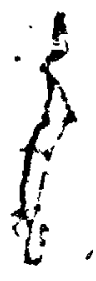

When,

The effect of varying values of $\mathrm{K}_{2}$ '

on the PGK assay

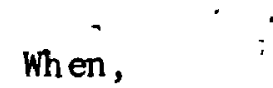

$$
\begin{aligned}
& \mathrm{K}_{1}=1 \\
& \mathrm{~K}_{2}=\text { Variable } \\
& \mathrm{K}_{3}=2838, \\
& \mathrm{~K}_{4}=2882 \\
& \text { and } \quad \\
& \mathrm{K}_{5}=2882
\end{aligned}
$$

(conditions as described in the text)

9 


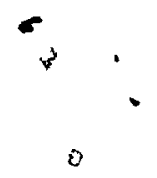

61

VARYING

VALUES OF $\mathrm{K}_{2}$
FORMATION OF

PRODUCT AT TIME 1
DECREASE IN CONCENTRATION OF

' $\dot{A}$ ' AT TIME 1

0

8712

4356

2178

217.8

- f $21: 78$

2.178

0.2178
0.6316

0.6316

0.6315

0.6300

.$\quad 0.6140$

0.4154

0.0740
0.3683

0.3683

0.3684

0.3699

0.3859

0.5845

0.9259

$\hat{\sigma}$

$\ell$ 
TABLE II

The effect of varying values of $\mathrm{K}_{3}$ on the PGK assay

When,

$$
\begin{aligned}
K_{1} & =1 \\
K_{2} & =2178 \\
K_{3} & =\text { Variable } \\
K_{4} & =2882
\end{aligned}
$$

and

$$
K_{5}=2882
$$

$s^{2}$

- (conditions as described in the text)

$\emptyset$ 


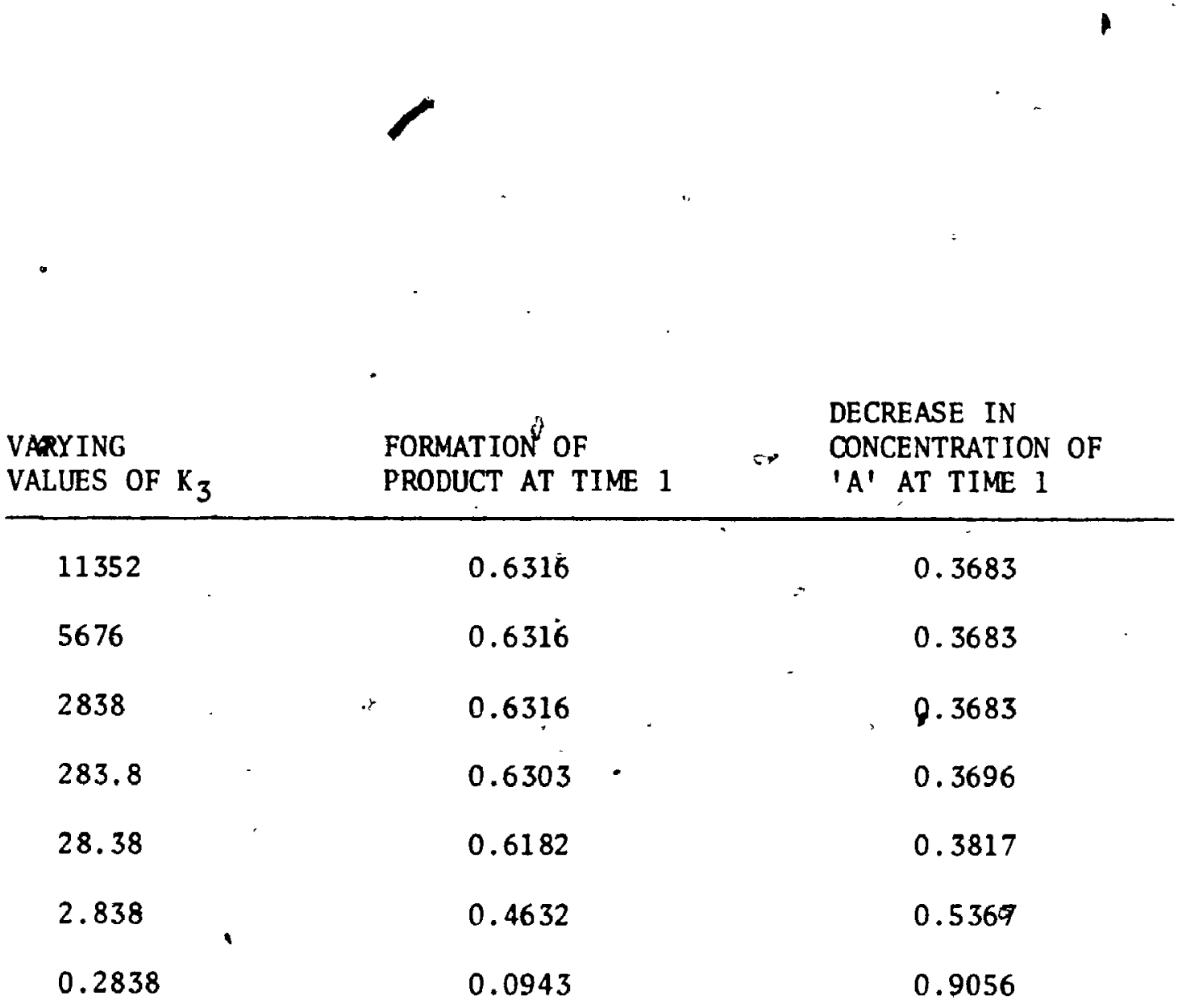


TABLE III

The effect of varying values of $\mathrm{K}_{4}$

on the PGK assay

When,

$$
\begin{aligned}
& k_{1}=>1 \\
& k_{2}=2178 \\
& K_{3}=2838 \\
& k_{4}=\text { variable }
\end{aligned}
$$

and

$$
\mathrm{K}_{5} \doteq 2882
$$

(conditions as described in the text) 
$\therefore ;$

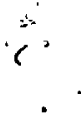

-

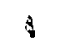

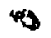

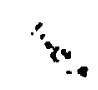

4

TABLE IV

7

The effect of varying values of $\mathrm{K}_{5}$

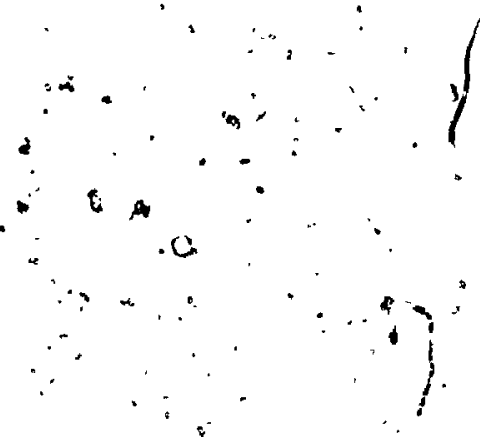

$$
\begin{aligned}
& \text { When } r \text { i } \\
& k_{1}^{\prime}=1 \\
& K_{2}:=2178^{\circ} \\
& \mathrm{K}_{3}=2838 \\
& K_{4}=2882 \\
& \text { and: } \\
& \Rightarrow \quad K_{5}=\operatorname{Vari} a b l e
\end{aligned}
$$

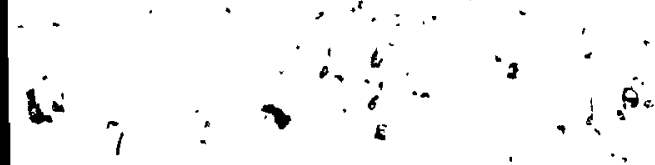

(conditions as described in the text)

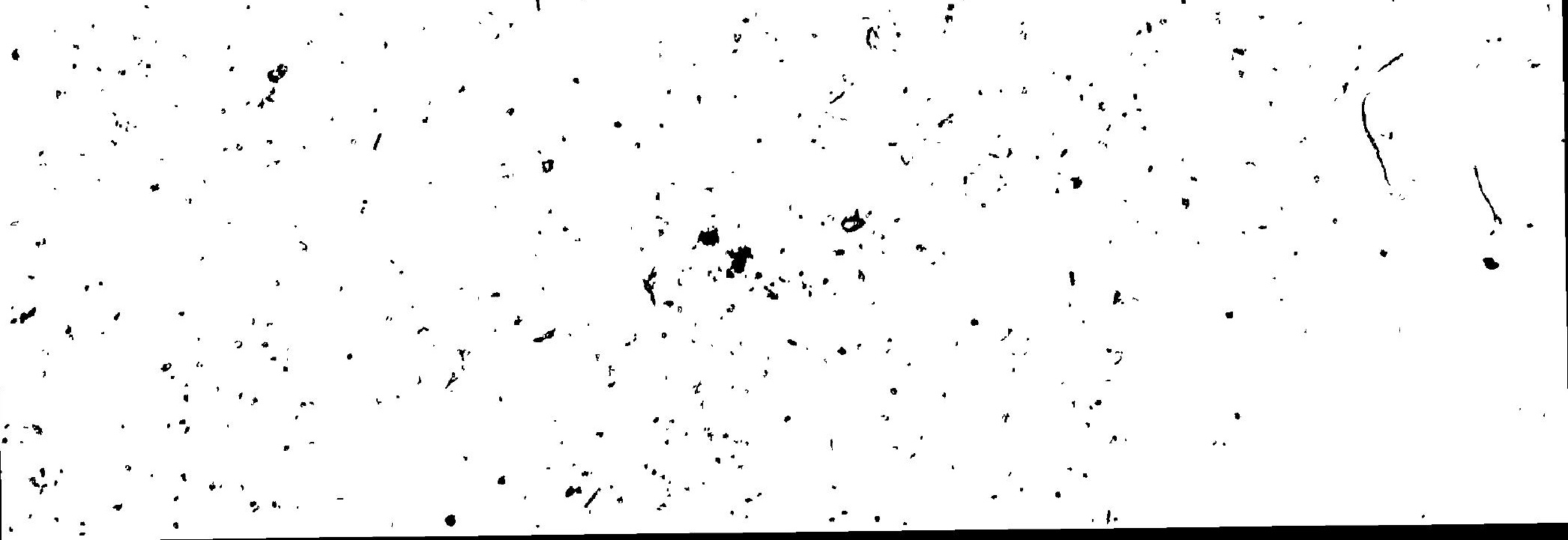




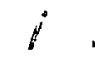

$\therefore$

3

VARYING

VALUES OF $\mathrm{K}_{5}$.
FORMATION OF

PRODHCT AT TIME 1
DECREASE IN CONCENTRATION OF 'A' AT TIME' I

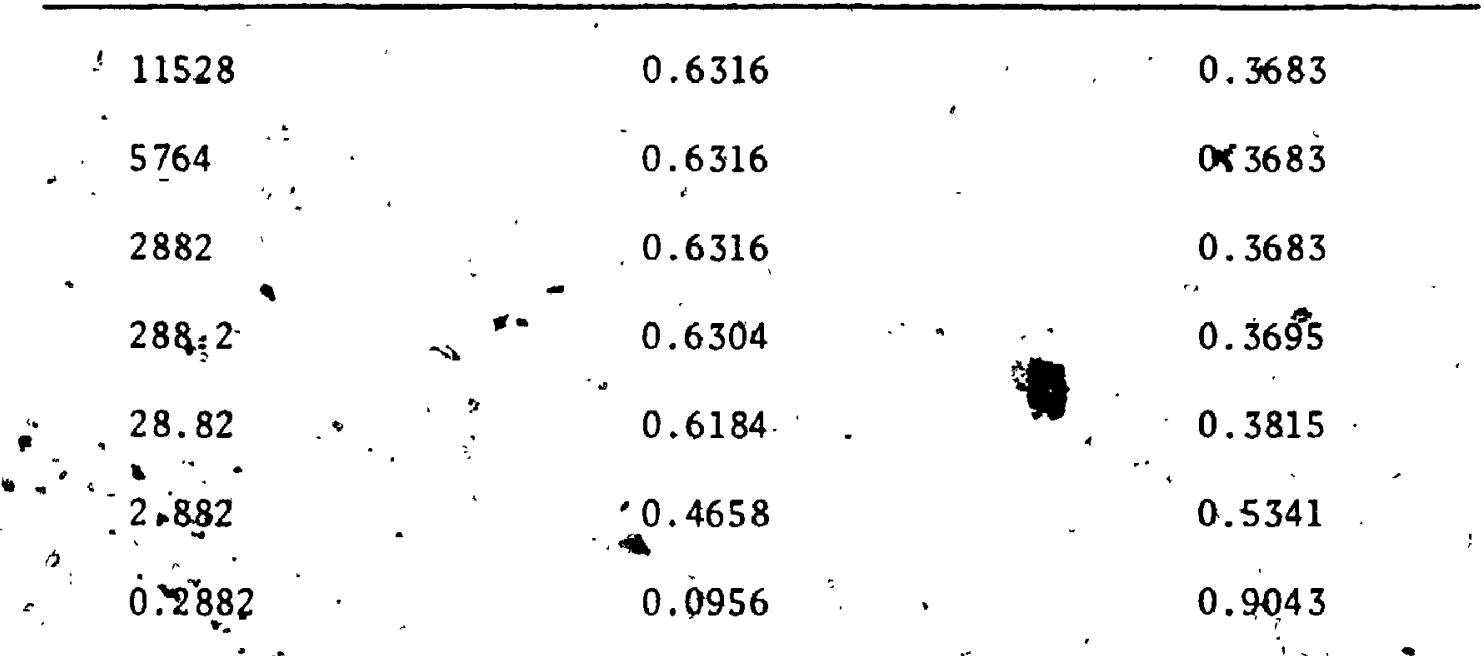

8.

6

$\therefore$

$$
\begin{aligned}
& . \quad . \quad 5764 \\
& 2882 \\
& \text {. }
\end{aligned}
$$

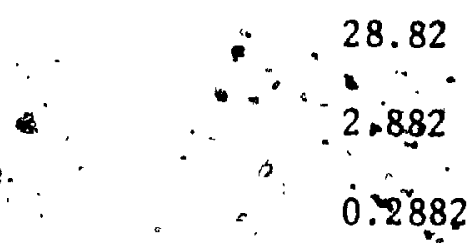$$
0.6184
$$$$
\text { " }
$$
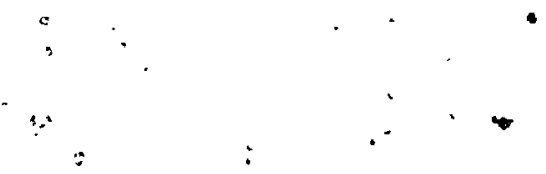

3 
$\mathrm{K}_{5}$ ), below this level resulted in the decreased formation of product at time 1 (see Table F, II, III and IV). The formation of product at time 1 was not affected by a further increase in the value of $K_{2}-K_{5}$ (i.e. to several times greater than the value used experimentally). A theoretical family of curves at different values of $K_{5}$ (i.e. $0.01,0.1,1.0 \ldots 400 \%$ of 2882) is shown in Figure 11. When the value of less than $1 \%(i . e .0 .2882$ and 2.882$)$ of the value employed experimentally waś used a prolonged lag peribd was observéd. A very short 1 ag period was observed at $1.0 \%$ of the $K_{5}$ value. No lag. period wás observed at $10.0 \%$ or greater $(10.0 \%$ of 2882$)$ of $\mathrm{K}_{5}$. Further increases in the value of $K_{5}$ (several times over the experimental value) did not change the nature of the curve. A similar family of curves wal obtained for each varying value of $\mathrm{K}$ i.e. $K_{2}, K_{3}$ and $K_{4}$. These curves are similar to those obtained by Bergmeyer (10a) for a sequence of two uncatalyzed first order reactions.

The above theoretical results demonstrate that a lag period in a sequence of 'five first order reactions can be avoided by using the proper ratio of $K$ i.e. $K_{2}, K_{3}, K_{4}$ and $K_{5}$. Since the concentration of reactants.used in these, experiments far exceeds the dimits in this manner, it provides further proof for the efficacy of the assay system employed.

5. Polyacrylamide gel Electrophoresis The pufified enzyme. PGK was electrophoresed on the 
$b^{\circ}$

FIGURE 11

A theoretical family of curves at varying values of $\mathrm{K}_{5}$ When,

$$
\begin{aligned}
& K_{1}=1 . \\
& K_{2}=2178 \\
& K_{3}=2838 \\
& K_{4}=2882 \\
& K_{5}=\text { Variable. }
\end{aligned}
$$

and

ib

$\because$ 
polyacrylamide gel by the method of Davis (26). Density of the purified enzyme solution from isoelectrofocusing (100-200 $\mathrm{\mu g}$ ) was increased by mixing with sucrose solution. It was then layered on the flat top surface of the stacking gel." Electrophoresis was carriled out at $4^{\circ} \mathrm{C}$ using Tris-glycine buffer, $\mathrm{pH} 8.3$, in both chambers (200 volts, 5mAmp per gel tube) for approximately three hours. At the end of the run the gels were stained for protein in Buffalo blue black dye for about one hour. After the end of one hour the gels were rinsed for a few minutes in tap water. The unbound dye was removed by daining in $7 \% \dot{g}$ lacial acetic acid solution for three hours at $15 \mathrm{mAmp}$ per țube.

6. Sedimentation Velocity and Molecular Weight Determination , by Analytical Ultracentrifugation

Sedimentation studies were done in double sector, synthetic boundary cells at $14^{\circ} \mathrm{C}$ in a Spinco Model $\mathrm{E}$ analytical ultracentrifuge at a speed of 42,040 r.p.m. with the An-D-rotor, absorption optics and photoelectric scanner. The observed sedimentation coefficient. ( $\left.\mathrm{S}_{\mathrm{obs}}\right)$ was calculated from the equation of Schachman (98):

$$
S_{\text {obs }}=\frac{1}{\omega^{2} \cdot x} \cdot \frac{d x}{d t}
$$

where $x=$ distance of the boundary in centimeters from the axis of rotation

$\cdot t=$ time in seconds

$\omega=$ angular velocity in radiths per second

The magnification factor was determined by measuring the distance between the reference edge images and dividing by the counterbalance dimenton (rominally $1.60 \mathrm{~cm}$ ). Radial distances were

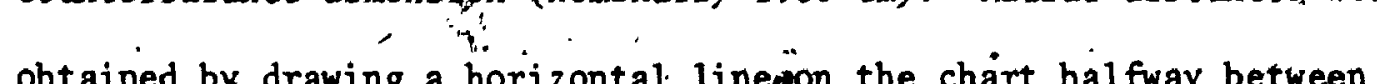

- obtained by drawing a horizontal lineaton the chart halfway between 
the tracing for the solvent region and the plateau region of the cel1. The point of intersection of the tracing and the boundary - region was designated the center of the boundary.

\section{Sedimentation coefficients are generally reported as} $S_{20 w}$, the value the material would have in a solvent with the density and viscosity of water at $20^{\circ}$. Corrections of the observed sedimentation coefficien $S_{\text {obs }}$ to this standard state were made according to the equation:

$$
s_{20, w}=s_{o b s}\left(\frac{n^{t}}{n_{20}}\right) \quad\left(\frac{\eta}{n^{0}}\right) \quad\left(\frac{1-\bar{v} p_{20, w}}{1-\bar{v} \rho t, s 01}\right)
$$

where $\mathrm{S}_{\text {obs }}=$ observed sedipentation cpefficient

$$
\begin{aligned}
& n^{\mathrm{t}}=\text { viscosity of } \mathrm{H}_{2} \mathrm{O} \text { at } t^{\circ} \text { (temp. of } \\
& \text { centrifuge run) } \\
& \mathrm{n}_{20}=\text { viscosity of } \mathrm{H}_{2} \mathrm{O} \text { at } 20^{\circ} \mathrm{C} \\
& \text { in } n / n_{0}=\text { relative viscosity of the solvent } \\
& \text { I to that water } \\
& \rho_{20}, w=\text { density of water at } 20^{\circ} \\
& \rho t, \text { Sol }=\text { "density of sample solution at } t \\
& \bar{v}^{\prime}=\text { partial specific volume }
\end{aligned}
$$

I The molecular, weight of phosphoglycerate kinase was determined by the sedimentation equilibrium method $(22,41$, $56,99-100)$ in a Spinco Model E ultracentrifuge equipped with 
a monochromator and photoelectric scanner. A $12 \mathrm{~mm}$ Kel F double sector cell was used. 0 il (fluorochemical F.C43) was used in the bottom of the sample cell to facilitate the measurement of the peak at the bottom of the fluid column. The samples were allowed to equilibrate for 45 to 48 hours at $8^{\circ} \mathrm{C}$ in a titanium An-D-rotor. The molecular weight was calculated by using the slope of the etuilibrium curve in the expression as given below:

$$
M=\frac{2 R T}{\left(1-\bar{V}_{0}\right) \omega^{2}} \frac{d \ln c}{d\left(X^{2}\right)}
$$

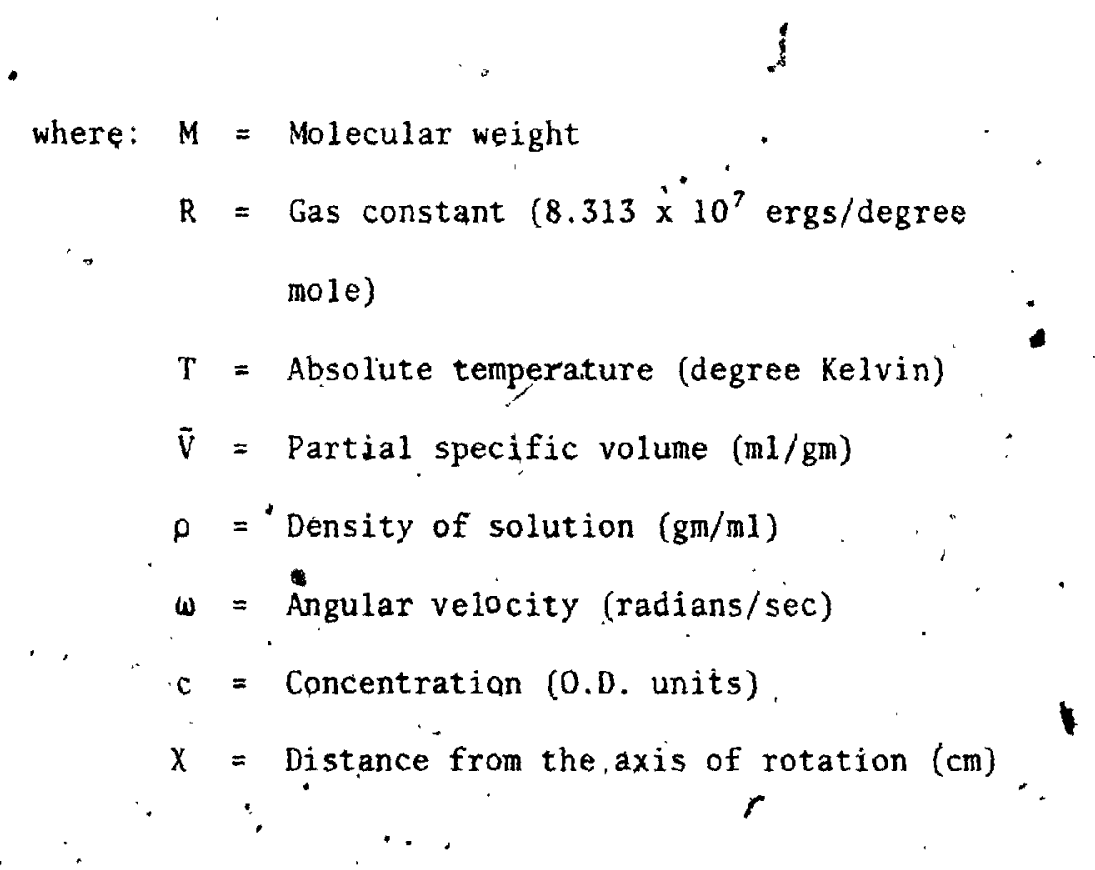


a monochromator and photoelectric scanner. A $12 \mathrm{~mm}$ Kel F double sector cell was used. Oil (fluorochemical F.C43) was used in the bottom of the sample cell to facilitate the measurement of the peak at the bottom of the fluid column. The samples were allowed to equilibrate for 45 to 48 hours at $8^{\circ} \mathrm{C}$ in a titanium An-D-rotor. The molecular weight was "calculated by using the slope of the equilibrium curve in the expression as given below:

$$
\therefore M=\frac{2 R T}{\left(1-\bar{V}_{\rho}\right) \dot{\omega}^{2}} \frac{d \text { lnc }}{d\left(X^{2}\right)}
$$

where: $M=$ Molecular weight

$$
\begin{aligned}
& \mathrm{R}=\text { Gas constent }\left(8.313 \times 10^{7}\right. \text { ergs/degree } \\
& { }^{n} \text { mole) } \\
& \overline{\mathrm{V}}=\text { Absolute temperature (degree Kelvin) }
\end{aligned}
$$$$
\rho=\text { Density of solution }(\mathrm{gm} / \mathrm{m} 1)
$$$$
\omega=\text { Angular velocity (radians/sec) }
$$$$
c=\text { Concentration (O.D. units) }
$$$$
X=\text { Distance from the axis of rotation }(\mathrm{cm})
$$

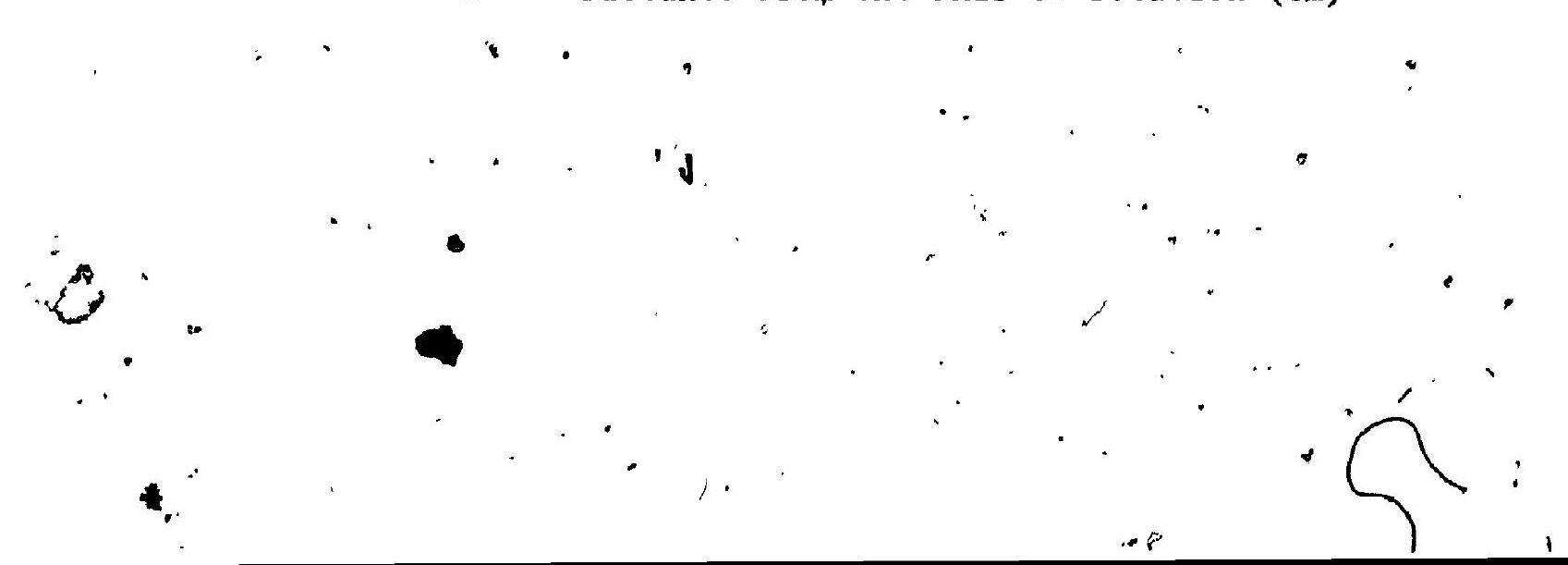


I. PURIFICATION OF - 1,3-DPG

Applying 1,3-DPG on a. DEAE-cellulose column accqrding to the procedure of Rose (94) did not thrther improve the purity of the substrate. The yield in the present work was somewhat lower when compared with Negelein's (73). The product was free of 3-PGA.

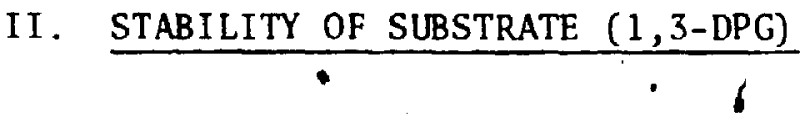 \\ The stability of 1,3-BPG was essential to the assay system.} A possible hydrolysis product, 3-PGA, would introduce an artifact into the reaction system. When 1,3-DPG was stored in the frozen state $\left(-20^{\circ} \mathrm{C}\right)$ at $\mathrm{pH} 7.6$ there was a minor loss in 24 hours ( 1 to $1.3 \%$ ) as. compared with 3\% reported by Negelein (73). As shown in Figure 12 there was no detectable loss for, several weeks when it was stored in liquid nitrogen.

$\mathbf{a}$

III. ISOLATION AND PURIFICATION OF PGK

Red cells of all mamalian species contain a high level of

PGK. This enzyme has been found to be stable in acid citrate

dextrose stored blood for 4 to 6 weeks at. $4^{\circ} \mathrm{C}$.

The procedure used in the isolation and purification of the enzyme from human erythrocytes was a modification of the method 
FIGURE 12

Stability of 1,3-DPG during storage in liquid nitrogen $(L N)$ and lat $-20^{\circ}$.

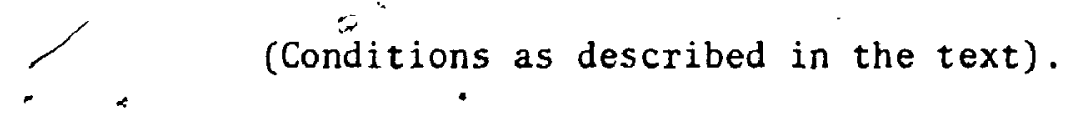

$$
=
$$


;

$-1.20$

.8

$r$

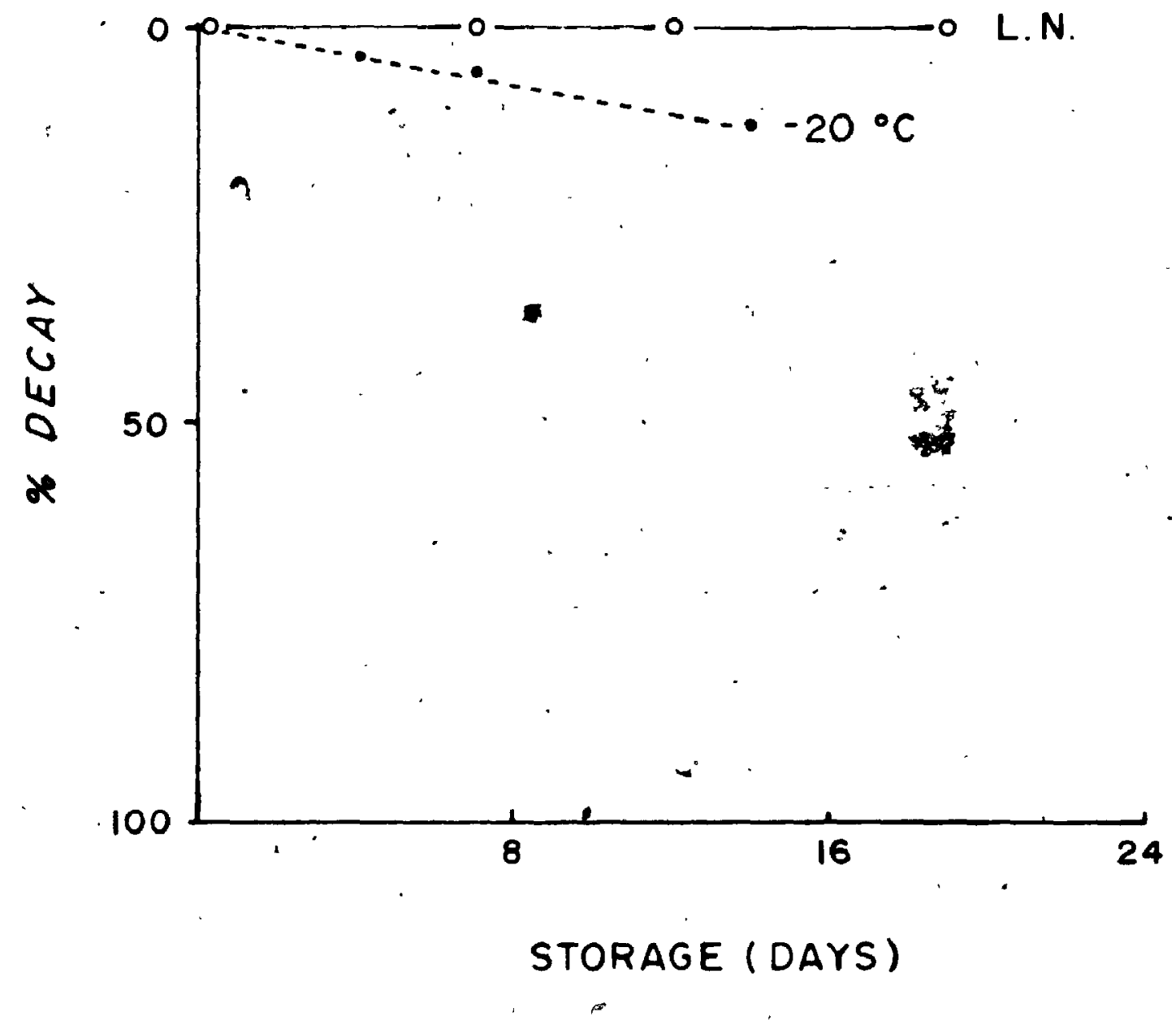


of Yoshida and Watanabe (113) and is summarized in Figure 2. The details of isolation and purification are described in Materials and Methods (Vide Supra). The main results obtained with the purification prócedure are described below:

\section{Crystallization of PGK}

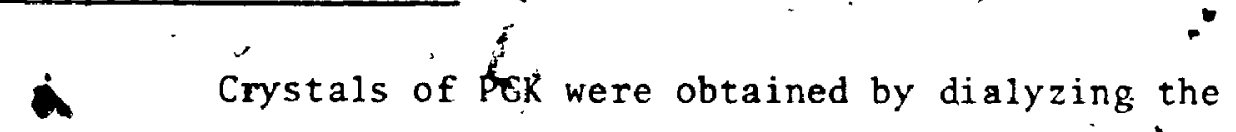
concentrated enzyme- obtained from, DEAE-cellulose chromatography against $0.1 \mathrm{M}$ phosphate buffer, $\mathrm{pH} 7.0$ containing ammonium sulfate. The concentration of ammonium sulfate was increased slowly from 30 to $65 \%$ saturation over a period of 24 hours. After 24 hours the concentration of ammonium sulfate was further increased from $6.5 \%$ to $85 \%$ in 24 hours time. The further delay and increase in ammonium sulfate from 65 to $85 \%$ (a modification of an earlier procedure (113) resulted in the formation of heedle like crystals. The crystals ' obtained were centrifuged and the supernatant which was free of measurable PGK activity was discarded. The crystals were dissolved in a minimum volume of $0.01 \mathrm{M}$ phosphate buffer $\mathrm{pH} 7.0$ containing about $12 \mathrm{mM}$ cysteine $\mathrm{HCl}(\mathrm{pH} 7.0)$. Small aliquots were sealed in pyrex glass tubes and kept frozen at $-20^{\circ} \mathrm{C}$.

\footnotetext{
polyacrylamide gel demonstrated two major and two minor protein.' components (Figure 13). The slower migrating protein band appeảred to contain the enzyme activity. These preliminary experiments demonstrated that the crystalline preparation contained other
} 
FIGURE 13

Polyacrylamide gel electrophoresis, of crystalline PĢK.

- Note: See Figure 19 for the purified PGK from

electro focusing.

(conditions as described in the text) ".

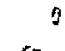

$\therefore$ 



proteins in addition to, the active enzyme (PGK).

\section{- 2. Further Purification by" Electrofocusing}

Further purification of the crystalline protein

by electrofocusing procedures, using carrier ampholytes ( $\mathrm{pH}$ ranges between 3 to 10 ) demonstrated a $\$$ imilar pattern to that obtained in the analytical gel "electrophoresis. It can be seef (Figure 14) that PGK activity ( $\mathrm{PI} 8.75$ ) was qugntitatively a minor component of the crystalline protein obtained previously. Further purification over narrower $\mathrm{pH}$ ranges ( $\mathrm{pH} 7-9)$ effected a higher resolution of the PGK activity since it appeared to'separate more discretely from other protein components (Figure 15). The pI of 8.75 was confirmed in this narrow range separation.

A 2000 fold purification of PGK was achieved in the steps from the crude hemolysate to the enzyme solution obtained from electrofocusing (Table V). A specific activity of approximately 2200 units per $\mathrm{mg}$ of protein was obtained. This preparation of PGK obtained after electrofocusing will be referred to as purified PGK. $\gamma$ The enzyme was free of contamination with other enzymes measured $\leftrightarrow \quad$ (carbonic anhydrase, phosphoglycerate mutase, enolase, lactic dehydrogenase, private kinase and-diphosphoglycerate mutase).

3. Further crystaplization of PGK

Purified 
8

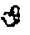

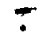

s

$\cdots$,
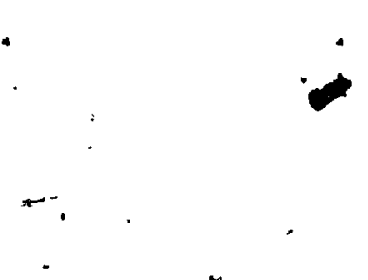

(1)

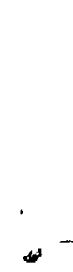

4

$\therefore$

FIGURE 14

$\ddot{n}$

( $\stackrel{0}{8} \cdot$

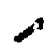

$\cdot 1$

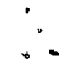

5

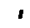
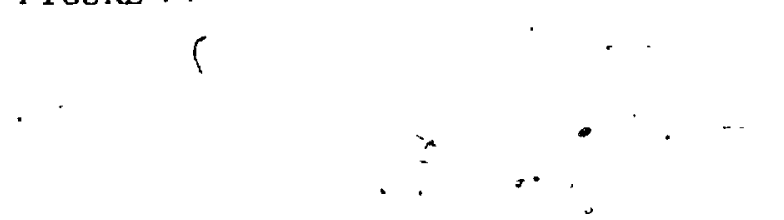

Separation of PGK by electrofocusing $\mathrm{pH}$ ranges

between 3 , to 10 .

(Conditions as described in the text).

,

$i+i+\infty$

$c$

$\because \cdots$

, 

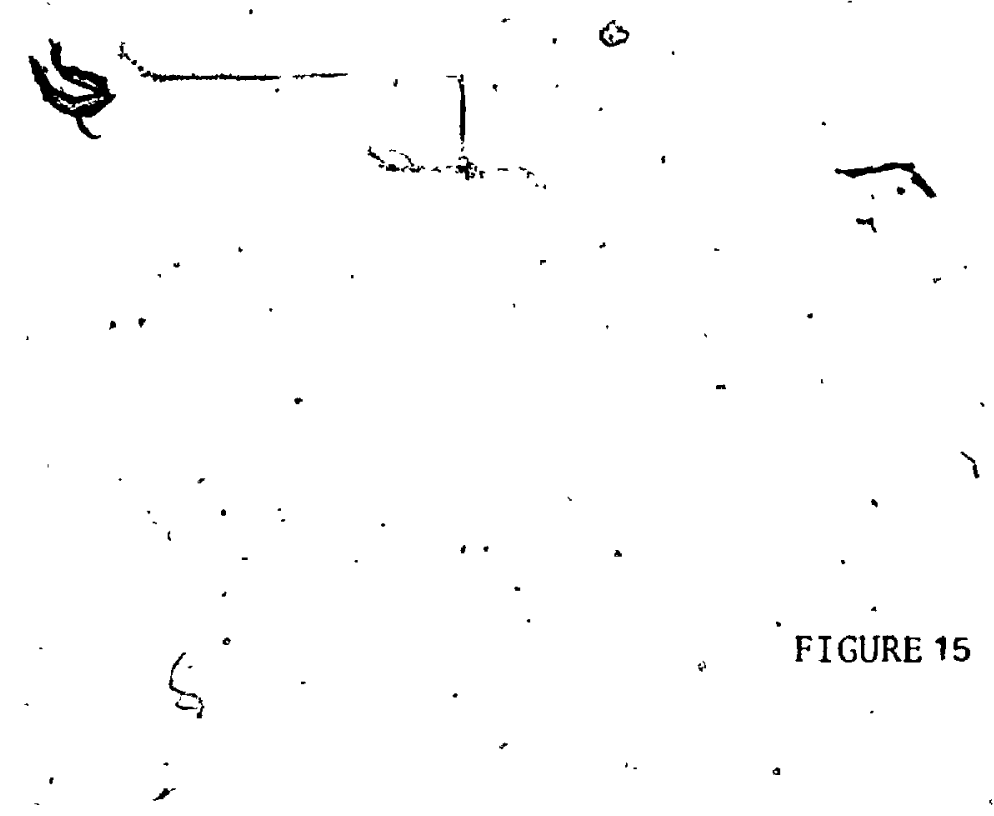

Separation of PGK by Electrofocusing $\mathrm{pH}$ ranges between 7 to 9 .,

(Conditions as described in the text).

1.
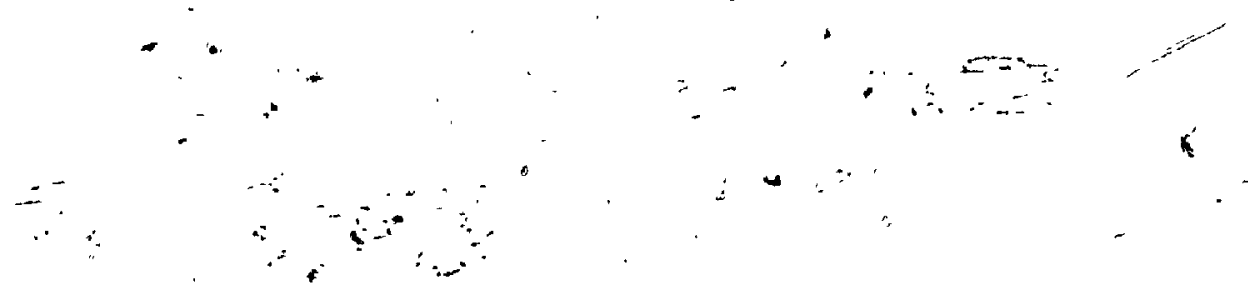
TABLE $V$

The purification of phosphoglycerate kinase from human blood. A unit of PGK is defined as the amount of enzyme which . catalyzes the formation of 1 mole of 3-PGA per minute. Specific . activity is expressed as units per mg of protein.

$$
\therefore
$$




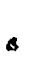

86

$n$

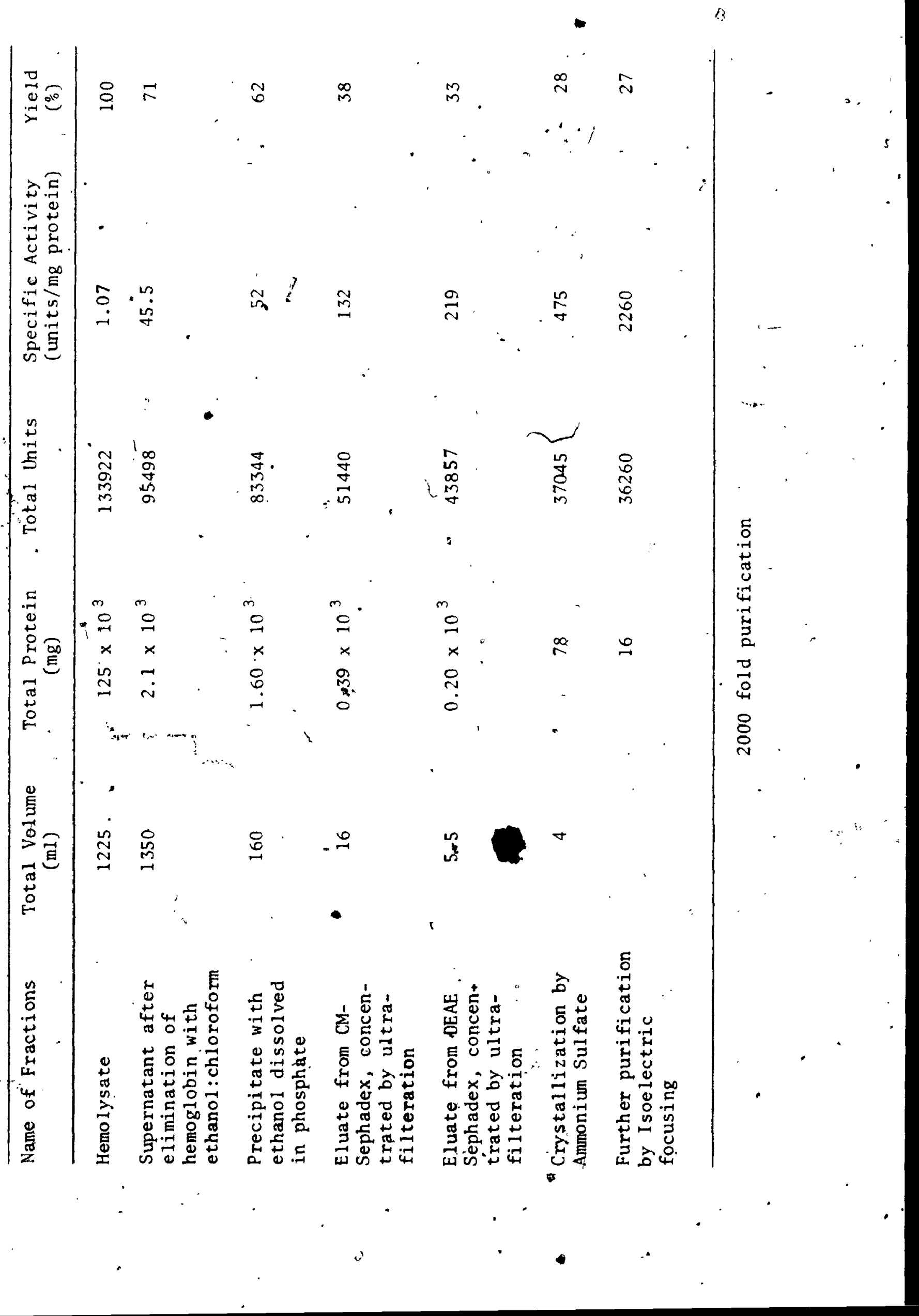


crystallized by the earlier described procedure. Sharp needle like crystals were obtained (Figure 16). Long rectangular crystals of PGK were obtained from human erythrocytes by Hashimoto and Yoshikawa (44).

\section{IV. 'PROPERTIES OF PGK}

\section{Stability of PGK during Storage}

PGK purified from haman red cells was stored at $4^{\circ} \mathrm{C}$ and $-20^{\circ} \mathrm{C}$ in $0.01 \mathrm{M}$ phosphate buffer pH 7.0 containing $12 \mathrm{mM}$ cysteine. When it was stored at $4^{\circ} \mathrm{C}$ there was a $15 \%$ loss in activity after 2 weeks (Table VI). Yoshida and Watanabe (113) reported that when bovine serum albumin' was added to their purified PGK from human red cells at a final concentration of $10 \mathrm{mg}$ per $\mathrm{ml}$ enzyme activity remains unchanged for at least a week at $4^{\circ} \mathrm{C}$. Purified PGK was quite stable for 9 weeks at $-20^{\circ} \mathrm{C}$ (Table VI). There was a $10 \% 10$ s of enzymatic activity after 9 weeks of storage.

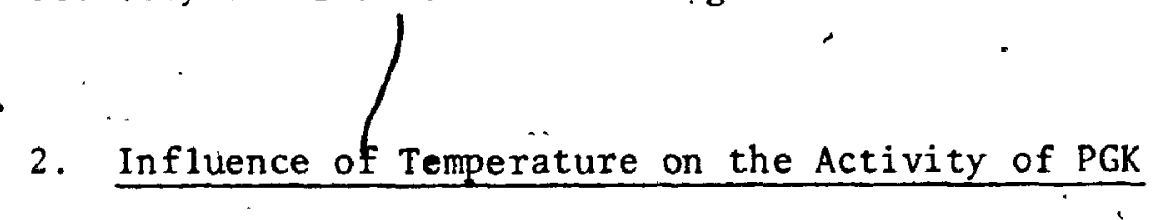

The activity of PGK was studied at various temperatures between 10 and $60^{\circ} \mathrm{C}$ while the concentration of hydrogen ion, substrate, cofactor and enzyme were mairmat, constant levels. Below $37^{\circ} \mathrm{C}$ the rate of enzyme reaction increased with : temperature. Thereafter a levelling off in activity was observed followed by a sharp increase in the rate of enzyme inactivation above 


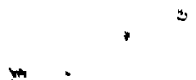

Q

FIGURE 16

$\circ$

- Crystals of Phosphoglycerate kinase grown at $\mathrm{pH} 7.0$.

$$
\begin{aligned}
& \text { Magnification, } \times 280(a, \bar{b} \text { and } c \text { respectively) } \\
& \text { Magnification, } x 1120 \text { (d) } \\
& \qquad)
\end{aligned}
$$

I

Note: Photographs of crystals were taken from the same smart (amorphous materials unknown).

$\therefore$ (conditions as described in text).

$S^{\prime}$

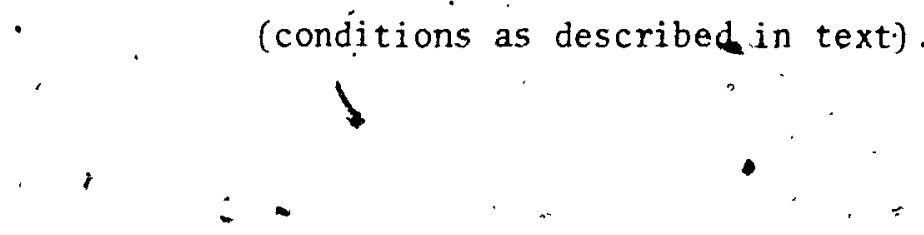

$\pi$

4

$D$ 


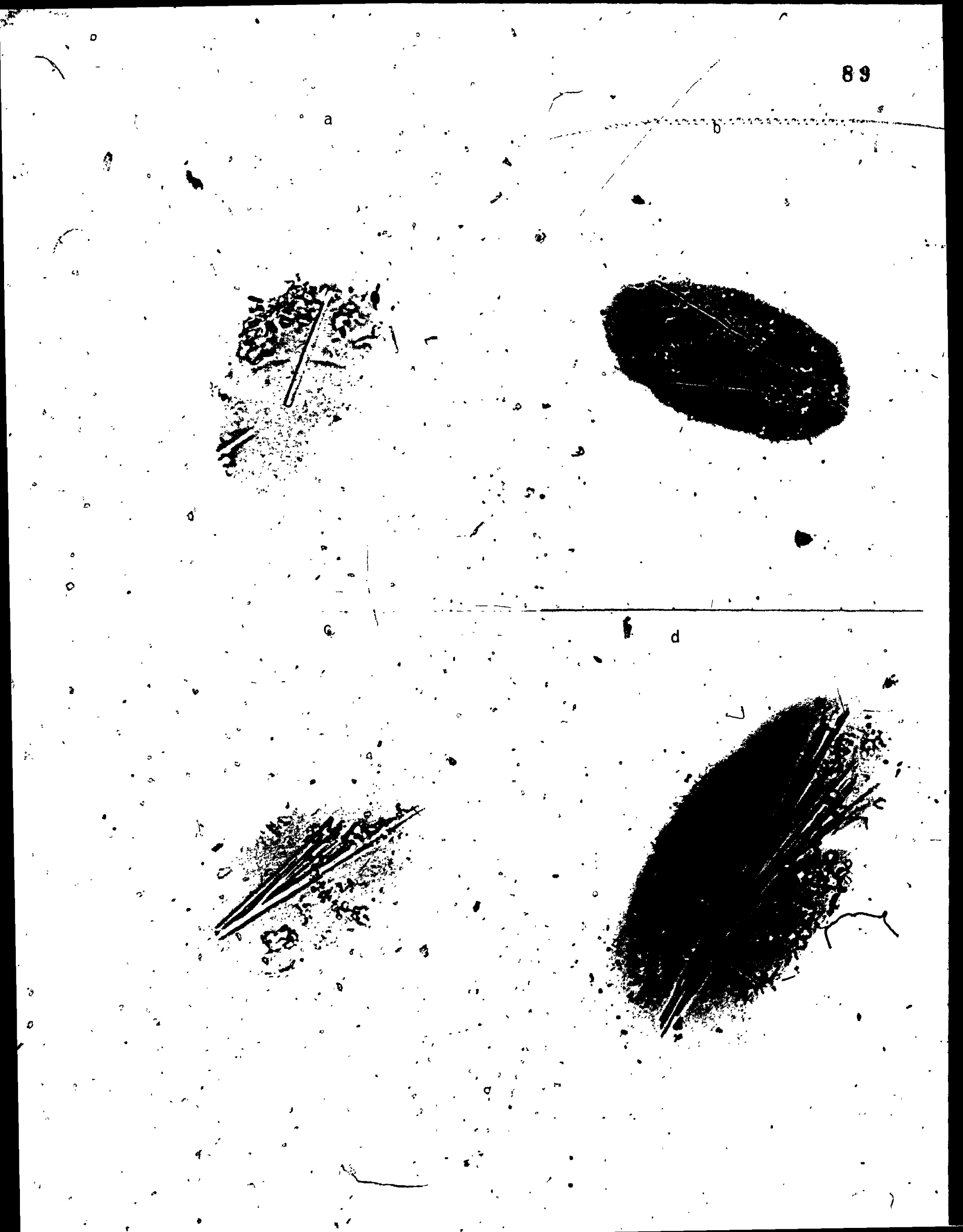


$a^{2}$

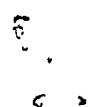

CABLE VI

Stability of PGK during storage at $4^{\circ} \mathrm{C}$ and $-20^{\circ} \mathrm{C}$. o a (Conditions as described in the urtext).

$5:$

$+?$

$-\mathcal{1}$ 
91

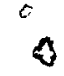

Duration ${ }^{n}$ of Loss in PGK. Duration of Loss in PGK storage at activity* storage at activity*

$4^{\circ} \mathrm{C}$

$(\%)$

$-20^{\circ} \mathrm{C}$

$(\%)$

Q

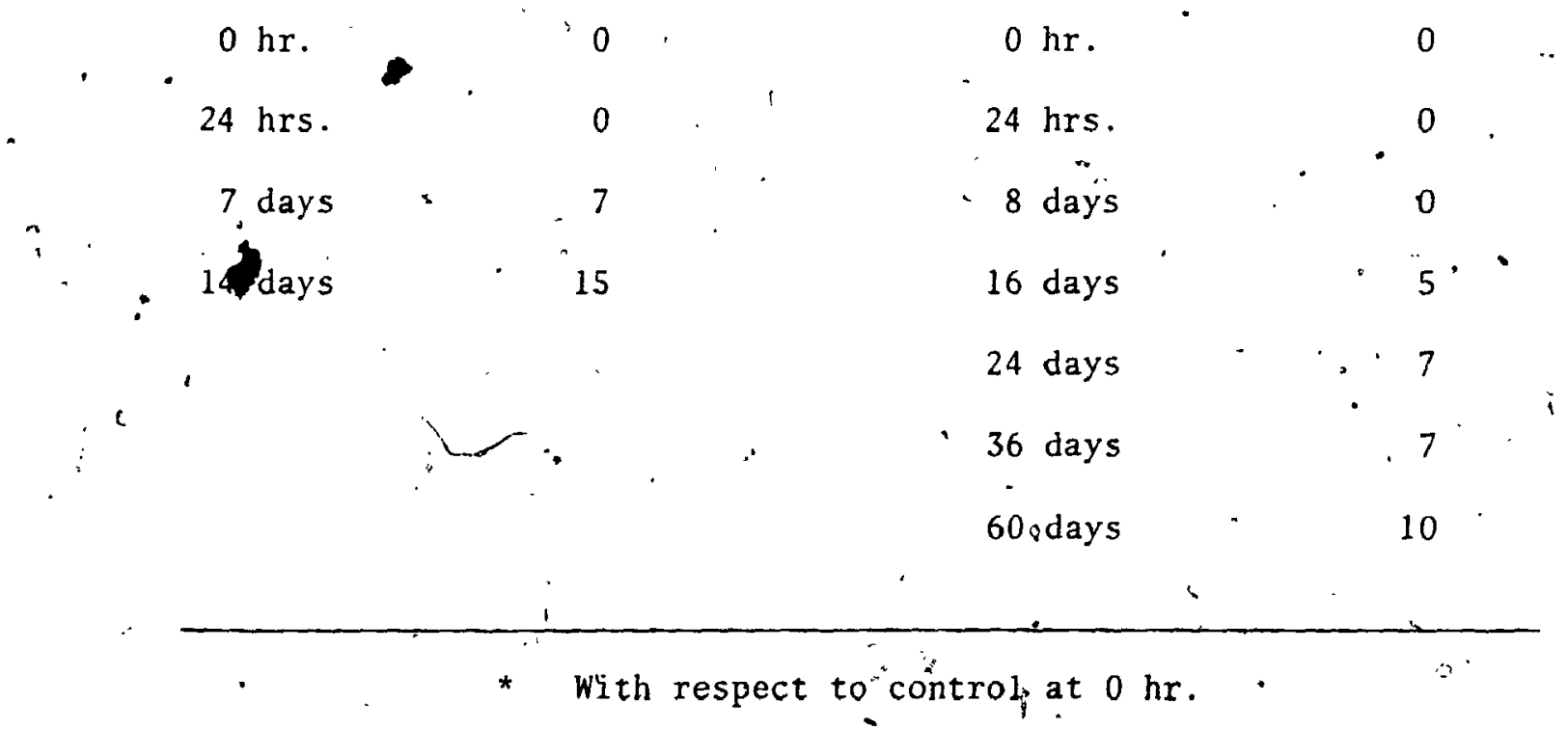


$50^{\circ} \mathrm{C}$. The value for the activation energy' $(\mu)$ for PGK formation of 3-PGA, calculated according to Arrhenius $(34,106,107)$ :

$$
\bar{\mu}=4.58 \frac{\left(\log _{10} \mathrm{~K}_{2}-\log _{10} \mathrm{~K}_{1}\right)}{(1 / \mathrm{T} 1-1 / \mathrm{T} 2)}
$$

Where

$\mu=$ activation energy

$\hat{K}_{1}$ and $K_{2}$ are the reaction rates at absolute

temperature $\mathrm{T} 1$ and $\mathrm{T} 2$

Exom

Yom the plot shown in figure 17 of the $\log _{10}$ of the reaction

velocity and the reciprocal of the absolute temperature, was of the order of 11,000 calories/mole.

-

3. Effect of $\mathrm{pH}$ on PGK Activity

Enzymatic activity was tested at different hydrogen ion concentrations. Greater than $95^{\circ}$ activity was observed between $\mathrm{pH} 7.0-9.0$ (Figure 18). The $\mathrm{pH}$ range for optimal activity of the enzyme PGK in red cells is not as broad as compared to the $\mathrm{pH}$ range of rabbit muscle 3-PGK reported by Krietsch and Bücher (55)

but is similar to that reported by Yoshida and Watanabe (113) for human erythrocyte enzyme.

\section{Polyacrylamide Gel Electrophoresis}

Purified 'PGK obtained from electrofocusing was tested for purity on polyacrylamide gel by the method of Davis (26). 


$$
\gamma
$$

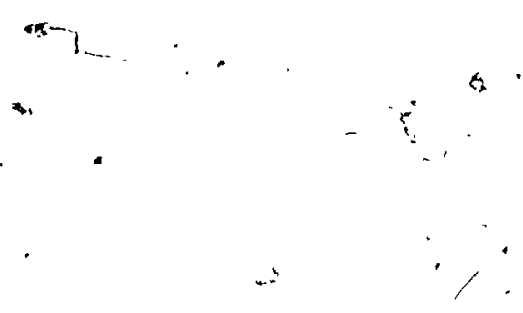

FIGURE 17

The influence of temperature on PGK activity. (Conditions as described in the text). 


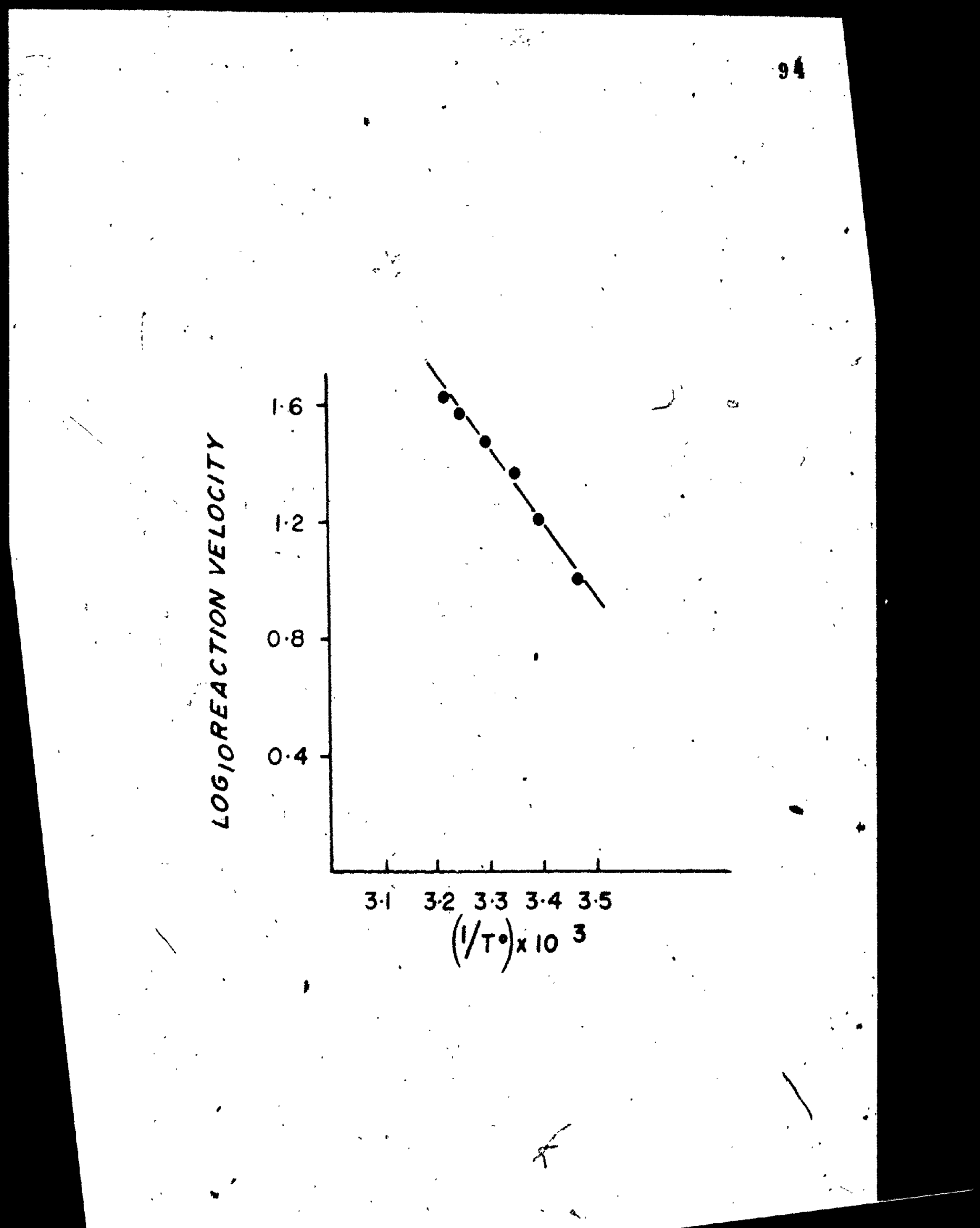



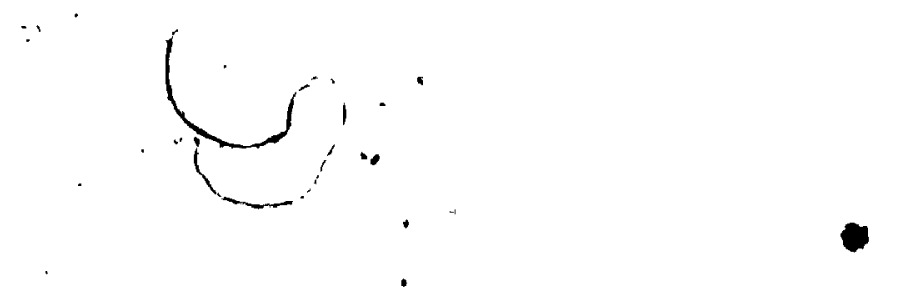

94

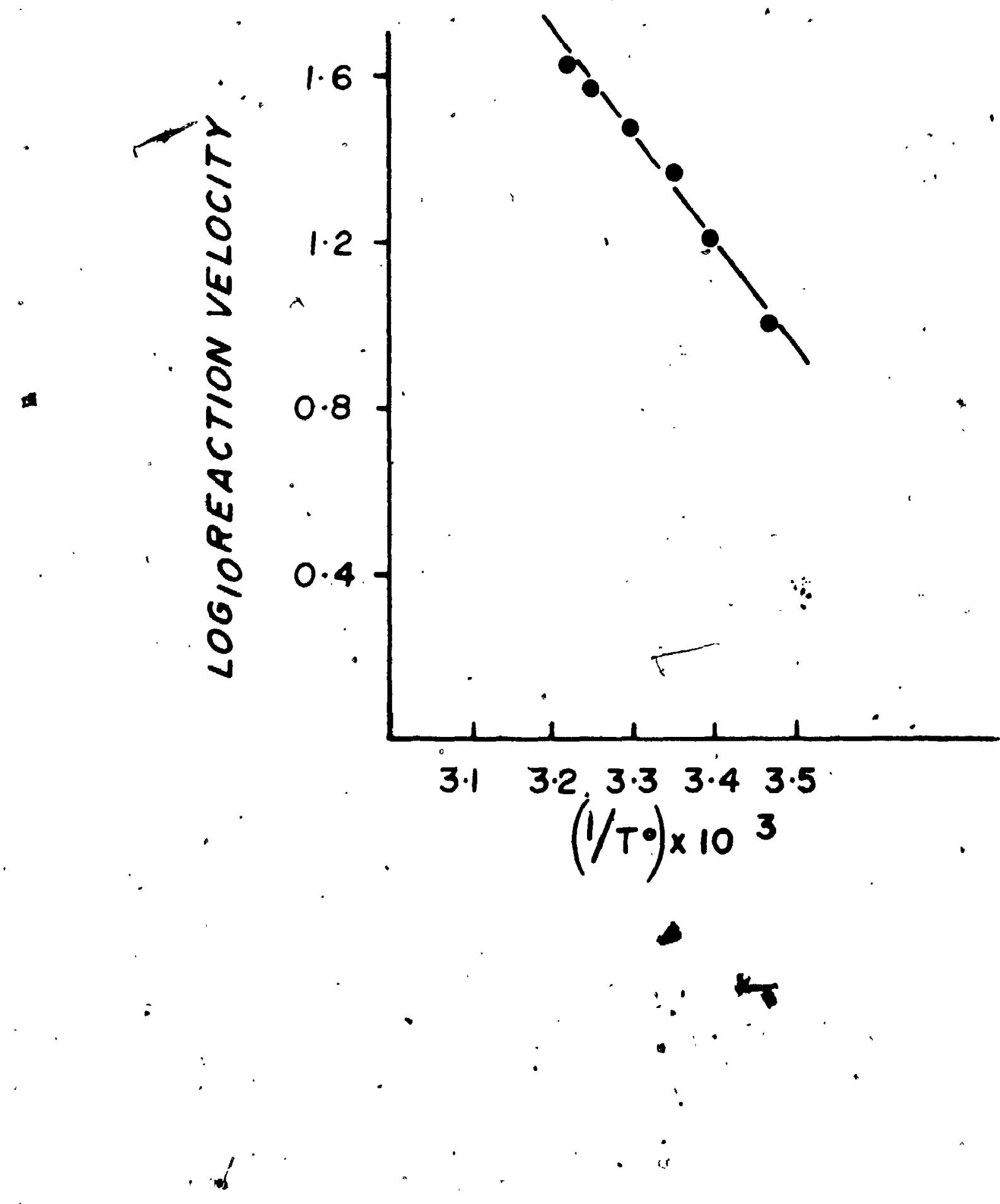



Electrophoresis was carried dut at $4^{\circ} \mathrm{C}$ using Tris-glycine buffer,. pH 8.3 for about 3 hours. No contaminating protein was detected. Human erythrocyte PGK migrated as a single sharp protein band in the buffer system used (Figure 19).

\section{Sedimentation Pattern of PGR}

The sedimentation pattern of $\mathrm{PGK}$ in $0.1 \mathrm{M}$

- phosphate buffer, pH 7.0 containing $5 \mathrm{mM}$ cysteine $\mathrm{HCl}$ showed a single sedimentation boundary (Figures 20 and 21). The sedimentation constant was calculated as $S_{20 w} 4.0$ at a protein concentration of $0.7 \mathrm{mg}$. per $\mathrm{ml}$. For most proteins' the partial specific volume (V) usually lies between 0.70 to $0.75 \mathrm{ml} / \mathrm{g}$ and its very accurate determination requires large amounts of protein. The partial specific volume of $0.74 \mathrm{ml} . \mathrm{g}$. obtained from the literature for PGK from different sources $(55,113)$ was used in the calculations herein.

6. Moleculary Weight of PGK

The molecular weight of purified.PGK from human - red cells was determined by.the sedimentation equilibrium method $(22,41,56,99-r 00)$ in a Spinco Model $\mathrm{E}$ analytical ultracentrifuge. The rotor speed for the equilibrium runs was obtained from the rotor speed selection chart (22) using the sedimentation values.

Photoelectric scans of the equilibrium runs were taken at different time intervals until equilibrium was achieved. In the molecular 
FIGURE I⿳9

Polyacrylamide gel electrophoresis of purified PGK

- from electro focusing.

Note: Fractions examined were Nos. 75,76 and 77

respectively obtained in the electrofocusing

- procedure (See Figure 15).

(conditions as described in the text).

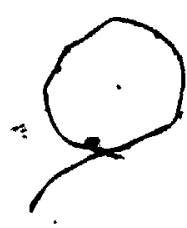




เิ
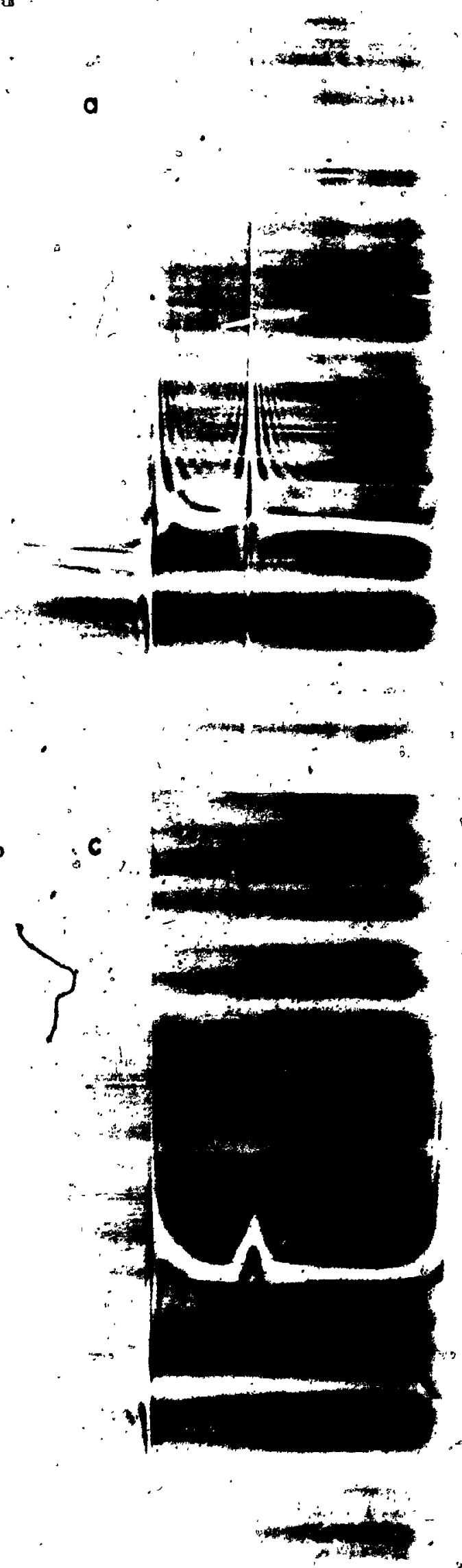

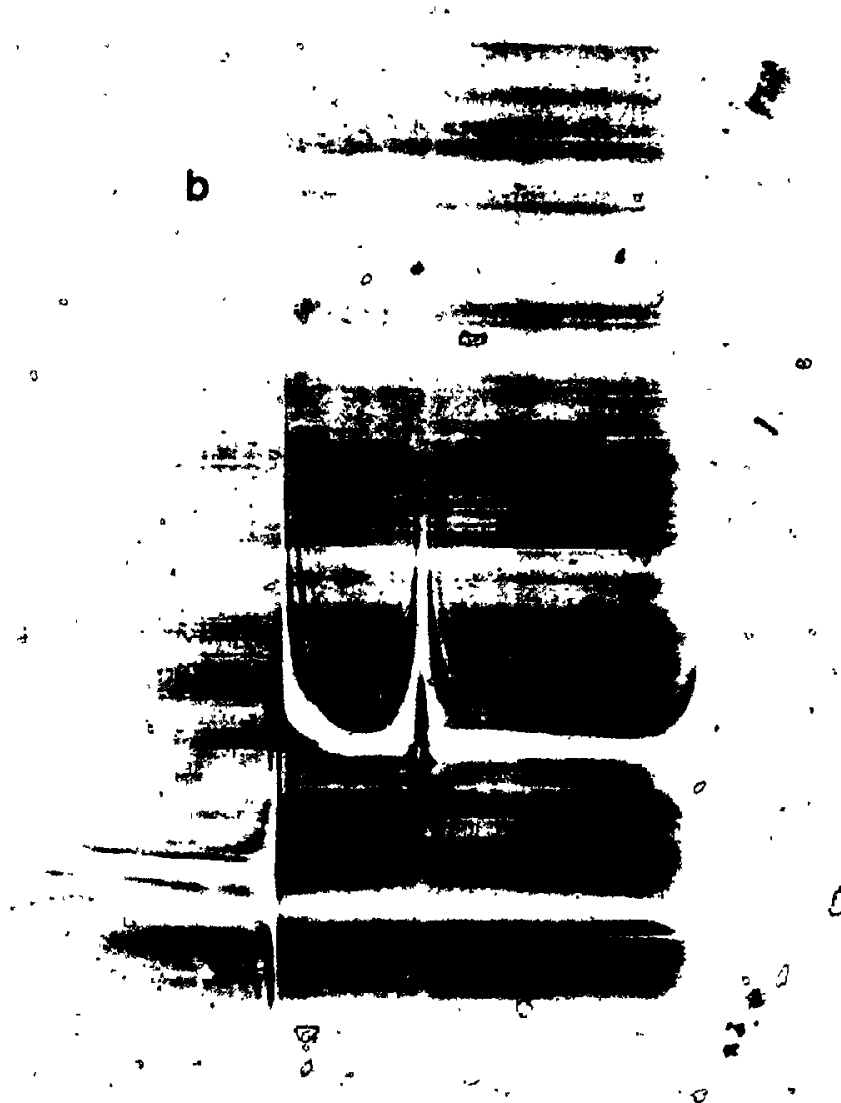

0

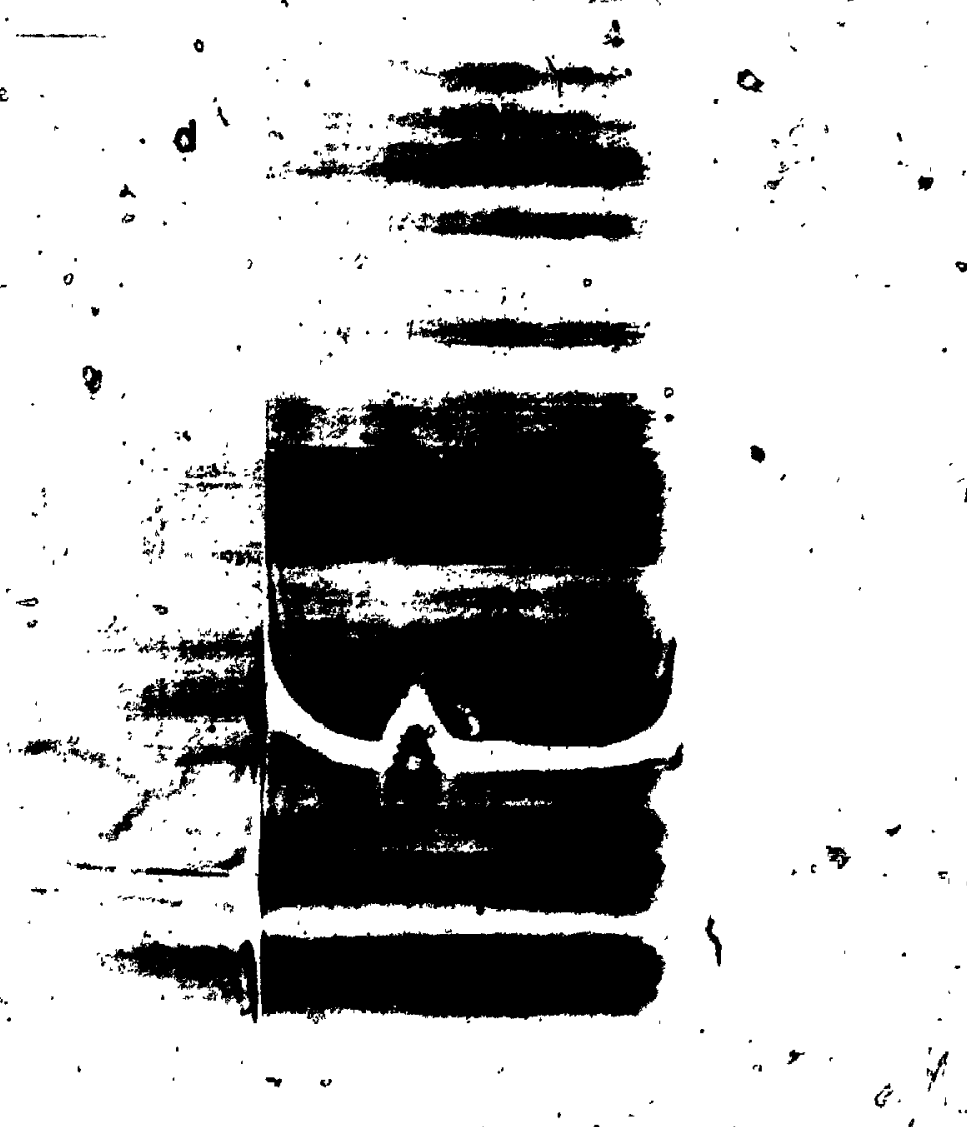



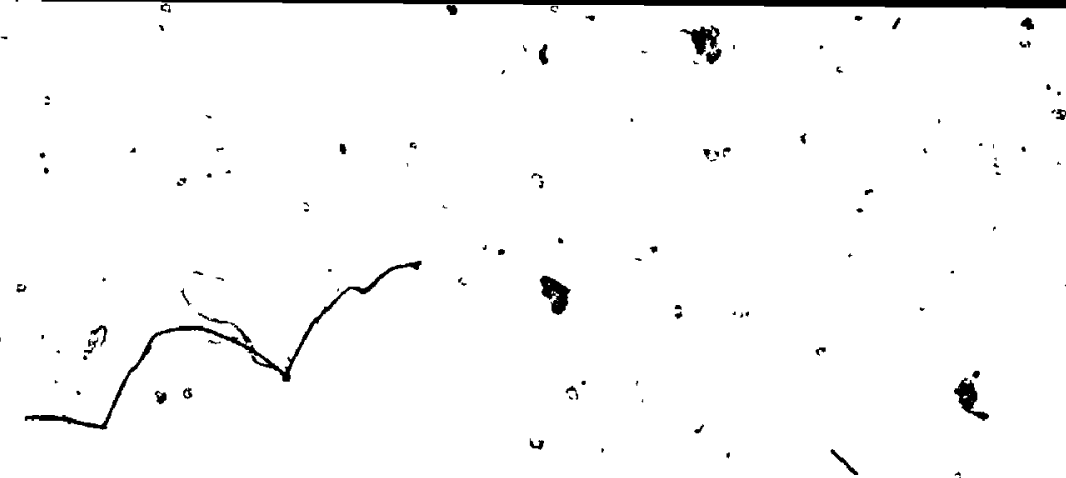

a
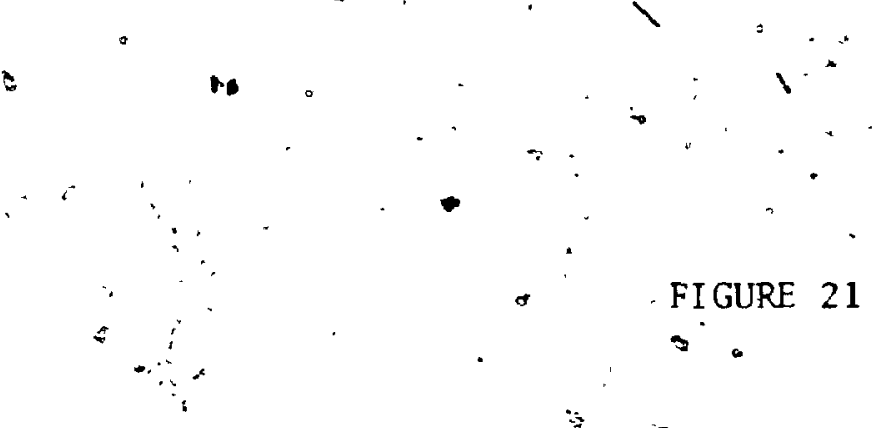

$\therefore$ Sedimertation pattern of PGK in $0.1 \mathrm{M}$ phosphate

. buffer, $\mathrm{pH} 7.0$ containing $5 \mathrm{mM}$ of cysteine $\mathrm{HCl}$. The direction of sedimentation is to the right:

a

Enzyme concentration

$0.70 \mathrm{mg} / \mathrm{ml}$

35

$\therefore$

Speed

42,040 r.p.m.

Tempexature of run $14^{\circ} \mathrm{E}$.

Optical density range

$0.0-1.00 .0$. units

(conditions as described in the text):

.

$-3$

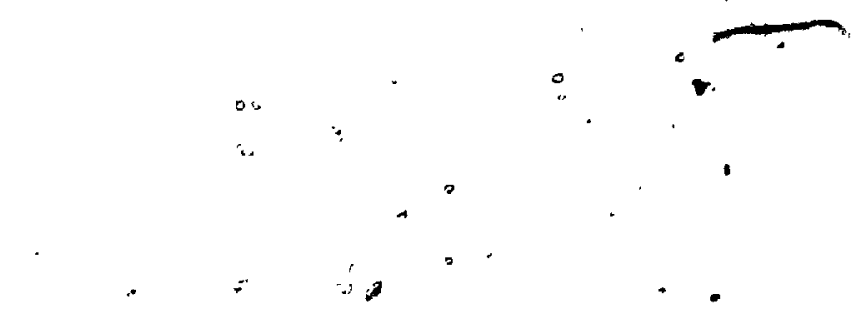



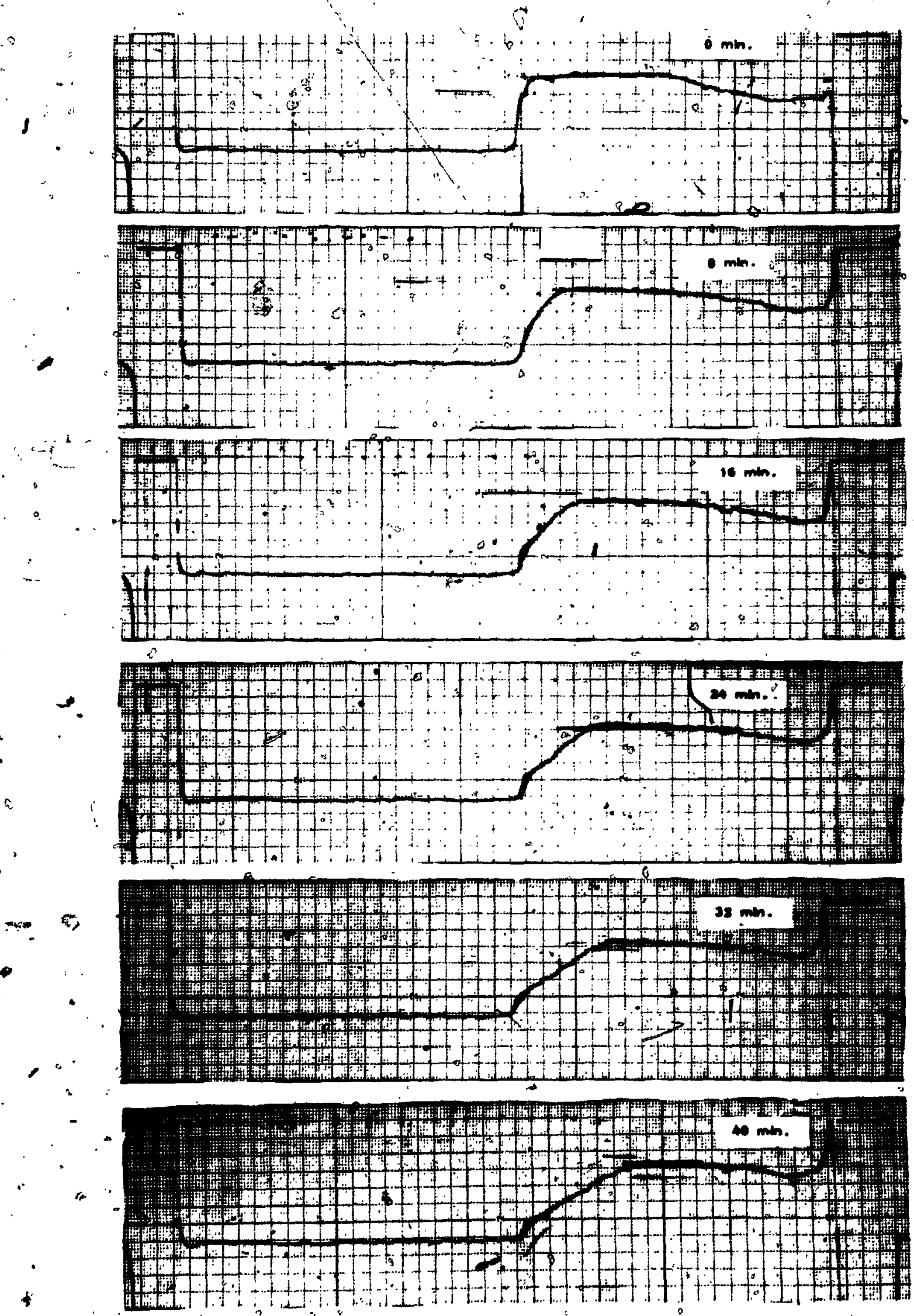
FIGURE 22

= Molecular weight determination of PGK by the equilibrim sedimentation method. The $\log$ plot of the optical density $(278.5, \mathrm{~nm})$ versus $\left(X^{2}\right)$ from the axis of rotation.

i

Rotor speed

9,945 r.p.m.

Tentperature of run

$8^{\circ} \mathrm{C}$

$\checkmark$ 

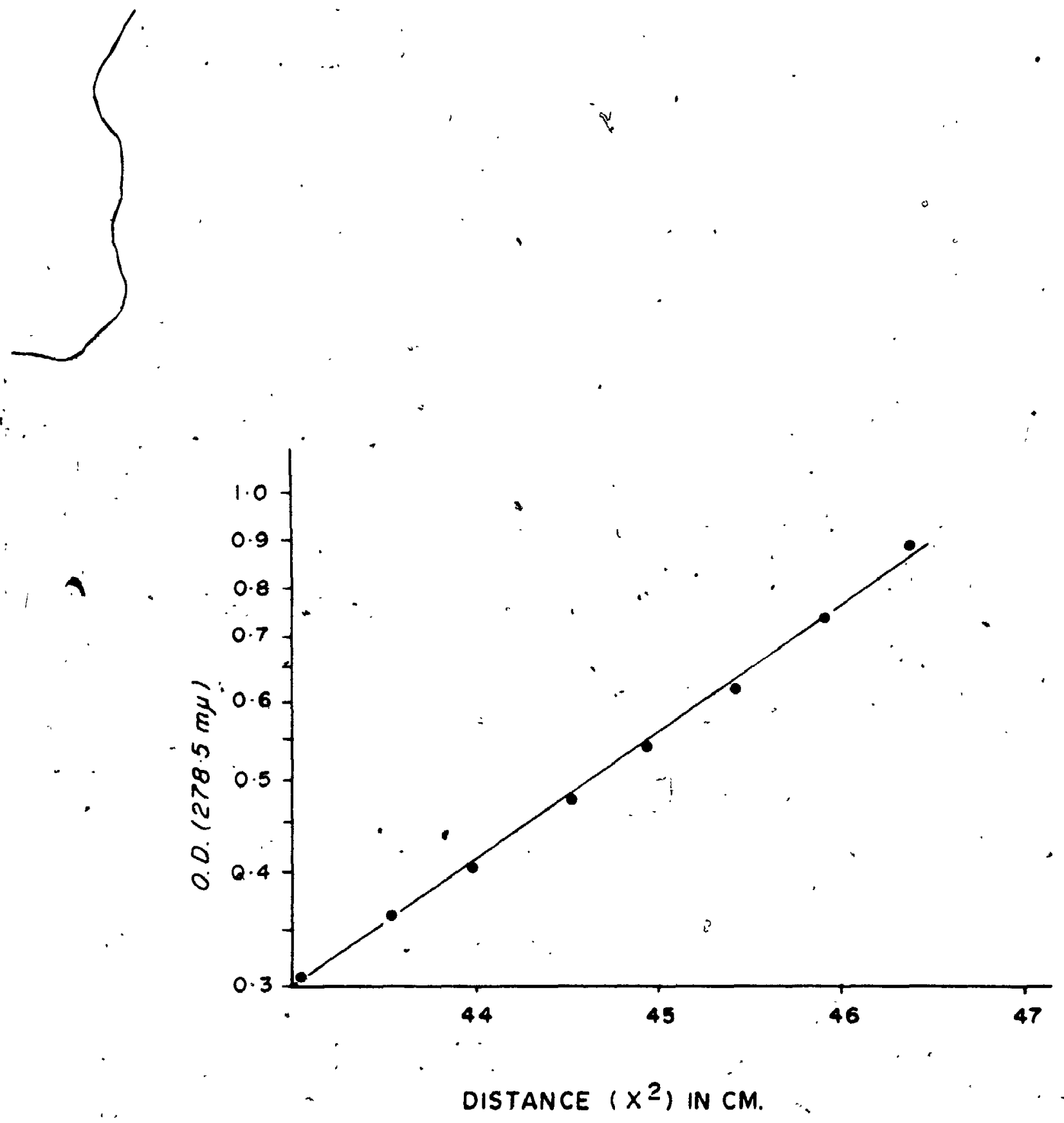
proportional to the apparent molecular weight of the purified enzyme (22) as shown in Figure 22. The straight line indicates that the solution is homogenous and ideal. The purity of the enzyme was also, verified by polyacrylamide gel electrophoresis which gave a single active protein band. The average molecular weight calculated from. a number of runs was 48,000 . The enzyme was found to be quite stable after a prolonged tun time (45 hours) in the ultracentrifuge at $8^{\circ} \mathrm{C}$. V. Kinetic Prdperties of PGK

The kinetic properties of PGK from muscle and yeast have been extensively studied $(19,55,84)$ in backward reaction (B).

$$
\text { 1,3-DPG + ADP } \underset{\mathrm{B}}{\stackrel{\mathrm{F}}{\rightleftarrows}} 3 \mathrm{PGA}+\mathrm{ATP}
$$

However the kinetic properties of PGK from human red cells have not been described in detail. The present studies on purified PGK from human red cel1s, were carried out in the forward reaction (F) leading from 1,3-DPG to 3-PGA and its properties were compared to that of yeast and múscle enzymes.

1. The Effect of ADP or $\mathrm{Mg}^{2+}$ on PGK Activity (fixed $[A D P]$ or $\left[\overline{\mathrm{Mg}}^{2+}\right]$, variable $[1,3-D P G]$ )

Substrate activation was observed when the effect of fixed concentrations of ADP $\left(0.025,0.05,0.1,0.4\right.$ and $\left.0.8 \times 10^{-3} \mathrm{M}\right)$ (Figure 23) or $\mathrm{Mg}^{2+}\left(0.125,0.25,1.0,2.5\right.$ and $5.0 \times 10^{-3} \mathrm{M}$ ) (Figure 24) and varying concentrations of 1,3-DPG (1-15 u Moles) on enzyme activity were studied. Biphasic curves (Figures 23 and 24) were obtained in the linear and double reciprocal plots demonstrating 
The, Effect of ADP and 1,3-DPG on PGK Activity

(fixed $[A D P]$, variable $[1,3-D P G]$ )

\section{Legend}

[ADP]:
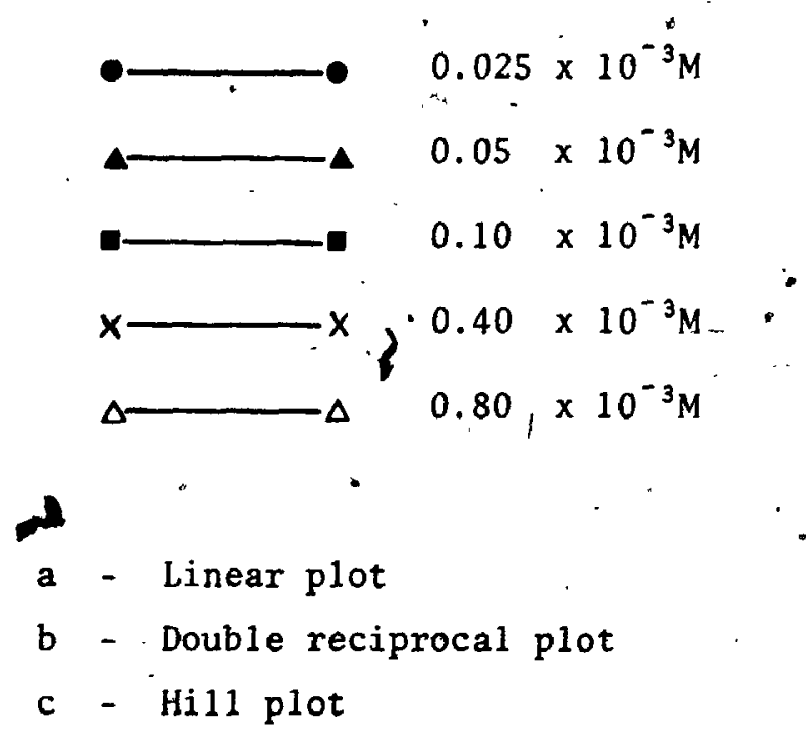

(Conditions as.described in the text, p. 107). 
$\bullet$

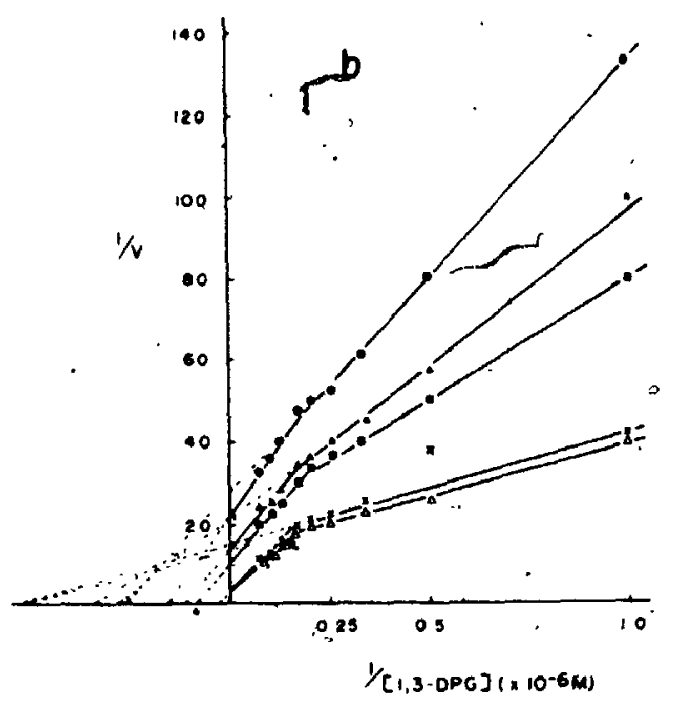

$?$

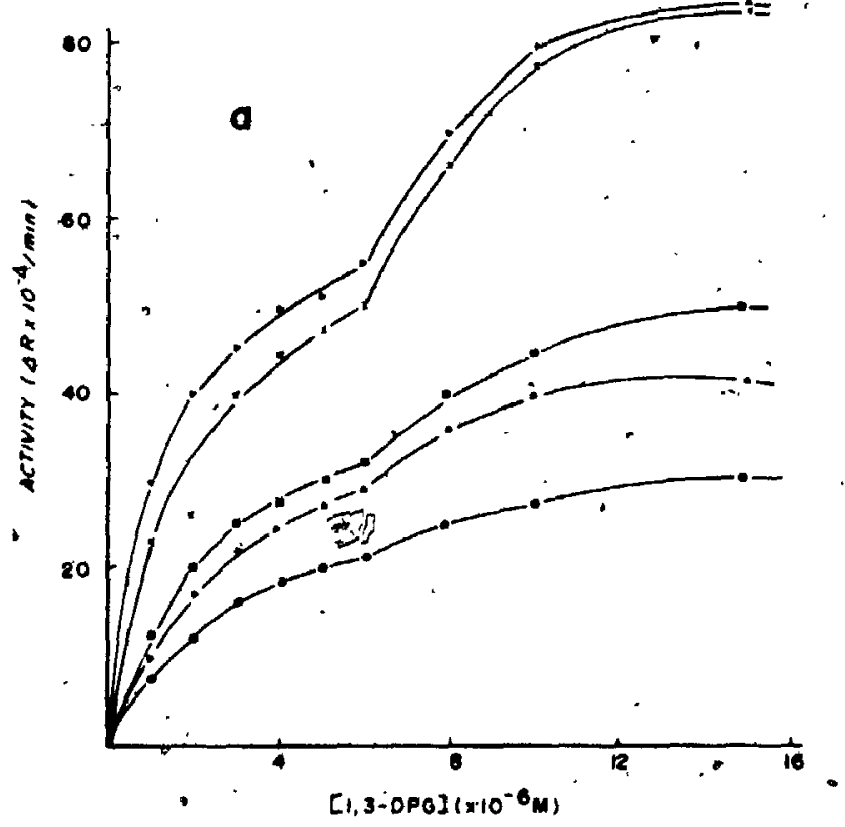

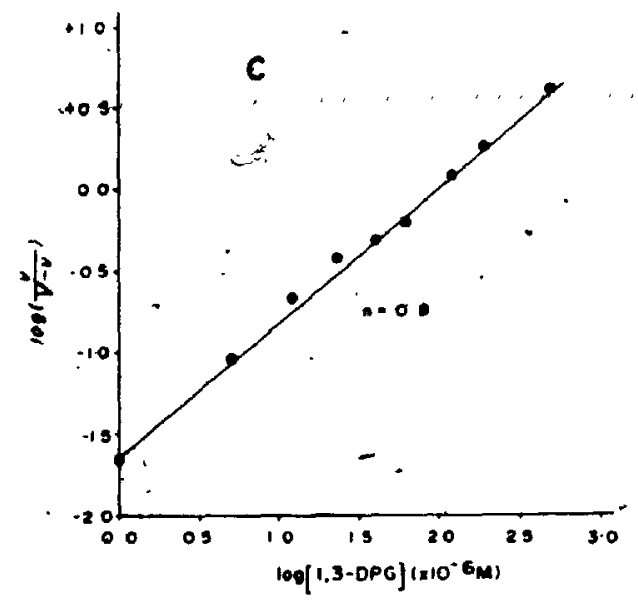

. 
FIGURE 24

The Effect of $\mathrm{Mg}^{2+}$ and 1,3-DPG on PGK Activity

(fixed $\left[\mathrm{Mg}^{2+}\right]$, variable $[1,3-\mathrm{DPG}]$ )

Legend"

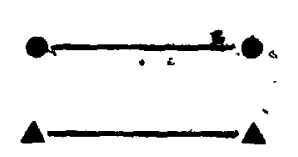

$$
\begin{aligned}
& 0.125 \times 10^{-3} \mathrm{M} \\
& 0.25 \times 10^{-3} \mathrm{M} \\
& 1.0 \times 10^{-3} \mathrm{M} \\
& 2.5 \times 10^{-3} \mathrm{M} \\
& 5.0 \times 10^{-3} \mathrm{M}
\end{aligned}
$$

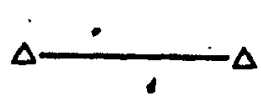

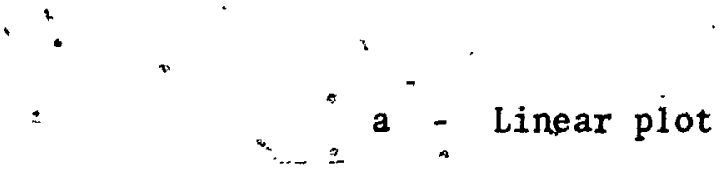

$$
\begin{aligned}
& \text {. } b^{*} \text { - Double reciprocal plot } \\
& \text { c - Hill plot }
\end{aligned}
$$

(Conditions as described in the text, p. 107). 
111
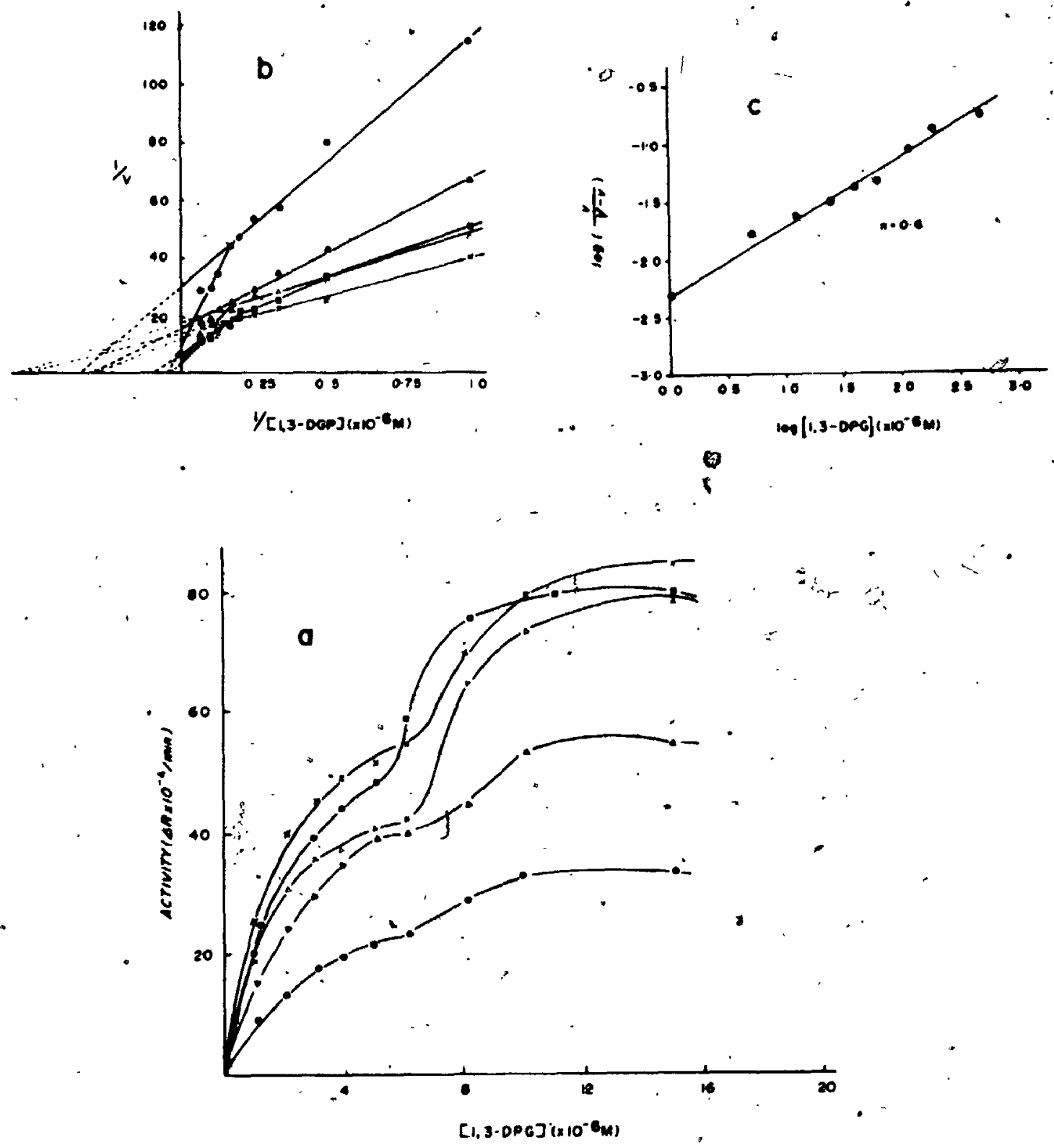
two $\mathrm{K}_{\mathrm{m}} \mathrm{s}^{2}$ : At optimal concentrations of $\mathrm{Mg}^{2+}$ and $\mathrm{ADP}$ the $K_{\mathrm{m}} \mathrm{is}$ calculated for $1,3-D P G$ from the double reciprocal plot were $K_{m l} 1.9 \times 10^{-6} \mathrm{M}$ and $\mathrm{K}_{\mathrm{m} 2} 9.8 \times 10^{-6} \mathrm{M}$. .

Substrate activation was observed at fixed levels of $\mathrm{Mg}^{2+}$ and varying concentrations of 1,3-DPG (Figure 24). A biphasic curve was obtained for each fixed level of $\mathrm{Mg}^{2+}$ in the double reciprocal plots. $\mathrm{Mg}^{2+}$ was observed (Figure 24 to have a non-competitive relationship, with respect to $1,3-\mathrm{DPG}$. When these results wefe plotted using the Hi11 $1^{\circ}$ equation (46) according to Levitzki and Kọs land (65) the interaction coefficient was 0.6 (the example shown in Figure 24 $\therefore$ is for optimal $\mathrm{Mg}^{2+}$ and ADP concentrations). A Hill coefficient less than 1 has been proposed as being characteristic for enzymes exhibiting negąive cooperativity (65). Apparent nëgatịve cooperativity was observed at fixed suboptimal $(0.125 \mathrm{mM})$ to optimal :(1):0 mM) concentrations of $\mathrm{Mg}^{2+}$ and varying concentrations of $1,3=\mathrm{OPG}$, with Hill coefficients at these levels ranging between $0.6^{\prime}$ to 0.7 . Similar allooteric effects were observed at fixed levels, of ADP and varying concentrations of i,3-DPG (Figure 23). The 1inear and double reciprocal plots for each fixed level of ADP described $:-$ biphasic curves. Substrate activation persisted at subsaturating 1 ) levels of ADP (0.025 mM). An apparent uncompetitive relationship 'was observed between $A D P$ and 1,3-DPG. When these results were plotted using the Hill equation as above, the Hill coefficient was calculated to be 0.8 (example shown in Figure 23 is for optimal $\mathrm{Mg}^{2+}$ and saturating $1,3-\mathrm{DPG}$ concentration). Negative cooperativity 


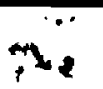

persisted at suboptimal to optimal $(0.025 \div 0.4 \mathrm{mM})$ concentrations

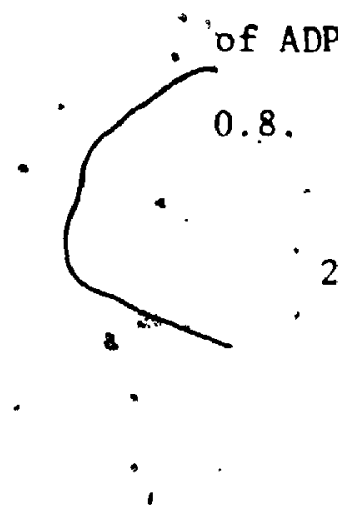

2. The Effect of 1,3-DPG and ADP or $\mathrm{Mg}^{2+}$ on PGK Activity (fixed $[1,3-D P G]$, variable $[A D P]$ or $\left[\mathrm{Mg}^{2+}\right]$ )

- Apparent Michaelis-Menten kinetics were observed under conditions of three fixed levels of $1,3-\mathrm{DPG}(2,0,5.0$ and 10.0 - . $x 10^{-6} \mathrm{M}$ ) and varying concentrations of $\mathrm{Mg}^{2+}$ (Figure 25). Similarly

- the linear plots of the three fixed levels of added 1,3-DPG (Figure 26) and varying concentrations of ADP appeared to be parabolic. However, the double reciprocal plots described biphasic curves with two $\mathrm{K}_{\mathrm{m}}$ 's. In both series (with $\mathrm{Mg}^{2+}$ and $\mathrm{ADP}$ ) maximum activity was obtained at a level of $10.0 \times 10^{-6} \mathrm{M}$ of $1,3-\mathrm{DPG}$. Maximal PGK activity was. observed with ADP (Figure 26) at a level of $0.4 \mathrm{mM}$ and $\mathrm{Mg}^{2+}$ at $1.0 \mathrm{mM}$ (Figure 25).

At fixed concentrations of $1,3-\mathrm{DPG}$ and varying $\therefore$ concentrations of $\mathrm{Mg}^{2+}$ Michaelis-Menten kineties were observed both in the linear and double reciprecal plot (Figure 25). A noncompetitive type of relationship was observed between $1,3-D P G$ and $\mathrm{Mg}^{2+}$. When these results were plotted using the Hill equation (46) the Hill coefficient was 1.0 (the example shown in Figure 25 is for the optimal ADP and saturating 1,3-DPG concentration). 


$$
\therefore:
$$

$\circ$

8

,
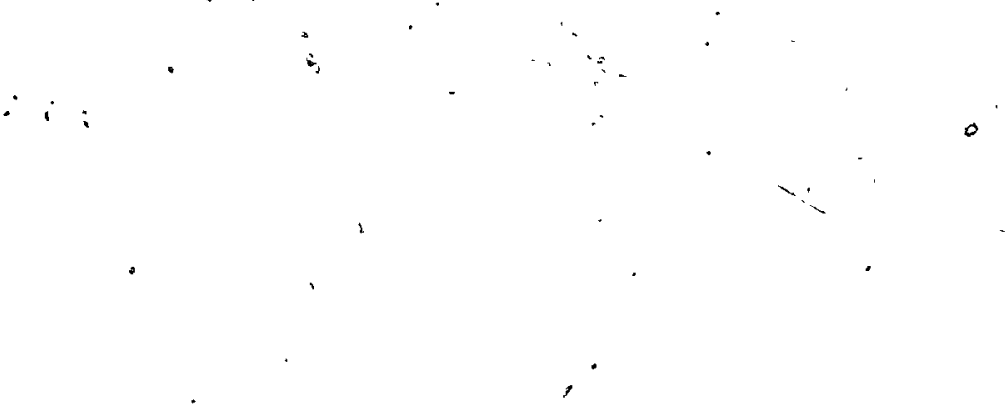

FIGURE 25

The Effect of 1,3-DPG and $\mathrm{Mg}^{2+}$ on PGK Activity

(fixed $[1,3-D P G]$, variable $\left.\left[\mathrm{Mg}^{2+}\right]\right)$.

Legend

$$
\begin{aligned}
& {[1,3-D P G]:} \\
& \text { int } \\
& 2.0 \times 10^{-6} \mathrm{M} \\
& \triangle \quad 5.0 \times 10^{-6} \mathrm{M} \\
& 10.0 \times 10^{-6} \mathrm{M} \\
& \text { a - Linear prot } \\
& \text { b - Double reciprocal plot } \\
& \text { c '- Hill plot }
\end{aligned}
$$

(Conditions as described in the text, 113).

$\therefore$

0 

$\infty$

FIGURE 26

2

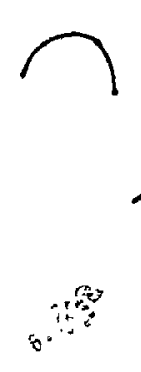

The Effect of $1,3-D P G$ and ADP on PGK Activity

(fixed $[1,3-D P G]$, variable $[A D P]$ )

Legend

$[1,3-\mathrm{DPG}]:$

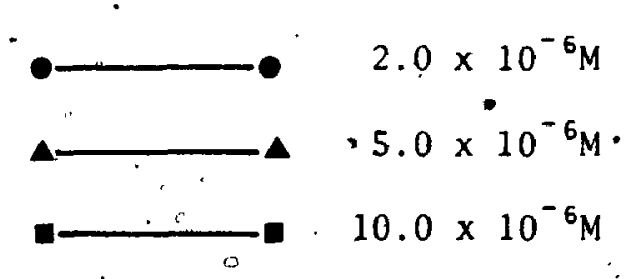

a - Linear plot

b - Double reciprocal plot.

c - Hill plot

(Conditions as described in the text, p. 113). - 


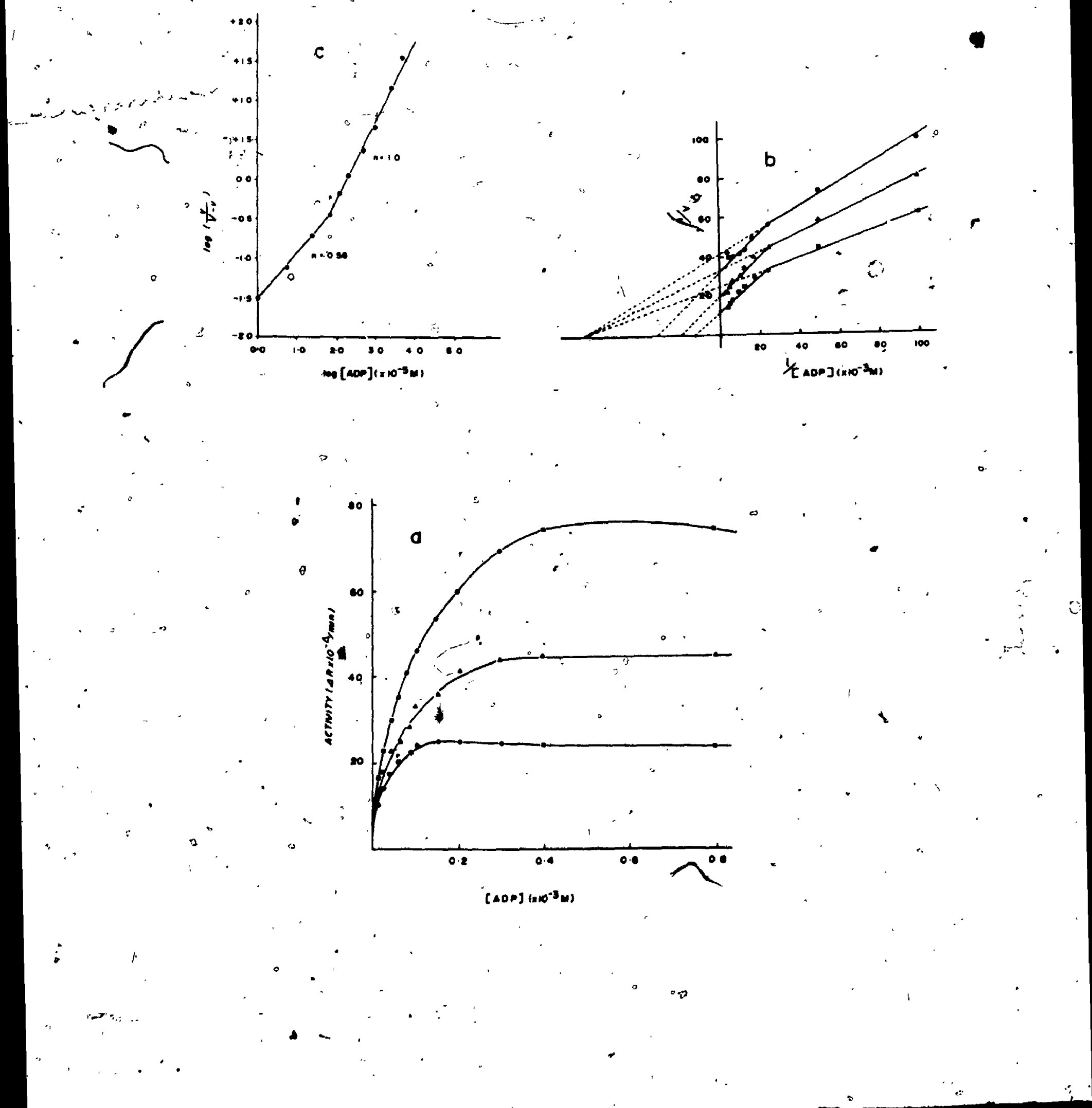


An apparent Michaelis-Menten curve was obtained in the linear plot at fixed levels of 1,3-DPG and varying concentrations of $A D P$, but the double reciprocal plots described biphasic curves. The lower part of the biphasic curve from the double reciprocal plot is characteristic of an uncompetitive relationship with respect to $A D P$ and the upper biphasic curve, a noncompetitive relationship (Figure 26). The interaction coefficient was 1.0 at higher levels of ADP 'concentrations. (lower part of the biphasic curve) for each" fixed level of $1,3-\mathrm{DPG}\left(2.0,5.0\right.$ and $\left.10 \times 10^{-6} \cdot \mathrm{M}\right)$. At subsaturating concentrations of ADP (i.e. upper.'part of the biphasic curve) apparent negative cooperativity persisted at fixed levels of $1,3-\mathrm{DPG}\left(2.0,5.0\right.$ and $\left.10 \times 10^{-6} \mathrm{M}\right)$ with the Hill Coefficient ranging between 0.60 to 0.75 .

\section{The Effect of $\mathrm{Mg}^{2+}$ and ADP on PGK Activity} (fixed $\left[\mathrm{Mg}^{2+}\right]$, variable $[A D P]$.

\section{Apparent Michaelis-Menten kinetics were described by} the linear plots under conditions of fixed concentrations. of $\mathrm{Mg}^{2+}$ $\left(0.125,0.25,1.0\right.$ and $\left.2.5 \times 10^{-3} \mathrm{M}\right)$ and varying concentrations of ADP (Figure 27). However, the double reciprocal plots for ADP described biphasic curves with two $K_{m}{ }^{\prime} s\left(K_{m 1} 0.17 \times 10^{-4} \mathrm{M}\right.$ and $K_{m 2} 1.0 \times 10^{-4} \mathrm{M}$. . respectively, Figure 27). At suboptimal concentrations of $\mathrm{Mg}^{2+}$ $(0.125 \mathrm{mM})$ Michaelis-Menten kinetics were observed in both linear agnd double reciprocal plots. At fixed'levels of. $\mathrm{Mg}^{2+}$ a noncompetitive 
FIGURE 27

$\sqrt[3]{3.2}$

The Effect of $\mathrm{Mg}^{2^{+}}$and ADP on PGK Activity

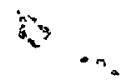

i

,

-

6

$\dot{\varphi}$

$\because=$.

0

Legend

$$
\left[\mathrm{Mg}^{2+}\right]:
$$

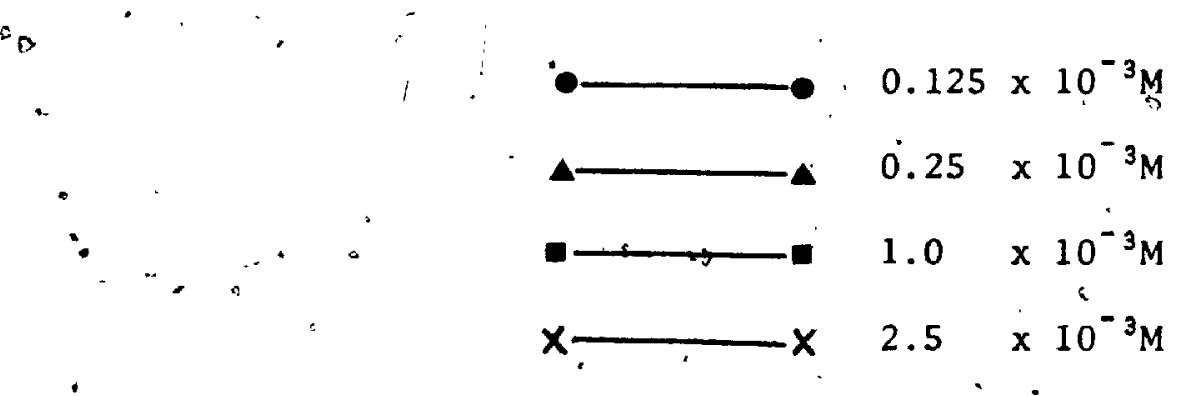

a - Linear plot

b" - Double reciprocal plot

c $-H i 11^{\circ} \mathrm{plot}$

(Conditions as described in the text, p. 118).

0 

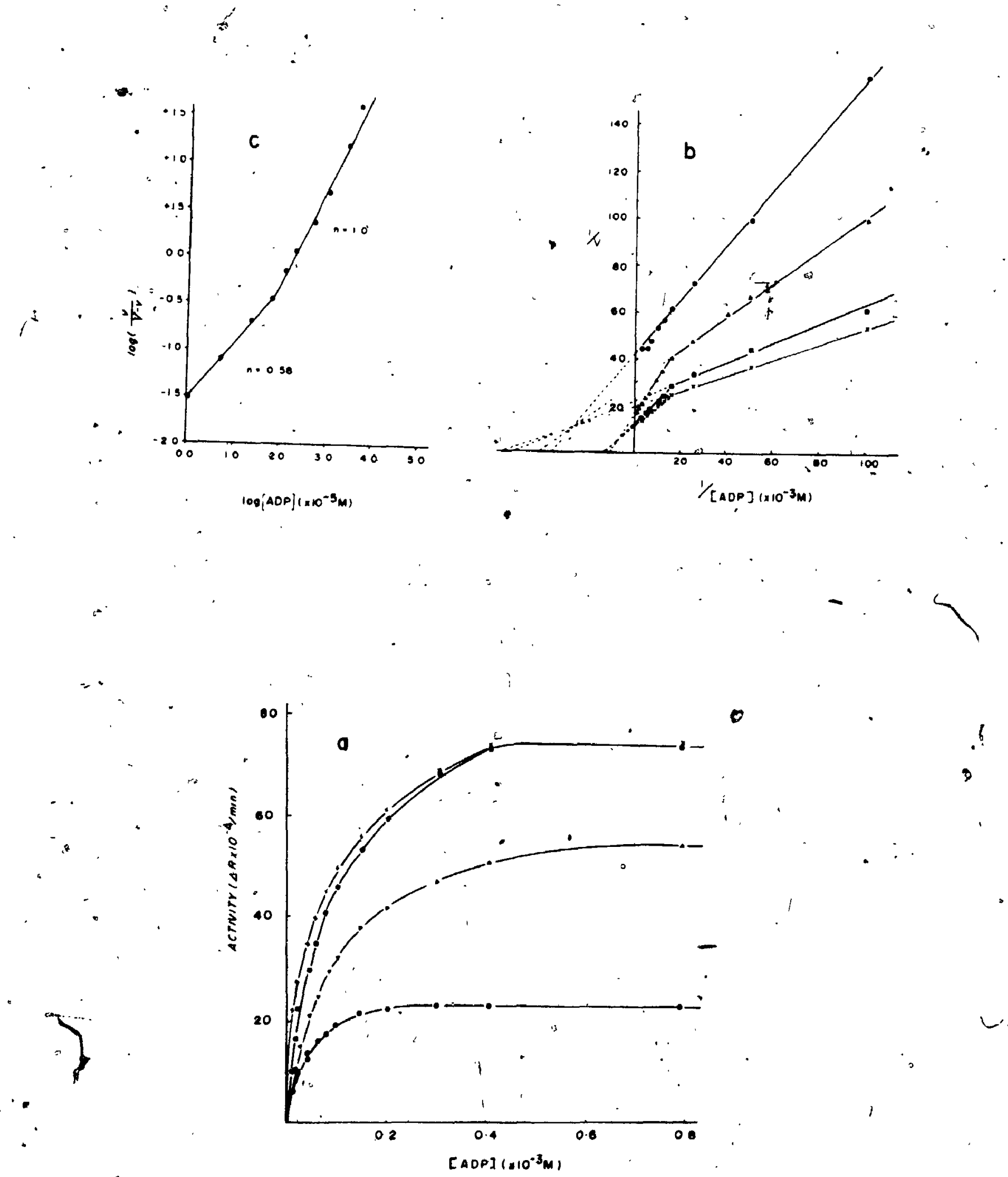
relationship is observed in both parts of the biphasic curve with respect to $A D P$ (Figure 27 ). When these results were plotted using the Hill equation (46) biphasic curves were obtained demonstrating two vălues for ' $n$ '. The interaction coefficient was 1.0 and 0.6 for the lower and upper portion of the biphasic curves respectively (the example shown in Eigure 27 is fọ optimal $\mathrm{Mg}^{2+}$ and saturating 1, 3-DPG concentrations).

4. The Effect of $\mathrm{ADP}^{\prime}$ and $\mathrm{Mg}^{2+}$ on PGK Activity (fixed $[A D P]$, variable $\left[\mathrm{Mg}^{2+}\right]$ )

Hyperbolic cúrves were obtained when enzyme aețivity was $\dddot{p}$ lotted at four fixed levels of $\operatorname{ADP}(0.025,0.05,0.1$ and $0.4 x$ $10^{-3} \mathrm{M}$ ) and varying concentrations of $\mathrm{Mg}^{2+}$ (Figure 28). Maximum velocity was observed at a level of $1.0 \mathrm{mM} \mathrm{Mg}{ }^{2+}$ and $0.4 \mathrm{mM}$ of $\mathrm{ADP}$ concentration. $V_{\max }$ varied with varying concentrations of fixed ADP. The $\mathrm{K}_{\mathrm{m}}$ for $\mathrm{Mg}^{2+}$ was calculated.at $0.5 \mathrm{mM}$.

There was no activation effect observed by ADP with respect to $\mathrm{Mg}^{2+}$. Michaelis-Menten kinetics were observed both in the linear and double reciprocal plots. A noncompetitive type of relationship was observed between $\mathrm{ADP}$ and $\mathrm{Mg}^{2+}$ (Figure 28). The interaction coefficient was calculated to be 1.0 (the example shown in Figure 28 is for the optimal ADP and saturating 1,3-DPG concentrafions) which is characteristic for Michaelis-Menten kinetics. 


\section{Legend}

[ADP] :

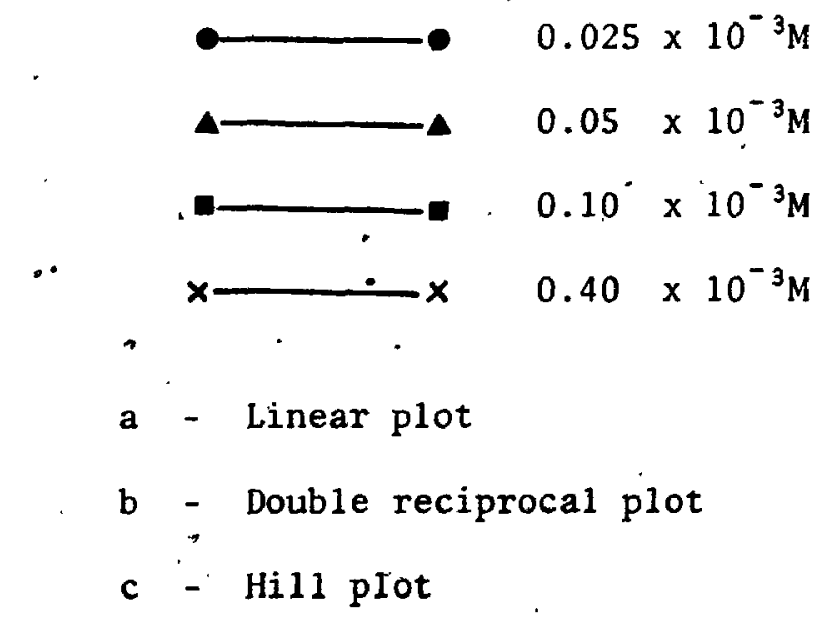

(Conditions as described in the text, p. 121). 

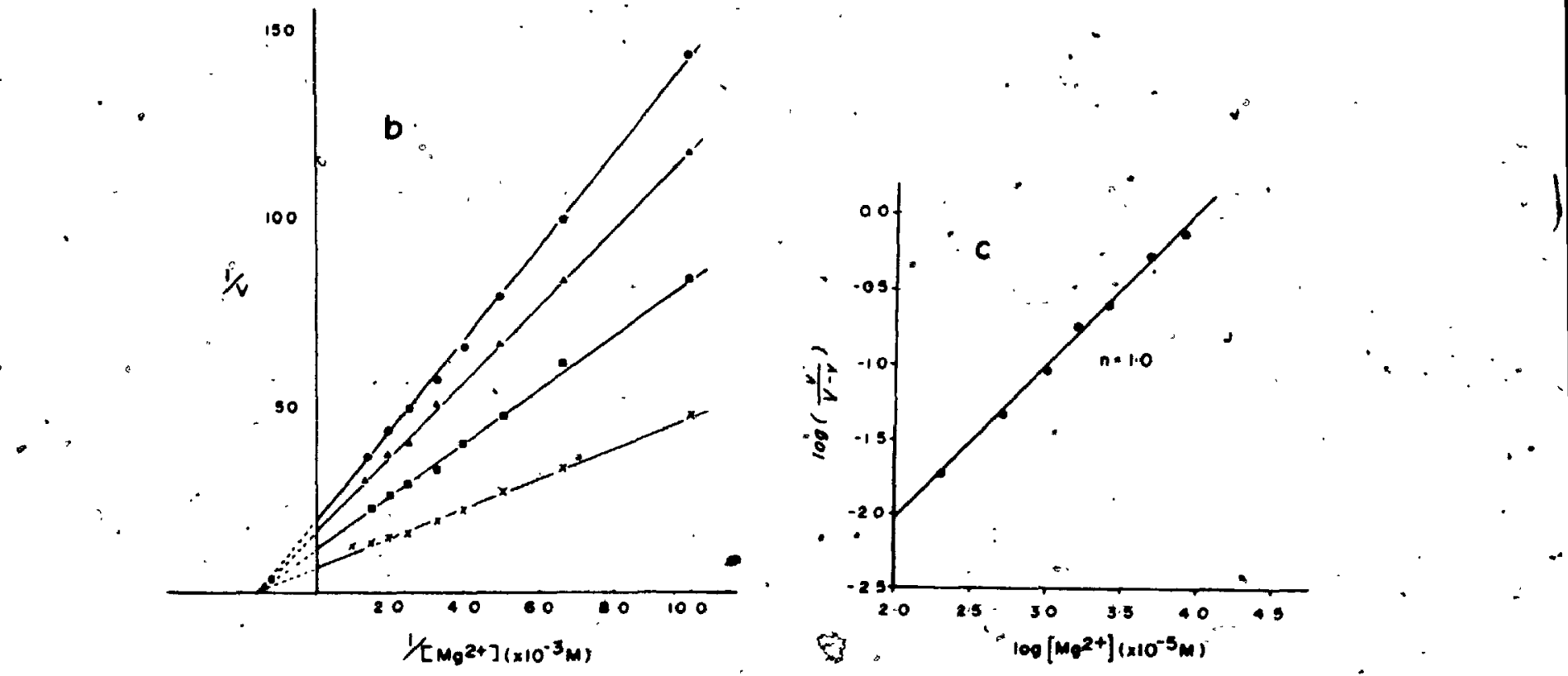
VI. Effects of AMP on PGK Activity

AMP was found to have an inhibitory effect on PGK actiyity

(Figure 29). Enzyme activity was inhibited to a maximum of 54 with added AMP $\left(10 \times 10^{-3} \mathrm{M}\right)$.

1. The Ef $\bar{f}$ ect of AMP and 1,3-DPG on PGK Activity

:(fixed $[\mathrm{AMP}]$, varịable $[1,3-\mathrm{DPG}]$

$\therefore$

The effect, of AMP on PGK àctivity, was studied at four

fixed levels of AMP $\left(0.25,1.0,2.0\right.$ and $\left.5.0 \cdot \dot{x}^{\circ} 10^{-3} \bar{M}\right)$ with varying.

concentrations of 1,3-DPG (Figure 30). The $\mathrm{V}_{\max }$ at these fixed levels

of AMP was lower compared to the control (without AMP) due to the ... .

inhibition of PGK activity. As in the earlier experiments without

added AMP biphasiç curveș were obtained from the double reciprocal

plots with two $\mathrm{K}_{\mathrm{m}}$ 's'. Substrate activation persisted at lower levels ,

$\because$ of AMP but at higher concentrations of this - inhibitor $\left(5 \times 10^{-3} \mathrm{M}\right)$

the curve approached the hypefbolic at 'a decreased level of'activity.<smiles>[Li][14CH2]</smiles>

The inhibition with respect to 3 -DPG in the presence of optimal concentrations. of $\mathrm{Mg}^{2+}$ and $A D P$. The interaction coefficient calculated from Hill plot was 0.75 . (the example shown in 'Figure 30 is for the optimal $\mathrm{Mg}^{2+}$ and:ADP concentration in the presence of $0.25 \times 10^{-3} \mathrm{M}$ of AMP). Negative cooperativity persisted up to a level of $2.0 \mathrm{mM}$ AMP with an interaction coefficient calculated at 0.90 . However, at highẹr 


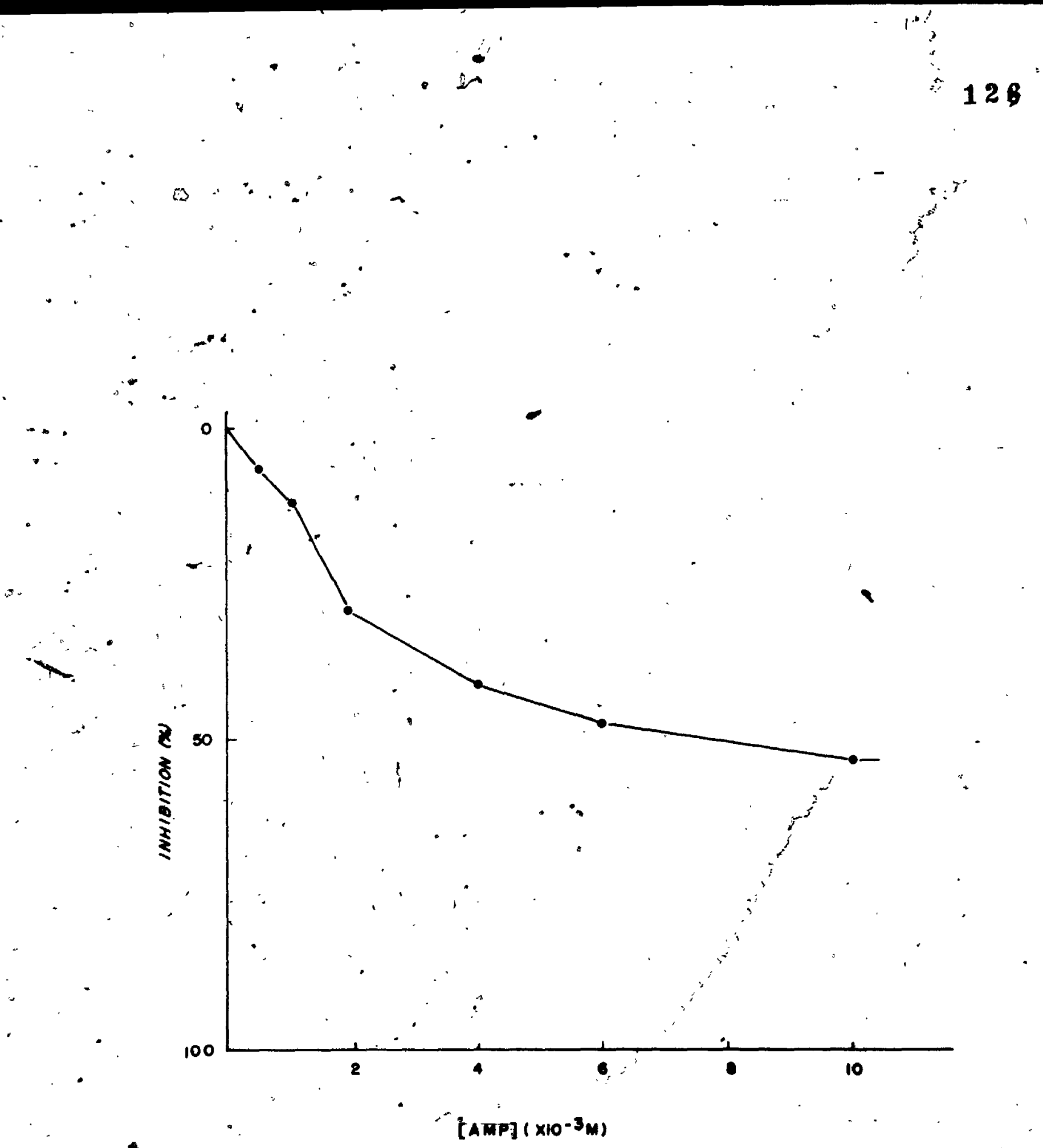
FIGURE 30

The Effect of AMP and 1,3-DPG on PGK Activity

(fixed [AMP], variable [1,3-DPG])

$y$

[AMP] :
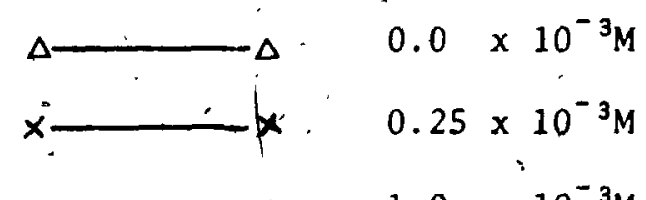

$1.0 \times 10^{-3} \mathrm{M}$

$2.0 \times 10^{-9} \mathrm{M}$

$5.0 \times 10^{-3} \mathrm{M}$.

: a - Linear plot

b - Double Reciprocal plot

c - Hill plot

(Conditions as described in the text, p. -124). 
के
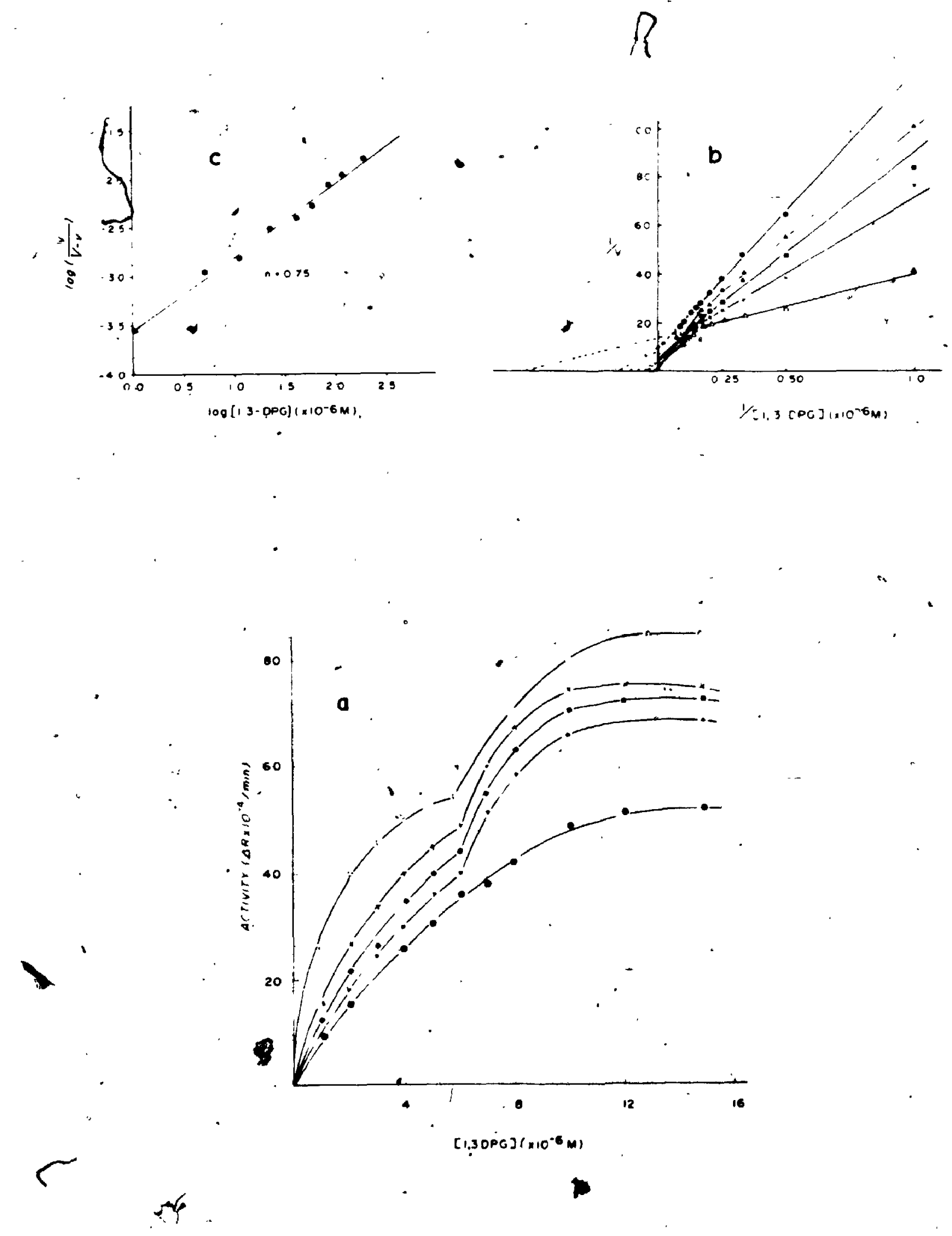

$\infty$ 
concentrations of AMP $(5.0 \mathrm{mM})$ the cooperativity was abolished with a Hill coefficient of 1.0 . The interaction coefficient of the control (without added AMP) was 0.6.

- 2. The Effect of AMP and ADP on PGK Activity (fixed [AMP], variable $[A D P]$

Apparent Michaelis-Menten curves were obtained in linear plots at fixed levels of AMP $\left(1.0,2.0\right.$ and $\left.5.0 \times 10^{-3} \mathrm{M}\right)$ and varying concentrations of ADP (Figure 31). However, the double reciprocal plots for ADP delionstrated biphasic curves with two $\mathrm{K}_{\mathrm{m}}$ 's. The maximum velocities observed in the presence of the above fixed Tevels of AMP were lower in comparison to the control (without AMP) due to the inhibitory effect on PGK activity.

A noncompetitive type of inhibition was observed by AMP with respect to ADP. When, the results were plotted using the Hil1 equation biphasic curves were obtained with two interaction coefficients, 0.6 and 1.0 respectively tho example shown in

Figure 31 is for the optimal $\mathrm{Mg}^{2+}$ and saturgejirg 1,3-DPG concentration in the presence of $5.0 \times 10^{-3} \mathrm{M}$ AMP). Apparent negative "cooperativity was observed in the upper part of the biphasic curve.

- Cooperativity was inoperative in the lower partof the biphasic curve. The interaction coefficient values for the enzyme treated with AMP. was similar to that without added AMP. 


\section{FIGURE 31}

The Effect of AMP and ADP on PGK Activity

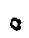

- (fixed $[A M P]$, variable [ADP])

\section{$\sum^{\infty} \quad$ Legend}

[AMP] :

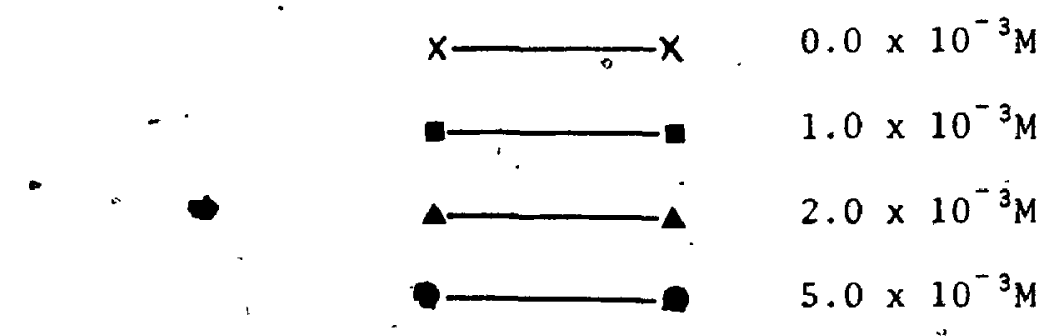

$$
\begin{aligned}
& a-\text { Linear plot } \\
& b-\text { Double reciprocal plot } \\
& c-\text { Hill plot }
\end{aligned}
$$

(Conditions as deseribed in the text, p. 129). 

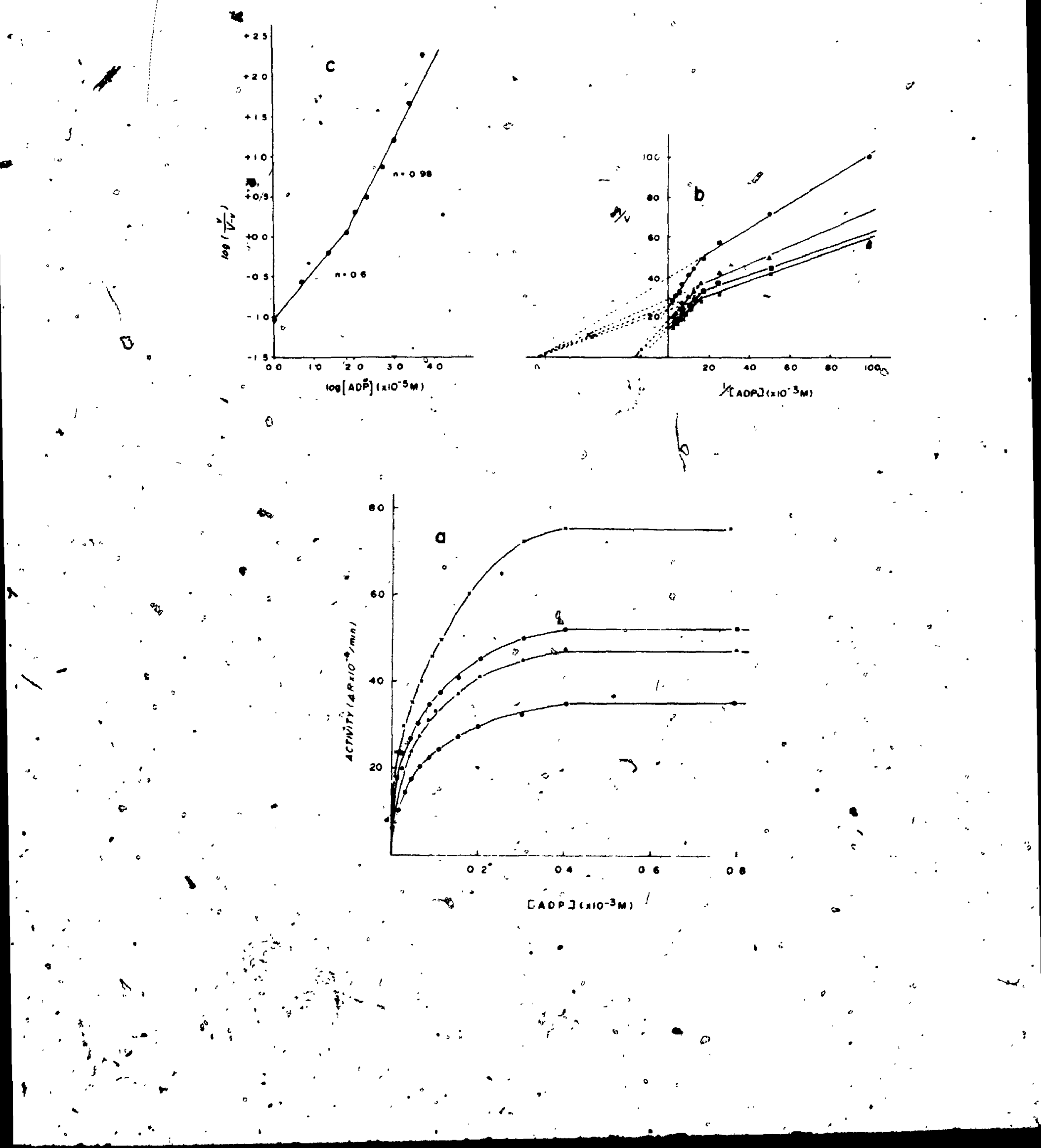
3. The Effect of AMP and $\mathrm{Mg}^{2}$ on PGK Activity" (fixed $[A M P]$, wariable $\left[\mathrm{Mg}^{2+}\right]$ ),

Michaelis-Menten kinetics were observed in the linear. and double reciprocal plot at fixed levels of $\operatorname{AMP}^{2}(1.0,2.0$ and 5.0 $\times 10^{-3} \mathrm{M}$ ) varying concentrations of $\mathrm{Mg}^{2+}$. Inhibition-was observed at various levels of AMP with respect to the control (without added AMP) (Figure 32). AMP was a noncompetitive inhibitor with respect to $\mathrm{Mg}^{2+}$ as observed in both the upper and lower parts of the biphasic curves. The interaction coefficient ('n') was 1.0 at all fixed levels of $\operatorname{AMP}(1.0,2.0$ and $5 \mathrm{mM})$ and varying concentrations of $\mathrm{Mg}^{2+}$ (the example shown in Figure 32 is for the optimal ADP and saturating concentration of $\mathrm{I}, 3-\mathrm{DPG}$ in the presence of $1: 0 \mathrm{mM}$ AMP) . Similarly, the interaction coefficient of the control (without added AMP) , was 1.0 .

VII. The Effect of 2,3-DPG on Legk Activity

2,3-DPG had an inhibitory effect on PGK activity

(Figure 33). Enzyme activity was inhibited to a máximum of $57 \%$ with. added $2,3-D P G\left(10 \times 10^{-3} \mathrm{M}\right)$

- Although enzyme inhibition was observed in the presence of $2, A D G$, substrate activation persisted in the presence of this inhibitor. At-higher concentrations of 2,3-DPG $\left(50 \times 10^{-3} \mathrm{M}\right)$ the "curve approached the hyparbolic (Figure" 34). "Biphasic curves were s. 


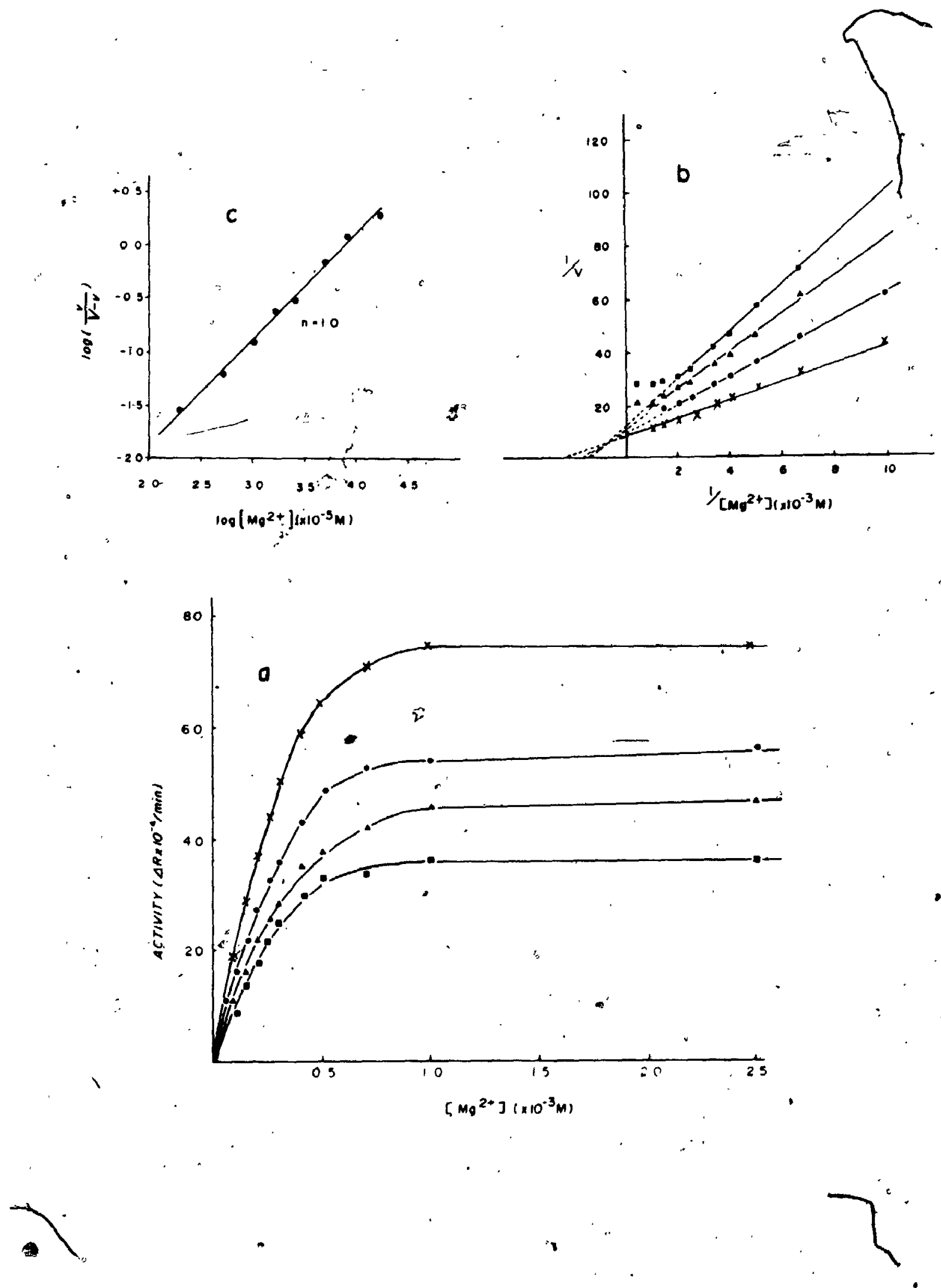
$\therefore 8$

FIGURE 33

Effect of 2,3-DPG on PGK Activity

(Conditions as described in the text, p. 132). 
4

136

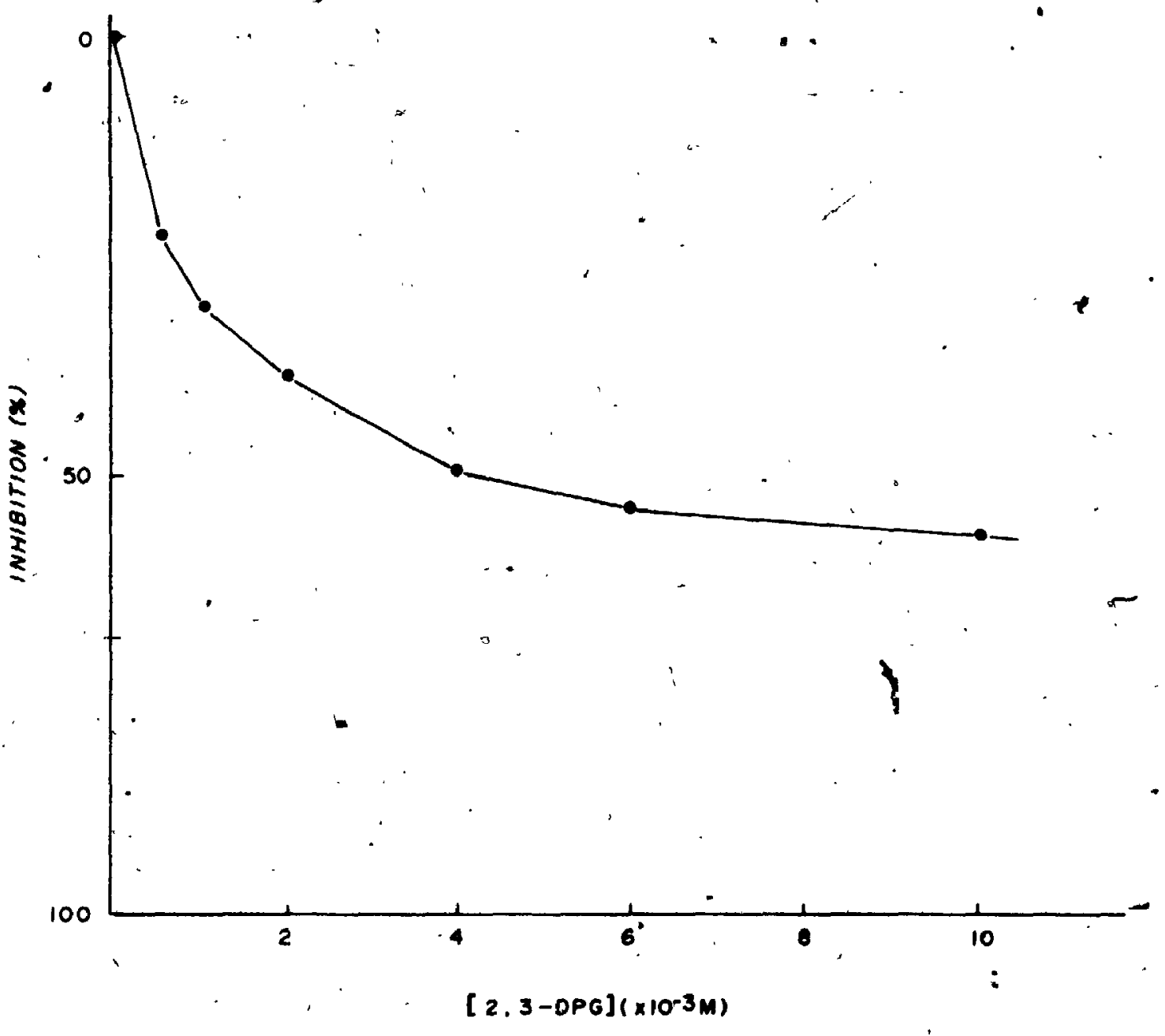


a

FIGURE 34

The Effect of $2,3-D P G$ and 1,3-DPG on PGK Activity

(fixed $[2,3-D P G]$, variable $[1,3-D P G]$ )
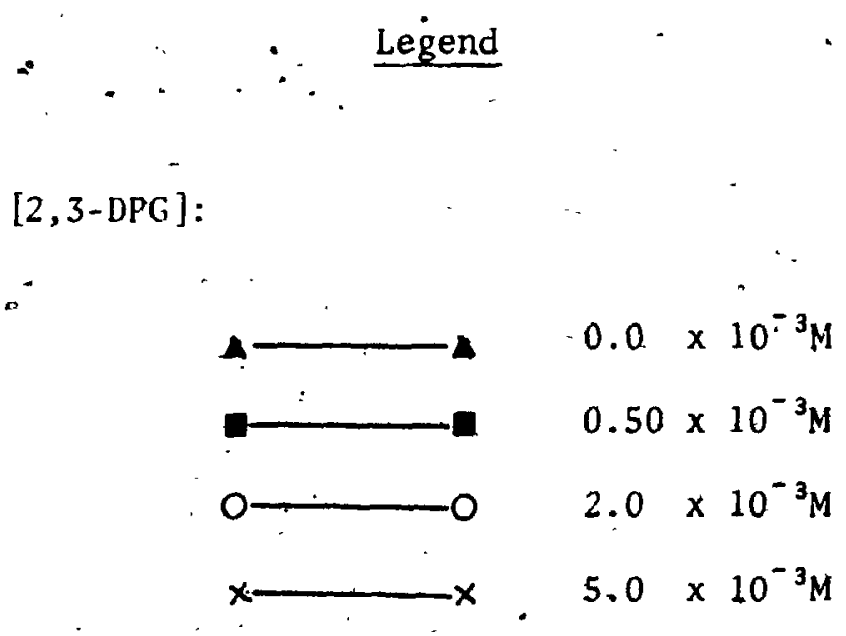

- a - Linear plot

b - Double reciprocal plot

c - Hill plot

s.

(Conditions as described in the text, p. 132).

0 


\section{FIGURE 34}

The Effect of 2,3-DPG and: 1,3-DPG on PGK Activity (fixed $[2,3-D P G]$, variable $[1,3-D P G])$

\section{Legend}

$[2,3-D P G]:$

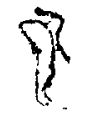

$s$

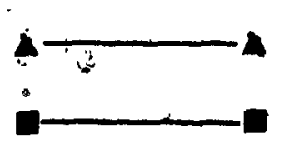

$0.0 \quad x^{-3} \mathrm{M}$

$0.50 \times 10^{-3} \mathrm{M}$

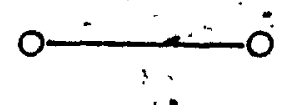

$\because 2,8, x_{0.1} 10^{-3} \mathrm{M}$
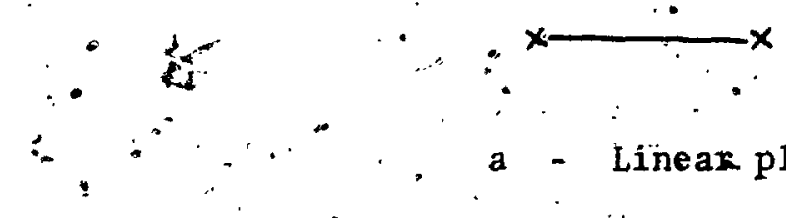

$5.0^{4} \times 10^{-3} \mathrm{M}$

$$
\begin{aligned}
a & - \text { Linear plot " } \\
b & - \text { Double recjprocal plot } \\
c & - \text { Hill prot }
\end{aligned}
$$

(Conditions as described in the text, p. 132). 
:
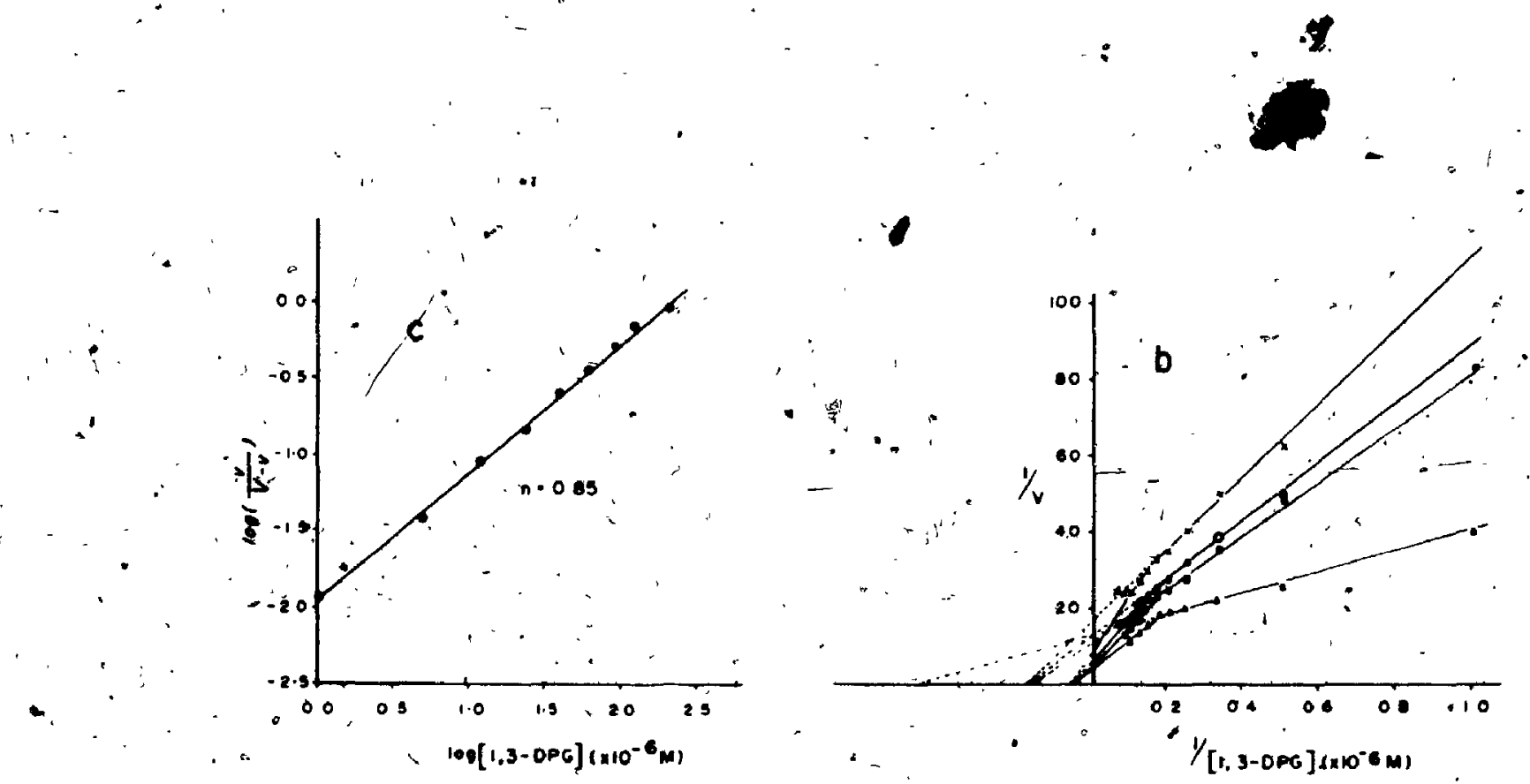

$-1$

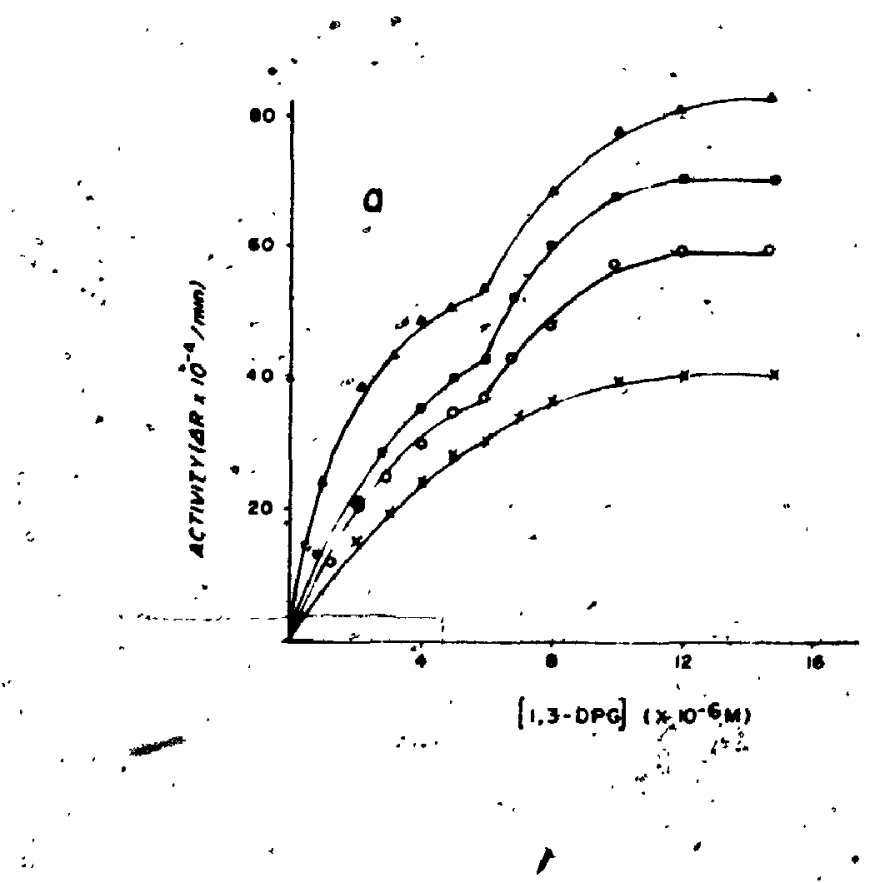

$\omega$

;. 
s.
i.

obtained both in the linear and double reciprocal plots at fixed levels of 2,3-DPG $\left(0.5,2.0\right.$ and $\left.5.0 \times 10^{-3} \mathrm{M}\right)$ and varying concentrations of $1,3-D P G$.

An apparent noncompetitive type of inhibition by 2,3-DPG with respect to 1,3-DPG was observed in both parts of the curve - The interaction coefficient calculated from the Hill plot was 0.88 (the example shown in Figure 34 is for the optimal $\mathrm{Mg}^{2+}$ and $A D P$ concentration in the presence of $5.0 \times 10^{-3} \mathrm{M} 2,3-\mathrm{DPG}$ ); the interaction coefficient of the control was 0.6 (without 2,3-DPG) . Apparent negative cooperativity persisted at high 2,3-DPG. concentrations $\left(5.0 \times 10^{-3} \mathrm{M}\right)$ but to a lesser degree. 


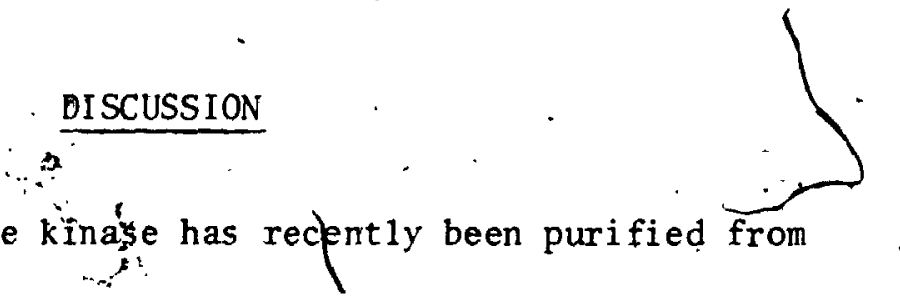

human erythrocytes by several workers $(45,76$ and 113$)$. Its kinetic properties have not been described in detail and information conceming its physical and chemical properties are lacking. Therefore, a detailed investigation of this enzyme was undertaken.

\section{Initial separations by polyacrylamide gel electrophoresis}

showed that the crystalline enzyme contained other prowins in addition to the active enzyme (PGK) (Figure 13): In order to achieve a high degree of purity the enzyme was furthey purified by electrofocusing (Figures 14 and 15). Electrophoresing the product on polyacrylamide gel demonsțrated a single sharp protein band which contained the enzyme activity (Figure 19). PGK from yeast, muscle (55) and human erythrocyte (113) have also been reported to demonsțrate a single protein band on polyacrylamide gel electrophoresis:

The isoelectric point for purified normal $P G K$ reported by Yoshida and Watanabe (114) was lower (7.9) in comparison to our findFngs (8.75). They reported that their.crystalline PGK was free of contaminating proteins although this point was not demonstrated by the electrofocusing technique described (114). The isoelectric point reported for muscle and yeast PGK (55) was 7.0 and 7.2 respectively. The difference in the isoelectric point may be due to the different 
conditions employed in its estimation.

i. The single discrete band of enzyme activity obtained by electrophoresis and the single sharp peak obtained by electrofocusing in the present study are evidence that the purified preparation is a single enzyme and $\underline{i}$.e. there are no isoenzymes.

Recently it has been reported by Jacobs (50) that the electrofocusing procedure affects the amino acid composition of proteins. He found the sulphur containing amino acids cysteine and methionine were present partly in the form of cysteic acid and. methionine sulfoxides. It was further suggested by the author that the oxidation of 'cysteine and methionine can be controlled by the use of a suitable antioxidant such as ascorbic acid. Since PGK is an - 'SH enzyme' the oxidation of cyșteine would result iña reduction of enzyme activity. However there was no significant loss in PGK activity (Table $V$ ) as a result of the electrofocusing procedure followed in this investigation (with added di thiothreitor $10 \mathrm{mg} \%$ ).

Further purification of the crystalline enzyme by electrofocusing resulted in an increase of four fold in specific activity from 470 units to 2200 units per mg of protein (Table V). A range in specific activity between 600-1000 units per'mg of protein has been reported from yeast (104), muscle (55) and human red cells (113) 
Highly purified proteins show homogeneous boundaries in the ultracentrifuge. A sedimentation constant of $3.095 \mathrm{~S}$ was obtained by Larsson-Raznikiewicz (61) for yeast PGK. The sedimentation constant of 4.0 reported herein for PGK from human erythrocytes was higher than that reported by Yoshida and Watanabe (113). The sedimentation rate depend on the size, shape and density of the particle: It also depends on the density and viscosity of the solvent. Any dissimilarity in the above conditions may result in the difference of the sedimentation rate.

The molecular weight obtained for $\operatorname{PGK}_{0}$ from yeast $(55,61)$, muscle (55) and human erythrocytes (113) lies between 46,000 to 50,600 by the equilibrium sedimentation method in the ultracentrifuge. Similar values for the molecular weight of human PGK (mol. wt. 48,000 ) were estimated by the sedimentation equilibrium method in this work.

! The efficacy of the assay system was confirme theoretically and experimentally. The auxiliary-indicator enzymes were added in excess to yield true initial velocity kinetics. i.e. without time 1 ap upon addition of the substrate $(1,3-D P G)$ : Further it was established that $P G K$ was the rate-limiting step and not the auxiliaryindicator enzymes wheri substrates were varied.

Kinetic studies of this enzyme (BGK) by previous workers $(1.9,55$ and 76$)$ were performed in the backward reacuion. This may be due to difficulties in carrying out the assay in the folward. direction. In the present work kinetic studies were performed in the forward direction leading from 1,3-DPG to 3-PGA. Phosphoglycerate 
kinase represents the first ATP-generating reaction of the glycoiytic chain. The enzyme capacity is very high in red cells of all mammals. The enzyme is highly specific for $1,3-\mathrm{DPG}$, for which it has a high affinity.

Substrate activation was observed with respect to $1,3-D P G$ when fixed levels of ADP or $\mathrm{Mg}^{2+}$ were studied. Biphasic curves were obtained on the double reciprocal plot demonstrating two $k_{m}$ 's (Figures 23 and 24$). K_{\mathrm{ml}} \cdot\left(1.9 \times 10^{-6} \mathrm{M}\right)$ for $1,3-\mathrm{DPG}$ obtained in the present work was similar to that reported for PGK from yeast (19) and muscle (84) $\left(1.80 \times 10^{-6} \mathrm{M}\right.$ and $2.2^{\circ} \times 10^{-6} \mathrm{M}$ respectively). The $\mathrm{K}_{\mathrm{m}}$ for b,3-DPG reported from human blood was higher $\left(3.5 \times 10^{-6} M\right)$ (45). The $K_{m}$ for muscle reported by Rao and Qesper (84) was based on tivity measurements at three levels of substrate only. The value for yeast was calculated from indirect measurements of the forward reaction (19). An apparent uncompetitive relationship was observed between $A D P$ and 1,3-DPG (Figuré 23) and a ņon-competitive relationsḥip" between $\mathrm{Mg}^{2+}$ and 1,3-DPG (Figure 24). Larsson-Raznikiewicz (60) has reported, a non-competitive type of inhibition at fixed levels of ATP or $\mathrm{Mg}^{2+}$ and varying concentrations of 3 -PGA in the backward reaction in yeast PGK. She demonstrated two $k_{m} \neq s$ but has not mentioned. the appearance of a biphasic curve in the double reciprocal plots. The author has not presented the data nor illustrated the linearplots for these experiments so that further comparison with the present work is difficult.

Substrate activation was not observed on the linear plot 
. when fixed levéls of $1,3-D P G$ (Figure 26) and $\mathrm{Mg}^{2+}$ (Figure 27) and varying concentrations of ApP were studied. However the double" reciprocal plot described a biphasic curfe. Apparent negative cooperativity was observed at subsaturating levels of ADR but at higher fevels of ADP it was not opeptive. According to Levitzki and Koshland $(68)$ in cases of negative cooperativity the saturation plot looks qualitatively like a Michaelis-Menten curve but the double reciproca1 plot is conçave downward and the Hill Coefficient is less than 1. The $K_{m}^{\prime}$ 's for ADP reported in yeast PGK $0.2 \times 10^{-3} \dot{M}(55)$, $0.4 \times 10^{-3} \mathrm{M}(84)$, musćle PGK $0.35 \times 10^{-3} \mathrm{M}(84), 0.15 \times 10^{-3} \mathrm{M}$ (55) and human PGK $0.78 \times 10^{-3} \mathrm{M}(45)$ fompared to ours $\dot{\mathrm{K}}_{\mathrm{m} 1}^{+} 0: 17 \times 10^{-4} \mathrm{M}$ and $K_{m 2} 1.0 \times 10^{-4} \mathrm{M}$ respectively. The difference may be due to the calculation of ' $\mathrm{K}_{\mathrm{g}}$ 's from the indirect estimation of the forward reaction.. Furthermore; substrate act the was not observed in the investigations and the calculated $\mathrm{K}_{\mathrm{m}}$ is simjlar to $\mathrm{K}_{\mathrm{m} 2}$ reported herein.

Michaelis-Menten kinetics were observed with respect to $\therefore . \mathrm{Mg}^{2+}$ at fixed levels of 1,3 -DPG or ADP (Figüres 25: and 28 respectively). The $\mathrm{K}_{\mathrm{m}}$ for $\mathrm{Mg}^{2+}\left(0.5 \times \mathrm{iO}^{-3} \mathrm{M}\right)$, in the present study appeared to be somewhat higher than reported in yeast $0.25-0.28$ $x 10^{-3} \mathrm{M}(19,84)$, muscl $0.27 \times 10^{-3} \mathrm{M},(84)$ and human red cells $0.32 \times 10^{-3} \mathrm{M}(45)_{2 *}$ The differences may be a result of the assay system úsed i.e. the hackward reactions.

Larsson-Razpikiewicz. (59) has fourd that free $\mathrm{Mg}^{2+}$ and free ATP inhibit PGK aetivity competitively in the backward reaction. In 
the present study this was not observed with free $\mathrm{Mg}^{2+}$ and free $\mathrm{ADP}$. The inhibition of PGK from human erythrocytes was observed in the presence of AMP and 2,3-DPG. At. levels up, to $2.0^{\circ} \mathrm{mM}$ concentration of AMP äpparent negative cooperativity was still observed but at a higher level $(5.0 \mathrm{mM})$ cooperativity was abolished (Figure 30$)$. The Hill coefficients ranged from 0.75 to 1.0 respectively. The interaction coefficient of the control (without added AMP) was 0.6 . The increase in the numeric value of interaction coefficient is inditative of a diminition in cooperativity as the concentration of AMP was increased.. The affinity for $1,3-\mathrm{DPG}$ was arso decireased in the presence of inhibitor AMP. It may that the allosteric site has been modified and there is no, cooperative interaction at this level of AMP "(5.0 mM). Larsson-Raznikiewicz and Arvidsson $(62)$ reported that AMP inhibited yeast FGK noncompetitively with respect to 3-PGA in the backward reaction. The same type of inhibition was observed "with respect to 1,3-DPG in the present study. The effect of AMP on

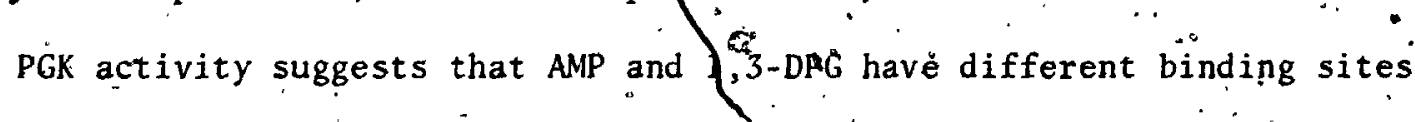
'on the enzyfine.

With respect to ADP the interaction coefficients for the enzyme treated. with AMP was similar to that without added AMP (Figure 31). This implaes that AMP doe not affect the binding of ADP' and does not induce any conformational change on the enzyme. AMP $\therefore$ inhibited the enzyme noncompetitively with respect to ADP. (Figure 31). It would appear. that AMP and ADP do not compete for the same site on the enzyme.

$\therefore$ A similar type of linhibition by AMP withespect to $\mathrm{Mg}^{2+}$ 
(Figure, 32) was observed. It is therefore reasonable to suggest that $\mathrm{AMP}$ and $\mathrm{Mg}^{2+}$ have different binding sites on the enzyme. $\mathrm{A}$ competitive type of inhibition by. AMP with respect to $\mathrm{Mg}$-ATP $^{-3}$ was reported by Larsson-Raznikiewicz and Arvidsson (62) in the backward reaction. ?

2,3-DPG was found to inhibit the enzyme noncompetitively with respect to 1,3 -DPG. Apparent negative cooperativity persisted at. Kigher $2,3-\mathrm{DPG}^{\circ}$ concentration $\left(5,0 \times 10^{-3} \mathrm{M}\right)$ but to a lesser degree (Figure 34). It appears that 2,3-DPG has partially modified the allosteric site of the enzyme at phyriological concentrations $(5.0 \mathrm{mM})$. Working with the backward reaction with partially purified enzyme from human erythrocytes Ponce et' al. (78) reported a competitive type of inhibition with respect to 3-PGA.

PGK isolated from human erythrocytes in the present study exhibited unique kinetic properties compared to the enzyme from other sources $(55,76,113)$.' Apparent negative cooperativity was observed with respect to: $1,3-D P G$ and ADP. The enzyme exhïbited Michaelis-Menten kinetics with respect to $\mathrm{Mg}^{2+}$. Enzyme activity was inhibited by AMP and 2,3-DPG: :

Levitzki and Koshland (65) suggested the following molecular events to explain negative homotropic kinetics:

(1) ligand induced conformationa changes which affect - subunit interaction.

(2) electrostatî repulsion betwé

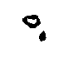

(3) Tonidentical peptide chains having active sites with

- different binding constyants as in isozymes. 
(4) two or more polymorphic forms of the same enzymes.

(5) geometric arrangements of identical chains which

produce non-identical sites eithér because of static geometry or because of subunit conformational changes during the association of subunits.

- The possibie interpretation of PGK kinetics (i.e. bumpy curves) obtging in the present study will be discussed on the basis of the five foplowing suggested molecular events. The first possibility was fuldout experimentally. The other four possible explanations can be treated potentially equal. These possibilities have not been tested because of the low yield of, the purified enzyme available:

1. The presence of isoenzymes of PGK with non-identical peptide chains having active sites with different binding constants. Isoenzymes of PGK were ruled out by polyacrylamide.gel electrophoresis and electrofocusihg reported in this study.

2. The presence of non-identical subunits with different catalytic activities. The higher catalytic activity sites would have a greater affinity for the substrate than the lower ones. This possibility would be tested by determoning whether the enzyme dissociates in the presence of guanidine hydrochloride, SDS and urea and then defining the size and structure of possible units by molecular weight anẩysis and amino acid composition.

3. The formation of enzyme aggregates at higher concentrations of substrate. If the enzyme aggregates to form a large molecule at higher substrate concentrations ther the' affinity of "the ággregated

$a$ 


\section{*}

enzyme for the substrate would be decreased. The appearance of a btphasic curve with two $\mathrm{K}_{\mathrm{m}}$ 's in the present study of PGK from human Trythrocytes could be related to the aggregation and disaggregation of the enzyme molecules. This possibility has not yet been tested because of the low yield of enzyme available. Further studies will include molecular weight measurements with added substrates and co1 fáctor.

4. Negative cooperativity is a characteristic of many enzymes with regulatory sites. In this.class of allosteric enzymes the binding of a modifier to the enzyme molecule decreases the affinity of the vacant site of the neighboring subunits causing cooperativity in a. negatife manner.

The apparent negative cooperativity observed with respect to 1,3-DPG and ADP in the present study of PGK from human erythrocytes is evidence for the presence of more than one binding site on the enzyme molecule for these substrates. "The conformational alteration. induced by 1 igand may effect the unoeetpind bindifig sites in the protein in such a way that their affinity for a ligand is deareased.

A sequential model of Koshland et al. (53a) though complicated, is flexible enough so that it may be used to explain a wide variety of kinetic observations. This model not only predicts positive and negative heterotropic interactions but also positive and negative homotropic interactions. In this model it is assumed $\circ$ that the binding of the Iigand induces a conformational change in. the neighboring subunitse A ligand wich strengthens substrate binding is an activator whereas a ligand which weakens substrate binding 
is an inhibitor. Binding of like ligands is said to be cqoperative if the addition of the first substrate molecule increases the affinity of the second and this sequential change is transmitted by neighboring units. If the addition of the first substrate molecule decreases the.binding of the second substrate molecule, a negative cooperative effect is observed. If the binding of the first ligand causes very little or no change in subunit interactions, then the kinetics will be of the Michaelis-Menten type even though the subunits are held together in a polymeric form.

5. The recent model of horse muscle PGK presented by Blake and Evans (12a) for their x-ray crystallographic studies may afford an explanation of the mechanism of apparent negative cooperativity observed herein:

The bilobular structure of horse muscle PGK has been confirmed by these workers by x-ray diffraction at high resolution ( $3 \stackrel{0}{A})$ (12a). They found that the two lobes or domains are clearly structurally independent and physically separated except that they are joined by a thin neck. They suggested that the active' sites of the enzyme difided between two domains with domain A carrying an ADP/ATP binding site. and domain $B$ a phosphoglycerate binding site. The workers have not been able to produce any clear results with 3-PGA binding experiments. However they indicated that 3-PGA induces a large conformational change in the enzyme that could ngt be accommiodated in the native crysta1 form. .

As the two domains are ghte apart at distance of $20^{\circ} \AA$ from 
each other they may behave in a similar manner to subunits of the enzyme PGK. Since the above workers have not been able to produce any clear results with $3-\mathrm{PGA}$ binding experiments (nor have they worked with 1,3-DPG) it is reasonable to suggest in the light of our kineticafindings that the enzyme (PGK) molecule may have more than one binding site for each substrate. The conformational alteration induced by a ligand on one labe may effect the unoccupied binding site for the same ligand on the other lobe of the single protein in such a way that its affinity is decreased. A negative homotropic interaction betyeen these domains would then be reflected in the type of kinetics observed.

The kinetic data obtained in the present study of PGK from human erythrocytes can be evaluated according to the diagnostic approaches to negative cooperativity in regulatory enzymes proposed by Levitzki and Koshland (65). These workers described that for independent non-interacting sites a classical Michaelis-Menten curve is obtained; the double recíprocal plot is linear and the Hill coefficient is 1. For enzymes exhibiting negative cooperativity the saturation plot fooks qualitatively like a Michaelis-Menten curve but the double reciprocal plot is concave downward and the Hill coefficient ís less than 1 . The findings in the present kinetic study. of human PGK are in conformity with three proposed characteristics of negative cooperativity, the saturation plot looks qualitatively like a Michaelis-Menten curve (as we have observed in our present kinetic study at fixed levels of $1,3-\mathrm{DPG}$ or $\mathrm{Mg}^{2+}$ and varying conceritrations 
of ADP (see Figures 26 and 28 )) the double reciprocal plat is concave downward and the Hill coefficient is less than $1(0.6-0.45)$.

Teipel and Koshländ (96a) presēnt possible explanations to account for the bumpy kinetic curves they observed experimentally. Firstly they demonstrated that enzymes displaying saturatian curves with an intermediary plateau region, must possess more than two.substrate binding sites. Examples of such enzymes are glutamate dehydrogenase (64a) cytidine trìphosphate synthetase (65) and glyceraldehyḍe 3-phosphate dehydrogenase (35a). They are composed of four or more. subunits and exhibit negative cooperativity. Secondly they demon-i strated that saturation curves with intermediary plateau reglions will not be produced by an enzyme possessing more than two binding sites, . when the magnitude of the catalytic or binding constants of these sites progressively increases, progressively decreases or remains egnstant with saturation. Bumpy curves of the type they observed could, however be generated by multisite enzymes when the rekative magnityde of the catalytic or binding constants first decreased, then incfeased as the enzyme was saturated. The appearance of bumpy curves in the present kinetic studies of PGK from human erythrocytes could.be generated by a multisite enzyme (PGK) where the relative magnitude of the catalytic or binding constants first deçreased, then increased as the enzyme was saturated (see Figures 23 and 24).

- Kinetic studies of PGK from human erythracytes in the present - investigation strongly implied that the regulation of its activity is $\therefore$, controlled by the levels of substrates (i.e. 1,3-DPG and, ADP). Apparent 
negative cooperativity was observed with respect to $1,3-D P G$ and ADP. Negative cooperativity may have the biological advantage of making some enzymes less sensitive to environmental changes and thus complements positive cooperativity which has the advantage of making certain key control enzymes more sensitive to environmental change. The level of substrates for PGK in human erythrocytes exist at micromolar concentrations and they are effected by various factors e.g. storage in ACD at reduced pH or a blockage in.the glycolytic pathway. It may be important to the overall metabolism of red cells that some enzymes be of constant activity despite of f,1uctuations in metabolite foncentrations: Since human red cells depend upon the four moles of ATP produced during glycolysis of each mole of glucose for their energy requirements and there is a production of two moles of ATP at the step catalyzed by PGK. There is an obvious physiological advantage to protacting this enzyme (PGK) in human red cells from severe changes in metabolite concentrations. If there is an inadequate supply of ADP phosphoglyceratekinasg activity is reduced and the cycle is diverted through $2,3-\mathrm{DPG}$ bypass. The pathway via $2,3-\mathrm{DPG}$ is energetically wasteful since ATP is not produced by this route of metabolism. Conway and Koshland (24a) suggested that it would be desirable to have sites of decreasing affinity so under normal workday conditions the turnover of substrates is rapid and efficient. "They postulated the existence of two types of binding sites, tight sites and loose sites with different/binding affinities for a single identical ligand in enzymes which exhibit negatipe cooperativity. The tight sites therefore would be a reservior to be utilized under more 
demanding conditions and the loose sites for operation under normal metabolite levels. The kinetic data obtained in the present study of PGK from human erythrocytes can be related to this hypothesis where both $K_{m}$ and $V_{\text {max }}$ are less at lower substrate levels than at higher substrate concentrations (see Figures 23, 24, 26 and 27), A sequential binding of ligand apparently produces successively new sites of lower affinity but higher turnover number. High substrate concentrations would then be required to saturate the weak affinity sites, which when saturated would have greater turnover than the tight sites. Conway and Koshland (24a) showed that the kinetic data from the enzymes which give a biphasic curve can be fitted with two different $K_{\mathrm{m}}$ values where the $K_{\mathrm{m}}$ at higher substrate concentration. is $5-12$ times the $K_{m}$. at the lower concentrations. Such effects have been called by these workers activation at high substrate concentration and they proposed the there may be a second activator site in addition, to the active site. In the present kinetic study of PGK similar - characteristics were observed by the substrates. Substrate activation was observed at higher concentration of 1,3-DPG. Biphasic curve was $\therefore$ obtained with respect to 1,3-DPG and ADP in double reciprocal plot. . demonstrating two ' $\mathrm{K}_{\mathrm{m}}$ 's. The calculated $\mathrm{K}_{\mathrm{m}}$ at higher substrates (i.e. 1,3-DPG and APP) concentrations was 5 - 7 times the $\mathrm{K}_{\mathrm{m}}$ at the lower concentration. The data conform to the above suggestion that each substrate has more than one site on the enzyme which may be a second activator site. $i$

- The inhibition by AMP and 2,3-DPG could well serve as a fine 
regulatory valve for red cell glycolysis at the PGK step. The level of AMP is very low compared to $2,3-D P G$ at physiological concentrations in human red cells. These levels of AMP have little inhibitory effect on PGK activity, compared to 2,3-DPG in vitro. At higher con, centration of AMP $(5.0 \mathrm{mM})$ PGK activity was inhibited $>50 \%$. This situation can arise in red cells when they have been stored for prolonged periods in ACD.1 PGK was inhibited noncompetitively by AMP with respect to substrates and cofactor. It appears therefore that $P G K$ has a separate binding site on, the enzyme for AMP. Low concentrations of AMP had little effect on the interaction between substrates (i.e. negative cooperativity). Substrate activation persisted to a concentration of $2.0 \mathrm{mM}$ but at higher concentrations of AMP $(5.0 \mathrm{mM})$ the curve approached the hyperbolic with respect to 1,3-DPG. It appears that the allosteric site has been modified and there is no cooperative interaction (i.e. substrate activation) at this level of AMP. Although reduced activity was observed at all levels of AMP did not effect the interaction coefficient of the enzyme with respect to ADP or $\mathrm{Mg}^{2+}$.

PGK activity in also inhibited by $2,3-D P G$. It inhibits tho enzyme noncompetitithy with respect to 1,3-DPG. At physiologica1 concentrations of 2,3-DPG inhibition of enzyme activity was more than $50 \%$ (see Figure 33). It appeàrs thàt $2,3-\mathrm{DPG}$ at physiological concentration inhibits PGK activity qn $^{2}$ itro by decreasing its affinity. fpr the substrate 1,3-DPG. If the enzyme in the intact cell is similarly affected this would account for the diversion of some of 


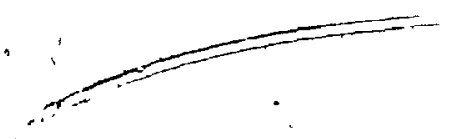

the glycolytic flux via the 2,3-DPG pathway. The role of 2,3-DPG in its interaction with hemoglobipand its effect on other glycolytic enzymes of the human red cell is well recognized.

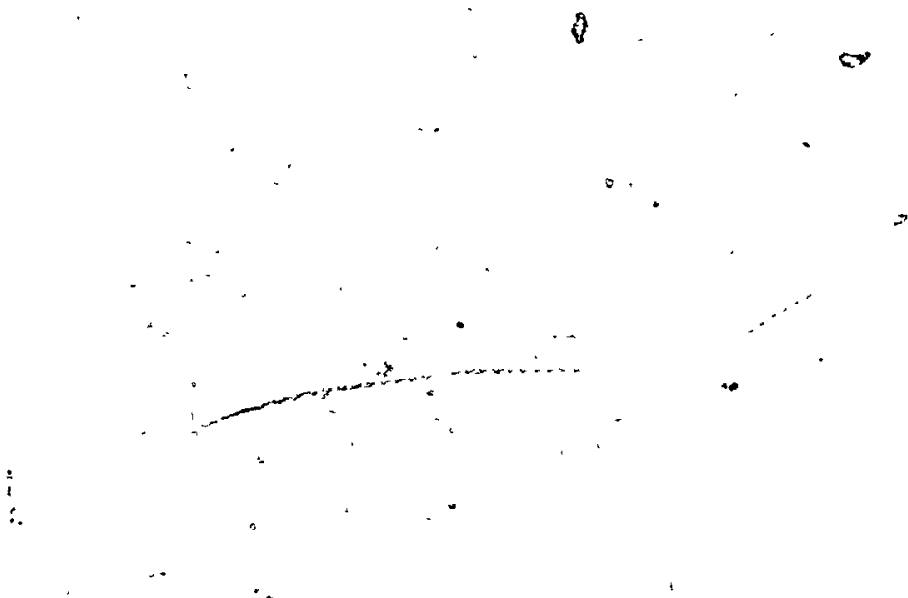




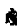

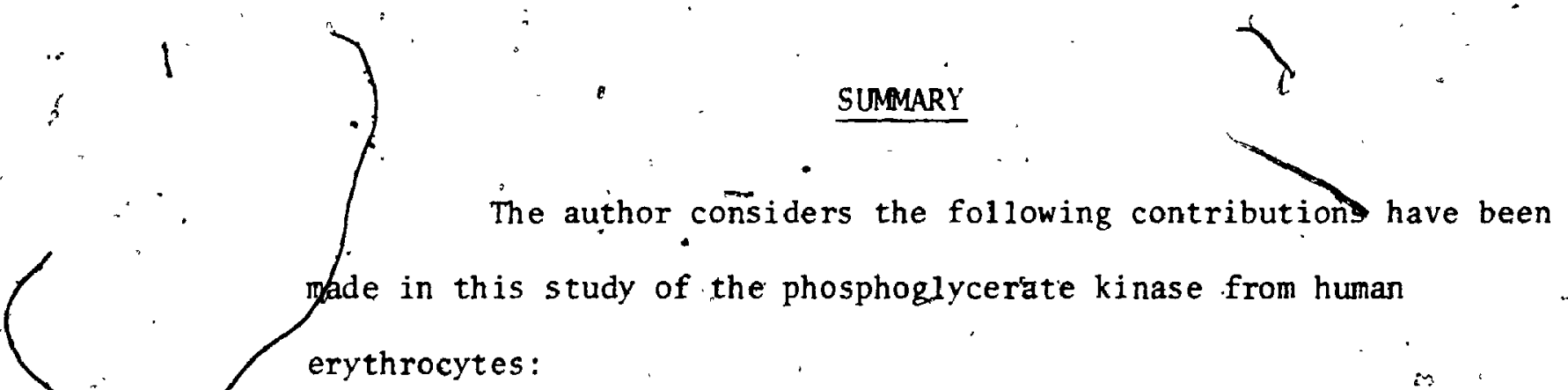

erythrocytes :

1. The purification of the enzyme phosphoglycerate kinase from human erythrocytes by electrofocusing techniques using carrier ampholyte ( $\mathrm{pH} 7-9)$.

2. The kinetic studies performed in the forward reaction leading from 1,3-DPG to 3-PGA using a highly sensitive assay procegdure to measure the small changes observed in this system.

3. The observation of apparent negative cooperativity at fixed levels 'of $\mathrm{Mg}^{2+}$ or $\mathrm{ADP}$ ' and varying concentrations. of 1,3-DPG. Cooperativity has also been observed at. fixed levels of $1,3-\mathrm{DPG}$ or $\mathrm{Mg}^{2+}$ and varying concentrations of ADP.

4. The demonstration of the inhibitory effect on PGK activity by AMP and 2,3:DPG at physiological concentrations.

5. The determination of the activation energy for BGK in the formation of 3-PGA: 11,000 calories/mole. 

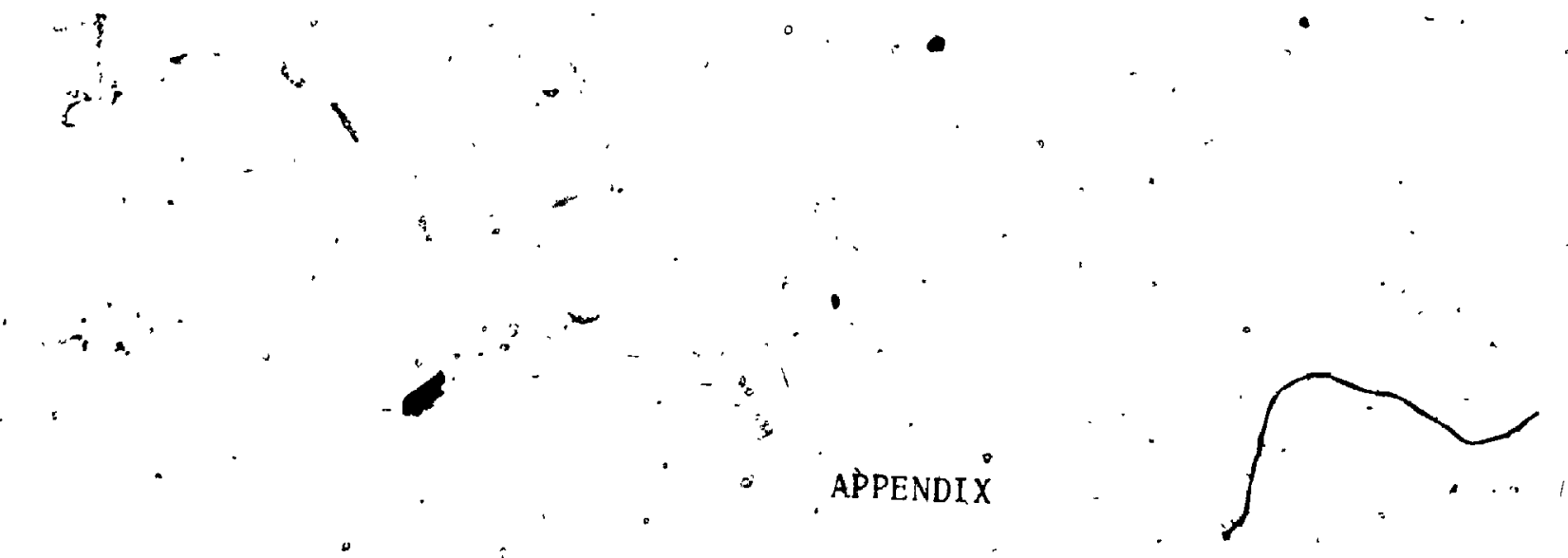

157

3

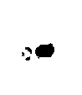

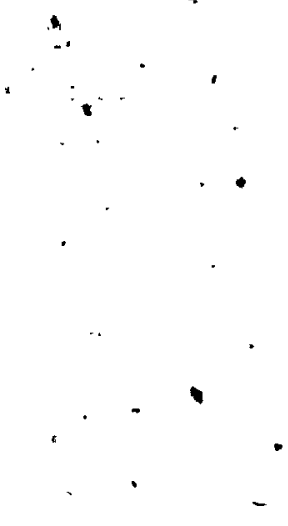

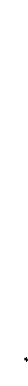




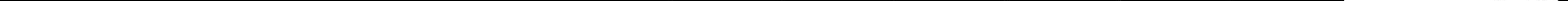


- $\dot{G}^{*} * * * * *$ PPOGPAMME FOP A FEACTION VELOCITYY ANE CONCENTRATION OF THE

, C****** PFODUCT OF A SERUENCE OF A IFREVELSIILLE FIRST OPLER REACTION IMFLICIT DOUELE PRECISTON $(A-H, O-Z)$

DIMENSION AC 5 I, AK (5), E( 5 )

TYPE 1

1
11
11
4
4
3
2
5

FORMAT $, ~ N N=\$, S)$

ACCEPT2, NN

DO $3 \quad 1=1, N N$

PRINT 4,1

FOFMAT (: $\left.K^{*}, 12,0^{\circ}=\cdot, \$\right)$

ACCEPT. 5, AK( 1$)$

FORMAT (I).

FOFMAT (D)

PPINT?

7

FÓPMATI: ICONCENTEATION )

FRINT 6

6

FOFMAT '.

( SUES $^{*}$ )

* PPINT 55.

- 55

FORMATC.

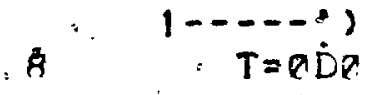

$100 \quad$ EETA $=1 . D P$.

DO $20 \quad 1=1, \mathrm{NN}$

$28 . \therefore$ EETA=EETA*AK(1)

DO $21 \quad 1=1, N N$

$A(1)=1 \cdot D \dot{C}$

- DQ $22 \cdot 9=1, N N$

IF(I.EO.J)GO.TO .23.

$A(1)=A(1) *(A K(4)-A K(1))$ GO TO 22

$23 . \because A(1)=A(1) * A K(i)$

$\therefore$ 22: CONTINUE

$A(1)=$ EEETARA $\mathrm{E}$ )

$21-\quad C C N T$ TUE:

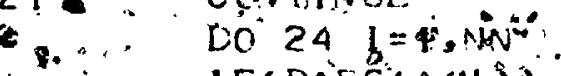

IF(DAFS(A (WW).GT. 1.D+3R)GO TO 60 .

IF(LASS(AK (I) T) OT. 88. DO)GO TO 61

$E(1)=[\operatorname{ExP}(-A K(1) ; * T)$.

61

-GO TO 24

24

$\therefore E(I)=R \cdot D T$

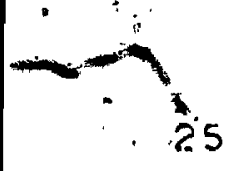

CONTINLE

$\mathrm{C}=1+\mathrm{LQ}$

$v=Q . D 2$

DO $25 \quad 1=1, \mathrm{NN}$

$A(1)=A(1) * E(1)$

IF(DAES(A(1)*AK(1)).GT:1.D+2. ANL. ('AK(1)*T).GT.88.DOTGO TO

IF(LAHS(ACI)*AK(1) $* G 9 \div 1 . D+13) 60^{\circ}$ TO 60

$C=C+A^{\prime}(1)$

$V=V-A K(1) * \dot{A}(1)$

$C C=1,0 \%+C$

PPINT IV,T, V, C, CC

$* 10$

FOFMAT (3F|2.6*F/4.6)

IF(T.GE.5.LD)GO TO, 1I

$T=T+. .1 \mathrm{DS}$

rio $\operatorname{To} 10 \%$

60. PEINT 7E $\because$

$70^{\circ}$ FOPMATC THE PPCOBAAME GTOPS IF THERE IS ANY POSSIHILITY OF. FOIND OFE. ERROFE", CTחD 


\section{BIBLIOGRAPHY}

1." Arvidsson, L. and Larsson-Raznikiewicz, M. The SH group of yeast phosphoglycerate kinase. Biochim. Biophys. Acta., 310: -430-436 (1973) .

2. Asakura, T. ,.Sato, Y., Minakami, S. and Yoshikawa, H. Effect of deoxygenation of intracellular hemoglobin on red cell glycolysis.' J. Bi ochem. (Tokyo) 59: 524-526 (1966) $\therefore$

3. Bandurski; R.S. and Axelrod, B..' Phosphoglyceryl kinase in higher plants. J. Biol. Chem., 204: 939-948, (1953).

4. Bartlett, G.R. and Marlow, A.A. Erythrocyte carbohydrate metabolism: 1. The flow of $\mathrm{C}^{14}$ glucose carbon into lactic acid, carbon dioxide, cell polymers, and carbohydrate intermediate pool. J. Lab. Clin. Med., 42: 178-192 (1953).

5. Bartlett, G.R. Organization of rid cell glycolytic enzymes: cell coat phosphorus transfer. Ann. N.Y. Acad. Sci., 75 : 110-114 (1958) .

6. Bártiett, G.R. Human red. cell glyçotytic intermediates. J. Biol. Chem., 234: '449-458'(1959):

7. Bartlett, $\therefore$ G:R. and Barnet, H.N'. Changes in the phosphate compounds of the human red cell during blood bank storage. J. Clin. Invesț., 39: " $56-61$ (1960)

8. Bartlott, G.R. and Shafer, A:W. Phosphorylated carbohydrate $\therefore{ }^{\circ}$, intermediates of the human erythrocytes during storage in ACD. Effect of addition of inosine in storage. J. Clin. Invest., 40: 1185-1193 (1961). 
8a. Bateman, $H_{1}$. The solution of a system of differential equations - occurring in the theory of radioactive transformations. Procis of Cambridge Phil. Soc. 15: 423-427 (1910).

. 9. Benesch, R. and Benesch, R.E. The effect of organic phosphates from the human erythrocytes on the allosteric properties of hemoglobin. Biochem. Biophys. Res. Commun., 26: 162-1.67 (2967).

10. Benesch, R., Benesch, R.E. and Yu, C.I. Reciprocal binding of oxygen and diphosphoglycerate by human hemoglobin. Proc. Nat1. Acad. Sci., 59: .526-532 (1968).

10a. Bergmeyer, H.U. Principles of Enzymatic analysis. 'Iǹ: Methods. of Enzymatic analysis.p.10-13. Academic Press, Nes York (1965):

11. Beutler, E. 2,3-diphosphöglycerate affects enzymes of glücose metabolism in red blood cells: Nature New Biology, 232: 20-21, (1971).

12. Blake, C.C.F. and Evans, P.R. Structure of horse-muscie phosphoglycerate kinase at $6 \AA$ resolution. Nature New Biology, 235: $195-198^{\circ}(1972)$.

12a. Blake, C.C.F. and Evans, P.R. Structure of horse-muscie phosphoglycerate kinase. Some results on the chain conformation, substrate binding and evaluation of the molecule from a $3 \AA$ Fourier Map. J. Mo1. Biol. 84: 585-601 (1974).

13. B1anchaer, M.C., Williams, H.R. and Afeiss, P. Presence of the glycolytic enzymes $\mathrm{D}$-glyceraldehyde-3-phosphate dehydrogenase, phosphoglycerate kinaseiand triose phosphate isomerase in hemolysate of preserved blood: Am. J. Physiol. 181: $602-608(1955)$.

14.. Blostein, R. Phosphoglycerate metabolis in the human erythrocyte: Ph.D. thesis. Dept. of Biochemistry, McGill University, Montreal Aprị 1, 1960 . 
-15. Brin, M. and Yonemoto, R, H. Stimulation of the glucose

oxidative pathway in human erythrocytes by methylene blue.

J. Biol.. Chèm., 230: 307-317 (1958) .

16. Brownstone, Y.S. and Denstedt, O.F. The pentose phosphate metabolic.pathway in the human erythrocyte. 1. The transformation of ribose-5-phosphate to ketopentose-5-phosphate."

Can. J. Biochem: Physio1., 39: 527-532,(196i).

17. Brownstore, Y.S. and Denstedt, O.F. The pentose phosphate metabolic pathway in the human erythrocytes." 11. The transKetolase and transaldolase activity of the human erythrocyte. Can. J. .Biochem.. Physiol., 39: 533-543, (1961)

18. Brownstone, Y.S. and Dehstedt, Q,F. The pentose phosphate metabolic pathway in the human erythrocyte. 111. The stability of the pentose phosphate metabalic system in preserved erythrocytes. Can J. Biochem. Physiol., 39: 544-550' (1961):

19. Bucher, T.H. Uber ein Phosphatubertragendes Garungsferment. Biochim. Biophys: Acta. 1: 292-314 (1947).

20. Chanutin, $A$, and-Curnish, R,R. Effect of organic and inorganic phosphates on the oxygen equilibrium of human erythrocytes. ?. Arch. Biochem. Biophys., $121: ; 96-102,(1967)$.

21:- Chern, C.J., Rittenberg, "M.B. and Black, J.H., Purification of human erythrocyte pyruvate kinase. J. Biol. Chem., 247: 
22. Chervenka, C.H. A manual of methods for the analytical ultra-

centrifuge. Published by Spinco Division of Beckman

Instruments Incorporąted, Stanford Industrial Park, Palo Alto, $\therefore$ California.

23. Clarkson, E.M. and Maizels, M. Distribution of phosphatases in human èrythrocytes. J. Physiol., 116: 112-128 (1952).

24. Cohn, M. Some michanisms of cleavage of adenosine trip ophate and 1,3-diphosphoglyceric acid. Biochim. Biophys. Acta., 20: $92-99 .(1956)$.

24a. Conwaý, A. and Koshland, D.E. Negative cooperativity in enzyme action. The binding of disphosphopyridine nucleotide to glyceraldehydé 3-phosphate dehydrogenase. Biochemistry, 7: $4011^{\prime}-4029(1968)$.

25.: Cori, 0., Abarca, F., Franke1, R. and Traverso-Cori, A: Synthesis of phosphocreątine by enzymes from heart skeletal. muscle: , Nature, 178:

26. Daviss B.J:' Disc electróphoresis-11. Method and applicatión to mumain seprum "proteing. Ann. N.Y., Acad. Sci.,
$404-427$ (1964).

$\rightarrow$ * $\quad$ 404-427, (1964).

27. D'Alessio; G, and Josse, J. "Glyceraldehyde phosphate dehydrogenase, phosphoglycerate kinasè and phosphoglyceronutase of Escherichia coli. Simultaneous purification and physical properties. 'J. Biol. Chem., 246: /4319-4325' (1971).

28. deloecker, W.C.J. and Prankerd, T/A.J. Factọ́rs influencing thè hexose "monophosphate shunt in red cells. "Cin. Chim. Acta.; 6: $, 641-647,(1961)$. 
29. Diederich, D.A. and Grisolia, S. Properties of pure acy 1 phosphatăse from bovine brain. J. Biol. Chem. 244:

$\rightarrow$ 2413-2417 (1969)

30. Dische, 2. The red ce11. Bishop, C. and Surgenor, D.M. Eds. New York: Academic Press, 189-209 (1961).

31. DDuhm, J., Deuticke, B. and Gerlach, E: Bfldung und Abbau der 2-3-0̈iphosphoglycerinsaure, in Menschoh-Erythrocyten unter verschiedenen expimentellen Bedingungen "In metabolistris verschiedenen expefimentellen Bedingungen. In'metabolism and membrane permeability of erythrocytes and thrombocytes, p. 69-76. Eds. Deutsch, E., Gerlach, E. and Moser, K. Stuttgart:G. Thieme (1968).

32. Duhm, J., Deuticke, B.' and Gerlach, E. Abhangi gkeit der 2,3-Diphosphoglycerinsaure-Synthese in Menschen-Ërythrocyten von der ADP-konzentration. Pflugers, Arch. Eur. J. Physiol. 306: $329-340$ (1969)

33. Estabrook, R. M. and Maitra, P.K. A fluorometric method for : the enzymic dterminatiog of glycolytic intermediatés. Anal. Biochem, I: 472-484 (1964):

34. Fruton; J.S. and Simmonds, S. General Biochemistry. Jü Wi Wiley and Sons, Inc., New York. sp. 254 (1953).

35. Garby, L., Gérber, G. and DeVerdier, C.H. Binding of 2,3-DPG and ATP to humart hemoglbbin A. ${ }_{3}^{3}$ Eur. J.. Biochem. , 10:a 110́-115 (1969). 
$\stackrel{4}{3+\infty}$

35a. Gelb, W. and Nordin, J.H. Kinetics of anomatous binding of substrate and cofactor to insect dyceraldehyde 3-phosphate dehydragendses. Fed. Proc., 28: 85) (1969).

36. Gerlach, E., Fleckenstein, A: and Gross, E. Der Intermediare Phosphat-Stoffwechsel des Menchen-Erythrosyten papier chromatographische Studien unter Verwendung von ' 32 -Markiertem orthophosphat. Pfluger's Archiv., 266: 528-555 (1958)

$\therefore$

37. Gerlach, E., Duhm, J. and Deuticke, B. Metabolic control mechanisms in the red cell. Advañ. Expt1. Med. Biol.; 6: $155-174(1969)$.

$$
+
$$

38. Gourley, D.R. The role of adenosine triphosphate in the transport of phosphate in the human erythrocyte. Arch. Biochem.

- Biophys.; 40: 1-12, (1952).

39. Greenwald, I. A new type of phosphoric acid compound isolated from blood, 'with some remarks on the effect of sibstitution on the rotation of $1-g l y$ çeric acid. $J$. Bio.1. Chem., 63: $339-349(1925)$.

40. Grisolia, S. Energy-generating systems. Annals. N.Y. Acad: Sci., 72: 462-465. (1959).

41. Hanlon; S., Lamers, K., Eauterbach, G., Johnson, -R. "and Schachman, H.K. Ultracèntrifuge studies, with absorption optics. 1. An automatic photoerectric scahing system. Arch. 'Bióchem. Biophys', 99; 157-174 (1962):

42. Harary, I: The in vitro inhibition of acetyl phosphatase by thyroxine. Biochim. Biophys.. Acta:, 25: 19.3-194 (1957). 


\section{1}

43. Harkness, D.R. and Roth, R. Purification and properties of 2,3-diphosphoglyceric acid phosphatase from human erythrocytes. Biochem. Biophys. Res. Comnun., 34: 849-856 (1969).

44. Hashimotó, T. and Yoshikawa, H. Crystalline PGK from human 8 erÿthrocytes. Biochim. Biophys. Acta., 65: 355-357 (1962):

45. Hashimoto, T. and Yoshikawa, H. Human erythrocyte adenosine triphosphate D-3-phosphaglycerate 1-phosphotrans ferasie. J. Biochem., (Tokyo), $56: 279-284$ (1964).

46. Hill, A.V. The possible effects of the aggregation of the molecule of hemoglobin on its dissociation curves. J. Physiol. (London), 40: fiv) (1910).

47. Holloway, B.W. and Ripley, S.H. Nucleic acid content of reticulocytes and its relation to uptake of radioactive leucine. in vitro. J. Biol. Chem., 196: 695-701 (1952).

48. Huennekens, F.M., Caffrey, R.W. and Gabrio, B. W. The electrion tranłport sequence of methemoglobin reductase. Ann. N.Y. Acad. Sci., 75 : 167-174, (1958).

49. Ichihara, A. and Greenberg, D.M. Studies on the purification and properties of D-glyceric acid kinase of liver. J. Biol. Chém., 225: 949-948 (1957).

50: Jacobs, S. Effect of isoelectric focusing on the amino acid compoșition of proteins. Analyst, 98 : $3^{3-33}$ (1973).

51. Joyce, B.K. and Grisolia, S: Studies on glycerate 2,3 -diphosphatase. J. Bio1. Chem., 233: 350-354 (1958):

52. Joyce, B.K. and.Grisolia, s, The purification and properties of. muscie diphosphoglycerate mutase. J. Bio1. Chem., 234: $1330-1337$ (1959). 
53. Kormberg, A. and Pricer, W.E.0 Diophosphopyridine nucleotide in E.E. Snell biochemical preparations. Wiley,'New York, Vol. III, ' p: $20-24(1953)$.

53a. Koshrand, Jr., D.E.; Nemethy, G. and Filmer, D. Comparison of experimental binding data and theoretical models in proteins containing subunits. Biochemistry, 5: 365-385 (1966).

54. Krebs, H.A. and Komberg, H.L. A survey of the energy trans formations in 1iving matter. Ergeb. Physiol., 49: $\quad 212-298(1957)$

55. Krietsch, W.K.G. and Bucher, T. 3-phosphoglycerate kinase from rabbit skelet muscle and yeast. Eür. J. Biochem., 17: $568-580(1970)$.

56. Lamers, K., Putney, A., Steinberg, I.Z.. and Schachman, H.K. 3. A sp1it beam photoelectric scanning absorption system. Arch. Biochem. Biophys., 103: 379-400 (1963):

57. Lardy, H.A., Paetkau, V.H. and Younathan, E.S. Phọsphofructokinase: studies on the subunit stmucture.' J. Mol.'Biol., 33: $721-736(1968)$.

"58. Larsson-Raznikiewicz, M. and Malnstorm, B.O.G. The metal ion activation of 3-phosphoglycerate kinase in correlation with metal binding studies. Arch. Biochem. Biophys., 92: 94-99 (1961).

59. Larsson-Raznikiewicz, M. Kinetic studiess on the reaction catalyzed by phosphoglycerate kinase. 1. The effect of $\mathrm{Mg}^{2^{+}}$ and adenosine 5'-triphosphate. Biochim. Bigphys. Acta." 85: $60-68(1964)$. 
60. Larsson-Rafuikiewicz, M. Kinetic studies on the reaction catalyzed by PGK. 11. The kinetic relationships between 3 PGK, MgATP and activating metal ion. Bio'chim. Biophys. Acta., 132: $33-40(1967)$.

61. Larsson-Raznikiewicz, M. Electrophoretic purification as well as some physical and chemical characterization of PGK from yeast. Eur. J. Biochem., 15: 574-580 (1970).

62. Larsson-Razrikiewicz, M. and Arvidsson, L. Inhibition of PGK by products and product homologues̀. Eur..J. Biochem., 22; $506-512(1971)$

63. Lee, L.M.Y. Puxification and some properties of phosphofructokizase from human erythrocytes. Arch. Biochem. Biophys., $148 ! 607-613(1972) \cdot$.

64. $:$ Lefant, C., Torrance,"J., Engligh, E., Finch, C.A., Reynafaye, C., Ramos J. and Faura, J. Effect of altitude on oxygen binding by hemóglobin and on organic phosphate levels. ' J. Clin.

\section{Invest., 47: 2652-2656 (1968).}

64a. Le. John, H.B. and Jackson, S., Allosteric interactions of a regulatory nicotinamide adenine dinucleotide-specific glutamate

- dehydrogenase from Blastọcladiella. A molectular hiodel for. the enzyme: J. Biol. Chem., 243:- 3447-3457 (1968).

'65." Levitzki, A, and Koshland, D.E. Negative cooperativity in

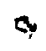
regulatory enzymes. Próc. Nat1. Acad. Sci. (U.S.), 62: 1121$1128(196 \overline{9})$. 
5.

66. Lowry, H., Rosebrough, N.J., Farravel, A. and Randa11, R.J.

Protein peasurement with the folin phenol reagent. J. Biol.

Chem., 193: 265-275 (1951).

66a. Lowry, O.H. and Passonneau, J.V. Kinetic evidence for multiple binding sịtes on phosphofructokinase. J. Biol. Chem. $a^{\circ}$

241: $2268-2279(1966)^{\prime}$.

67. Minakami, S., Suzuki, C., Saito, .T. and Yoshikawa, H. Studies" on erythrocyte glycolysis. 1. Determination of the glycolytic intermediates in hypan erythrocytes. J. Biochem. (Tokyo). 58: $543-550(1965)$.

68. Mi nakami, S. and Yoshikawa, H. Thermodynamic consideration on erythrocyte glycolysis. Biochem. Biophys. Res. Commun., 18: $\quad 345-349(1965)$.

69. Minakami, S. and Yoshikawa, H. Studies on erythrocyte giycolysis.

1i. Free energy changes and rate limiting steps in erythrocyte glycolysis. J. Biochem. (Tokyó), 59: 130-144 (1966).

70. Minakami, S., Suzuki, C. and Yoshikawa, H. Studies on erythrooyte glycolysis. IV. Kinetics of $\mathrm{p}^{32}$ incorporation $\therefore$ into 2,3 -qiphosphoglycerate and ATP. J. Biochem. (Tokyo), 60: $707-712(1966)$.

71. Murphy, J.R. Erythrocyte metabolism. 11. Glucose metabólism * and pathways.. J. Lab. Clin. Med., 55: 286-302 (1960).

72. Nakao, M., Nakoa, T., Yamazoe, S. and Yoshikawa, H. Adenosine

$\therefore \quad$ triphosphate and shape of erythrocytes, J. Biochem.

(Tokyo), 49: 487-492 (1961). 't 
73. Negeleiñ, E. Synthesis, determination, analysis and properties of 1,3-diphosphoglyceric acid. In: Methods in Enzymology (Colowich, S.P. and Kaplan, N.0., eds). Vo1. 111 , p. 216-220, Academic Press, Newo York (1957).

74. Negelein, E. D-1,3-diphosphoglycerate. In: Methods of enzymatic analysis. (Bergmeyer, H.V.), p. 234-237, Academic Press; New York (1965).

75* Oguchi, M., Hașhimoto, T., Minakami, S. and Yoshikawa, H. The preparation of crystalline human erythrocyte glyceraldehyde 3-phosphate dehydrogenase. J.: Biochem. '(Tokyo), 60: 99-101 (1966).

76. Okonkwo, P. . , Askari, A, and Konngold, L. Hunan erythrocytes phosphoglycerate inase. Purification properties and interaction with its antibody. Biochim. Biophys. Acta., 321: 583-511 (1973).

77. Oski, F,A. Red cell metabolism in the prematufe infant. 11: The pentose phosphate pathway, $\because$ pediatrics, 39 : 689-695, (1967).

78. Ponce, J., Roth, S. and Harkness, D.R. Kinetic studies on. the inhibition of ycolytic kinase of human erythrocytes by 2,3-DPG .. Biochim. Biophys: Acța., 250: 63-74. (1971).

79. Post; R.L., Merrit, C.R.; Kinsol ling, C.R. and Albright, C.D. Membrane adenosine triphosphatase as a participant in the active transporf of sodium and potassium in the puman erythrocyte." J: "B̀ol. Chem., 235:" 1796-1802 (1960). 
B

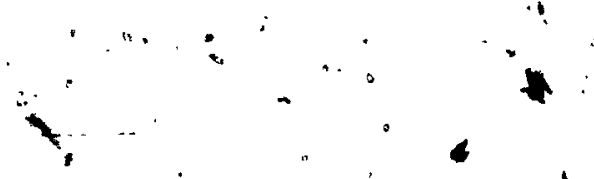

80. Prankerd, T.A.J. and Altmanth. A study of the metabolism of phosphorus in mammalian red cells.' Biochem. J., 58 : $622-6.33(1954)$.

81. "Prankerd, T.A.J: The réd cell." Qxford:Blachwell Scientific publications (1961).

82: . Rall, $h$, and Lehninger, A.L. Glutathioné reductise of animal tissues. J. Biól. Chem., 194: - H 9-130 (1952).

83. Rakitzis, E.T. and Mills, G.C. Purificption and properties of acyl phosphatase from human erythrocytes. Arch. Biochem: Biophys., 134: 372 380 (1969):

84: Rao, D.R. and Oespers 5 . Purification. and properties of muscie phospboglycerate kinas"e: Biochen. J:, $81: 405-$ 411 (1961).

85. Rapoport, S. and Guest, G.M. The decomposidion of DPG in acidified blood: its relationship to reactions of the glycolytic cycle. "J. Bịl. Chefin, 129: $781-790 "$ (1939).

86. Rapoport, S. and Caest, G.M. Distribution of acid-soluble phosphorus in the blood cells of various vertebrates.

- Bitel, Chem., 138: 269-282 (1941)

87. 'Rapoport, S. Dimensional osmotic and chemical changes' of erythrocytes in stored blood. 1. Blood" preserved in sodium - . citrate, neutral, and acid ctrate-glucose (ACD) pixtures .j.clin. Invest. 26: "591-615 (1947). 


$$
33
$$




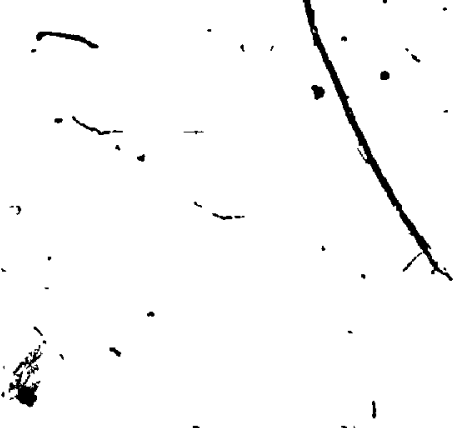

88. Rapoport, S. and Luebering, J. - The formation of 2,3 -diphosphoglycerate in rabbit erythrocytes. The existence of a diphos$\therefore$ phoglycerate mutase. J Biol. Chem. $\because 183$ : ' 507-516 (1950).

89. Rapoport, $S$. and Leubeting, J. Glycerate 2,3 -diphosphatase. J. Bìot. Chem, 189: 683-694 (1951).

90. Rapoport, S. and Leubering, J. An optical study of diphòsphoglycerate mutase. J. Biol: Chem., 196: 583-588 (1952).

91. Rapoport, S., Dietze, F. and Sauer, G. Quantitative Aspekte def̧ $\therefore$ Phosphogceratzyklus in roten Blutzellen: Acta. Biol. Med. Germ. , L3?. 693-702 (1964).

92.- Rapoport, S. in P.N. Campbèli and G.D. Greville' (eds.) Essay in Biochemistry, 4: 69-103, Academic Press, New York, (1968). $\because \quad 93$. Rọse, I.A. and Warms, J. ‥B. Control of glycolysis in the human, red blood cell. J B Biol. Chem., 241: 4848-4854 (1966):

94. Rose, Z.B. The purification and properties of diphosphoglycerate mutase from human erythrocytes. J. Biol. Chem:, 243: 4810-4820 (1968).

95. Rozacky, E.E., Sawyer, T.H., Barton, R.A. 'and Gracy, R.w.

Studies on human triose phosphate isomerase. 1. Isolation and properties of the enzyme from erythrocytes. Arch. Biochem. Biophys., 146: 312-320 (1971).

.96. Rubinstein, D., Ottolenghi, P. and Denstedt, O.F. The metabolism of the erythrocyte. 'XIII. Enzymè activity in the reticulocytè. Can. J. Biochem. Physiol., 34: .222-235 (1956). 
96a. Teipel, J. and Koshland, Jr., D.E. The significance of intermediary plateau regions in enzyme saturation curves. Bíochemistry, 8: "4656-4663 (1969) ...

97. Saito, T. and Mịnakami, S. Studies on erythrocytes glycolysis. VI. 'Control of glycolysis by. ATP level in. human erythrocytes. J. Biochem. (Tokyo), 61: 211-219 (1967).

98. Schachman, H.K. Ultracentrịfugation, diffusion and viscometry. Methods in enzymology, 4: 32-103, colowi k, S.P. and Kaplan, N.0. eds. New York, Academic Preș̣ (1957).

99. Schachman, H.K., Gropper, L., Hanlon, S. and.Putney, 'F. Ultra: centrifuge studies with absorption optics. $2 .{ }^{\prime}$ '. Incorporation. of a monochromator and application to the study of proteins and interacting systems. Arch. Biochem. Bióphys., 99: $\quad 175-190(1962)$.

100. Schachman, H.K. The ultracentrifuge:problems and prospects. Biochemistry, 2: 887-905 (1963).

101. Schroter, w. and Heyden, H.V. Kinetik des 2,3-Biphosphoglycerátumsatzes in menschlichen Erythrocyten. Biochem.

- 2., 341: 387-398 (1965).

102. Schroter. W. Regulation des 2,3-Diphosphoglycerat-Zykius in den roten Blutizellen des Menschen. In: Metabolism and membrane pexmeability of erythrocytes and thrombocytes, p. 50-69. Ed. 'Deutsch, E., Gerlach, E., and Moser, K.

'stuttgart: .G. Thiene, (1968). 
103. Scopes, R.K. Crystalline 3-phosphoglycerate kinase from skeletal musçle. Biochẹm. J., 113: 551-554 (1969).

104. Scopes, R.K. An improved procedure for the isolation of 3-phosphoglyceratakinase from yeast., Biochem. J́., 122: $89-92(1.871)$.

105. Shemin, D. and Rittenberg, D. The life span of the human red blood cell. J. Biol. Chem., 166: 627-636 (1946).

106. Sizer, I.W. Effect of temperature on enžyme kinetics. Advances in enzymology, $\underline{3}: 35-62$ (1943).

107. Sizer, I.W: Temperature activation and inactivation of the crystalline catalase-hydrogen peroxide system. J. Bíol. Chem., 154: . 461-473. (1944).

107a. Staal, G.E.J. and Koster, J.F. Influence of 2,3-diphospho-. glycerate on phosphofructokinase on human fythrocytes. FEBS Letters, 23: 29-30 (1972):

' 108. Sutherland, E.W., Pastemak, T. and Cori, C.F. Mechanism of the phosphoglyceric mutase reaction.: Jo Biol. Chem., 181: $-153-159(1949)$.

109. Valtis, D.J. and Kennedy, A.C. Defective gas transport function of stored red bliood cells. Lancet, 266: 119-124 (1959)

110. Vesterberg, 0 . Isoelectric focusing of proteins: In Methods of enzymology (Colowick, S.P. and Kaplan, N.O., eds), Vo1. 凶XXII - Académic Preșs, p. 389-412 (1971). 
111. Watson, H.C. X-ray diffraction studies on three neighbouring 'enzyme in the glycolytic pathway. Proceedings Ninth International Congress of Biochemistry; Stockholm 1-7

$\therefore \quad$ July $(19 \overline{73) \text { P. } 39 .-}$

-112. Wendel1, P.L.; Bryant, T.N. and Watson, H.C. Low resolution structure of yeast phosphoglycerate kinase. Nat. New Biol.',

$\because \quad 240: 5-7(1972)$.

113. Yoshida, A. and Watanabe, S. Human phosphoglycerate kinase. ' 1 .' Crystallization and characterization of normal enzyme. $j$.

- Biol; Chem., 247: 440-445 (1972).

114. Yoshida, A. and Watanabe, S. Human phosphoglycetate kinase.

11. Structure of a variant enzyme. J. Biol. Chem., 247: '446-449 (1972).

115. Zipursky, A., Maymän, D. and Israels, L.G." Phosphate metabolism in erythrocytes of normal humans and of patients with hereditary spherocytosis. Can. J. Biochem. Physiol., 40: $.95-104(1962)$. 